DANIELA DE ASSIS ALVARES

\title{
ESTUDO DA INFLUÊNCIA DA MORFOLOGIA SOBRE AS PROPRIEDADES ELÉTRICAS DA BLENDA DE PANI COM EPDM DESVULCANIZADO POR MICROONDAS, PROVENIENTE DO DESCARTE DA INDÚSTRIA DE AUTOPEÇAS
}

\author{
Dissertação apresentada à Escola \\ Politécnica da Universidade de São Paulo \\ para a obtenção do título de Mestre em \\ Engenharia Elétrica.
}

SÃO PAULO 
DANIELA DE ASSIS ALVARES

\title{
ESTUDO DA INFLUÊNCIA DA MORFOLOGIA SOBRE AS PROPRIEDADES ELÉTRICAS DA BLENDA DE PANI COM EPDM DESVULCANIZADO POR MICROONDAS, PROVENIENTE DO DESCARTE DA INDÚSTRIA DE AUTOPEÇAS
}

\author{
Dissertação apresentada à Escola \\ Politécnica da Universidade de São Paulo \\ para a obtenção do título de Mestre em \\ Engenharia Elétrica. \\ Área de Concentração: \\ Engenharia Elétrica \\ Orientador: Prof. Doutor Roberto Koji \\ Onmori
}


Alvares, Daniela de Assis

Estudo da influência da morfologia sobre as propriedades elétricas da Blenda de PAni com EPDM desvulcanizado por microondas, proveniente do descarte da indústria de autopeças I D.A. Alvares. -- São Paulo, 2008.

p.

Dissertação (Mestrado) - Escola Politécnica da Universidade de São Paulo. Departamento de Engenharia de Sistemas Eletrônicos.

1.Tecnologia de microondas 2.Polímeros (Materiais) 3.Microeletrônica I.Universidade de São Paulo. Escola Politécnica.

Departamento de Engenharia de Sistemas Eletrônicos II.t. 
Esta Dissertação de Mestrado gerou os seguintes trabalhos:

\section{APRESENTAÇÃO EM CONGRESSOS}

1. Álvares, D. A.; Moreira, J. C.; Scuracchio, C. H. and Onmori, R. K. - Study of Electrical Properties of Blends of PAni with dEPDM - IV SBPMat, Recife, PE, Brazil, 2005.

2. Álvares, D. A.; Moreira, J. C.; Scuracchio, C. H. and Onmori, R. K. Morphlogy and Electrical Properties of dEPDM Rubber and PAni Blends - V SBPMat, Florianópolis, SC, Brazil, 2006.

3. Álvares, D. A.; Moreira, J. C.; Moreira, T. A. A. G.; Carminati, R. A. and Onmori, R. K - Morphlogical and Electrical Characterization of PAni/dEPDM Blends - V IMMP, Nazaré Paulista, SP, Brazil, 2006.

4. Álvares, D. A.; Moreira, J. C.; Moreira, T. A. A. G.; Schuracchio, C. H. and Onmori, R. K - Morphology of dEPDM Rubber and PAni Blends $-41^{\text {st }}$. International Symposium on Macromolecular, Rio de Janeiro, RJ, 2006.

5. Álvares, D. A.; Moreira, J. C.; Scuracchio, C. H. and Onmori, R. K. - Study of Morphology and Electrical Properties of dEPDM Rubber and PAni Blends 17. CBECIMAT, Foz do Iguaçu, PR, 2006.

6. Álvares, D. A.; Moreira, J. C.; Scuracchio, C. H.; Silveira, A. C. F. and Onmori, R. K. - Polyaniline/dEPDM Blends: FTIR, DSC, WAXS and Electrical Characterization - CBPol, Campina Grande, PB, 2007.

7. Álvares, D. A.; Moreira, J. C.; Scuracchio, C. H. and Onmori, R. K. Characterization of a Conductive Elastomer Based on dEPDM and Polyaniline - The Polymer Processing Society 23rd Annual Meeting, Salvador, BA, 2007.

8. Álvares, D. A.; Moreira, J. C.; Scuracchio, C. H. and Onmori, R. K. Morphlogy Influence on the Electric Properties of the PAni and EPDM Rubber Devulcanizated Blends - VI SBPMat, Natal, RN, Brazil, 2007. 


\section{ARTIGO PUBLICADO EM REVISTA}

1. Álvares, D. A.; Moreira, J. C.; Soares, D. A. W.; Machado, W. S.; Scuracchio, C. H. and Onmori, R. K. - Study of Conductivity of dEPDM Rubber and PAni Blends - Macromolecular Symposia, 343-346, 2006. 


\section{RESUMO}

Blendas poliméricas de PAni dopada com ácido dodecilbenzeno sulfônico (PANI-DBSA) e copolímero etileno-propileno-monômero dieno desvulcanizado por microondas (dEPDM) foram obtidas por processo mecânico em diferentes concentrações. Caracterizações físico-químicas, morfológicas e elétrica foram realizadas para analisar as blendas. Um estudo sobre a desvulcanização da borracha EPDM foi descrito. Os ensaios de DSC mostraram temperaturas de transição vítrea diferentes nas blendas indicando que os componentes poliméricos não são totalmente miscíveis, o que permite a formação de uma rede condutora (PANI-DBSA) na matriz isolante (dEPDM). As análises de FTIR indicaram uma interação basicamente física entre o polímero PANI-DBSA e o copolímero dEPDM. As análises de raios- $X$ confirmaram a presença de uma fase cristalina no interior das blendas atribuída à PANI-DBSA. Os ensaios de TGA mostraram que a PAni-DBSA diminuiu, significativamente, a estabilidade térmica do dEPDM. As análises de DMTA apresentaram a diminuição do amortecimento do sistema ocasionado pela presença da PAni, que é mais rígida, no segmento flexível do EPDM; ou seja, a mobilidade da cadeia fica mais limitada. Finalmente, o estudo de condutividade elétrica das blendas foi realizado e como esperado, esta aumenta com a concentração de PANIDBSA nas blendas, e um baixo limite de percolação pode ser observado devido à condutividade ocorrer para baixas concentrações de material condutor $(<20 \%)$. A condutividade máxima alcançada foi de, aproximadamente, $10^{2} \mathrm{~S} / \mathrm{cm}$ para a composição de $50 \%$ de PANI-DBSA em massa.

Palavras-chave: Polímero Condutor, Blendas, Polianilina, EPDM, Borracha. 


\begin{abstract}
Polyaniline doped with dodecylbenzenesulfonic acid (PAni-DBSA) and ethylene-propylene-diene-monomer (EPDM) rubber devulcanizated by microwave (dEPDM) blends have been prepared by mechanical process. Flexible, free-standing and stretchable films have been obtained, which have been characterized by electrical conductivity measurements, FTIR, XRD, DSC, TGA, DMTA and SEM. Study about EPDM rubber devulcanization has been described. DSC analysis have showed different glass-transition temperatures in the blends and it has been observed that the compositions present enough compatibility to form a conductive network (PAni-DBSA) in the elastomeric matrix (dEPDM). By FTIR analysis, it has been noted that there was not modification about the spectrum of blends; therefore the interactions between the components were, basically, physics. X-ray analysis have confirmed the presence of a crystalline phase into the blends that is attributed by PAni-DBSA. TGA analysis have showed that the PAni-DBSA decreased significantly the rubber thermal stability. DMTA analysis have indicated that the system damping decreased according to the presence of PAni because of its stiffness. Finally, blends electric conductivity study has been carried out and as expected, the conductivity have increased with PAni-DBSA concentration in the blends and a low percolation threshold has been observed with the onset of conductivity occurring at lower concentrations of the conductive materials $(<20 \%)$.
\end{abstract}

Key Words: Conductive Polymer, Blends, Polyaniline, EPDM, Rubber. 
Dedico esta dissertação aos meus pais, Lairton de Souza Álvares e Maria Lúcia de Assis Álvares, sem os quais nada disso seria possível. Eles que não mediram esforços (às vezes, quase sem condições) para que eu pudesse, agora, apresentar este trabalho. 
"Eu quero saber como Deus criou este mundo. Não estou interessado neste ou naquele fenômeno, no espectro deste ou daquele elemento. Eu quero conhecer os pensamentos Dele, o resto são detalhes." 


\section{Agradecimentos}

Agradeço, principalmente, ao $\operatorname{Prof}^{\circ}$. Dr. Roberto Koji Onmori pela orientação, oportunidade e paciência.

Ao Prof ${ }^{\circ}$. Dr. José Carlos Moreira, ao Prof ${ }^{\circ}$. Dr. Carlos Henrique Scuracchio e a Prof ${ }^{\mathrm{a}}$. Dr ${ }^{\mathrm{a}}$. Wang Shui Hui por terem me auxiliado em análises do meu trabalho.

À minha amiga Taís Moreira por ter sido o meu braço direito em, praticamente, todas as etapas deste trabalho. E também pelas risadas nos passeios dos Congressos.

Ao amigo Gabriel Apolinário Lopes por todas as longas horas de suporte em meu computador.

Ao meu namorado André Almeida Chícole por ceder a paz de sua casa para o término da escrita desta dissertação.

Ao meu querido irmão Fernando de Assis Álvares que não me ajudou em nada neste trabalho, mas é parte fundamental para completar a felicidade da minha família.

E a todos que colaboraram direta ou indiretamente, na execução deste trabalho. 


\section{SUMÁRIO}

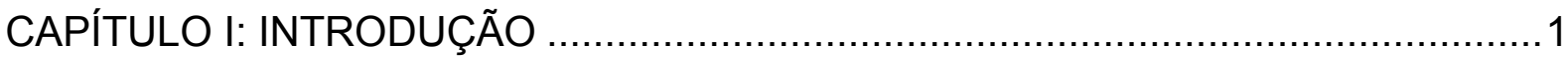

1.1 INTRODUÇÃO

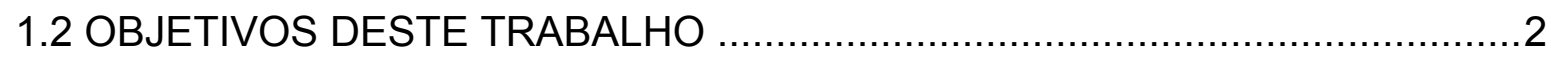

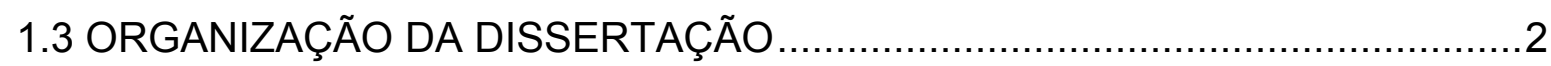

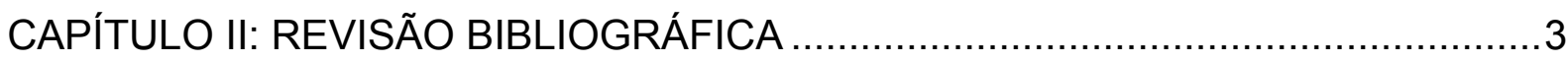

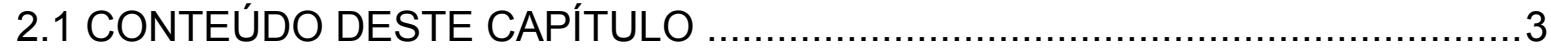

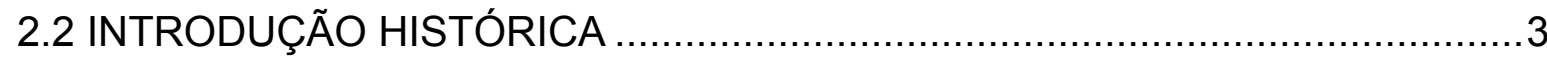

2.3 POLÍMEROS CONDUTORES INTRÍNSECOS .........................................

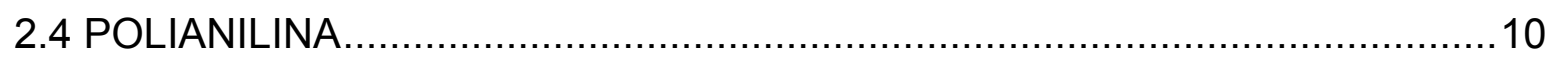

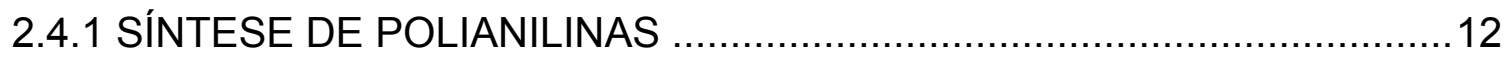

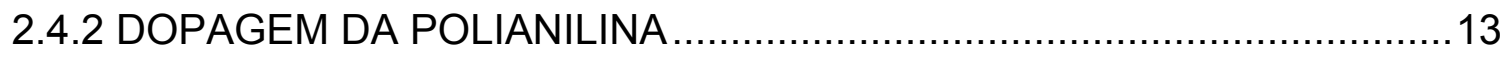

2.4.3 ESTRUTURA E MORFOLOGIA DE POLIANILINAS ............................15

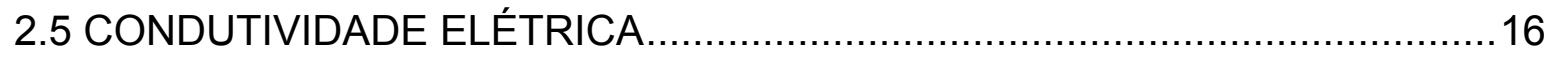

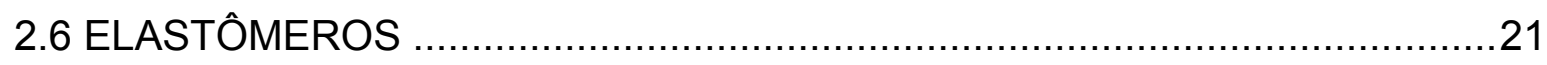

2.7 PROPRIEDADES DOS ELASTÔMEROS TERMOPLÁSTICOS ….................23

2.8 EPDM (Etileno-Propileno-Monômero Dieno) [56,62] .....................................24

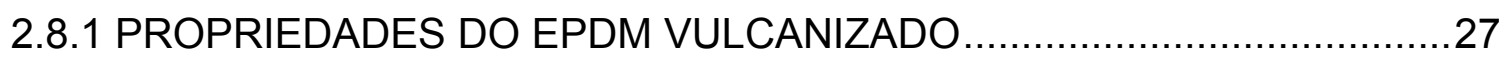

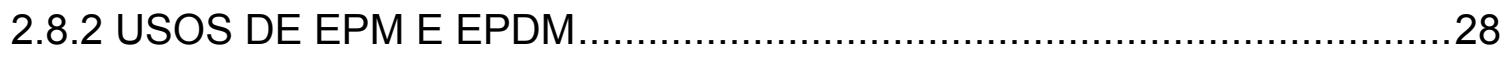

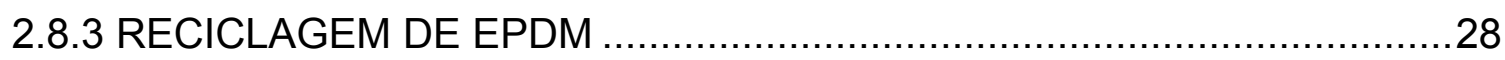

2.9 NEGRO DE FUMO

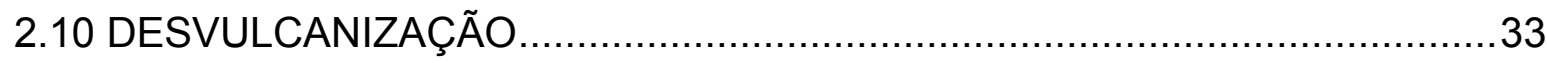

2.10.1 INTERAÇÃO ENTRE MICROONDAS E MATERIAIS …........................35

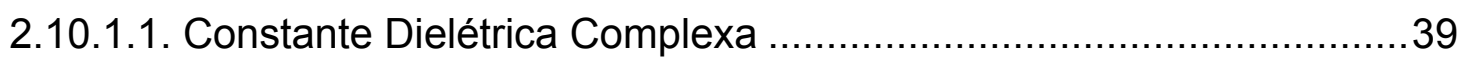

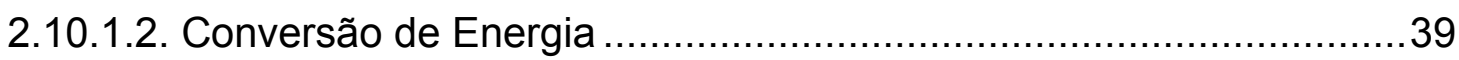

2.10.2 INFLUÊNCIA DO NEGRO DE FUMO NA ABSORÇÃO DE

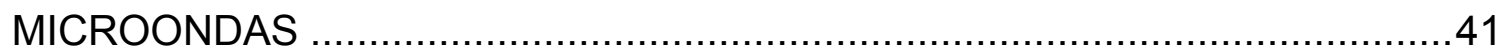

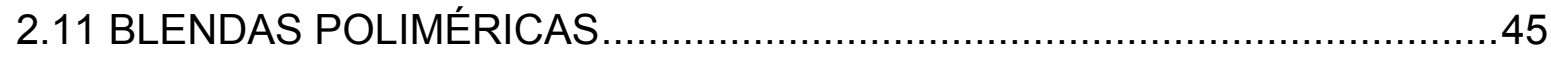

CAPÍTULO III: MATERIAIS E MÉTODOS EXPERIMENTAIS ...............................47

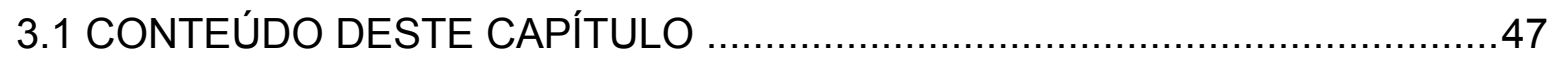

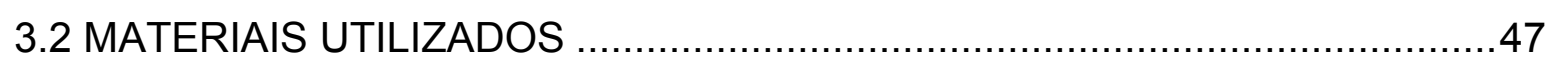

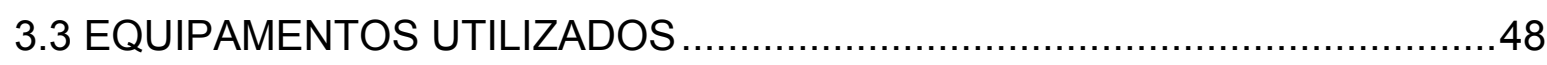

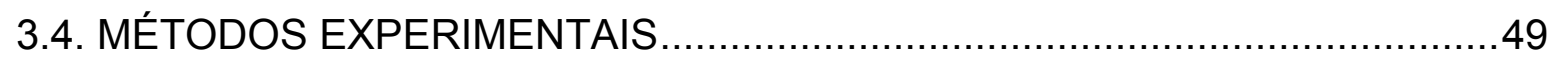


3.4.1 DESVULCANIZAÇÃO DA BORRACHA EPDM POR MICROONDAS ......49

3.4.2 OBTENÇÃO DAS BLENDAS DE PANI-DBSA/dEPDM............................51

3.5 CARACTERIZAÇÃO DOS MATERIAIS POLIMÉRICOS …...........................53

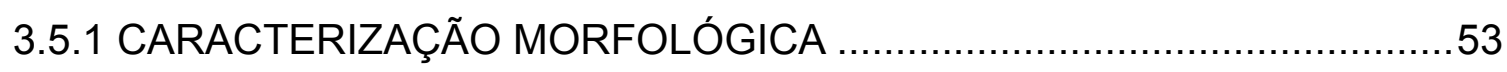

3.5.1.1 Microscopia Óptica (MO) ......................................................... 53

3.5.1.2 Microscopia Eletrônica de Varredura (MEV) .....................................53

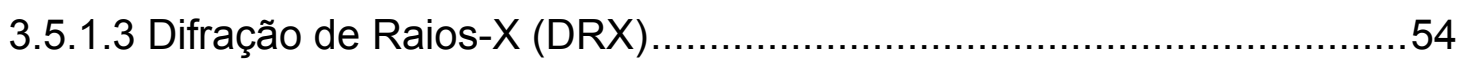

3.5.1.4 Análise Térmica Dinâmico-Mecânica (DMTA) …………………......55

3.5.1.5 Calorimetria Exploratória Diferencial (DSC)...................................56

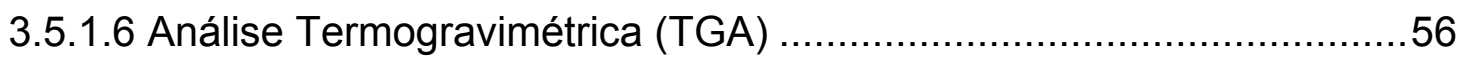

3.5.2 CARACTERIZAÇÃO DA ESTRUTURA QUÍMICA ................................58

3.5.2.1 Espectroscopia no Infravermelho (FTIR) ......................................59

3.5.3 MEDIDAS DE CONDUTIVIDADE ELÉTRICA ........................................59

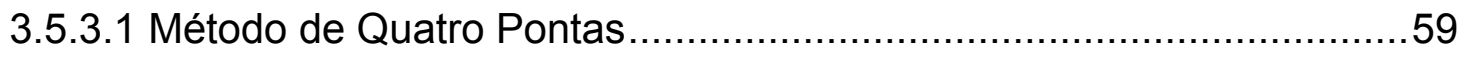

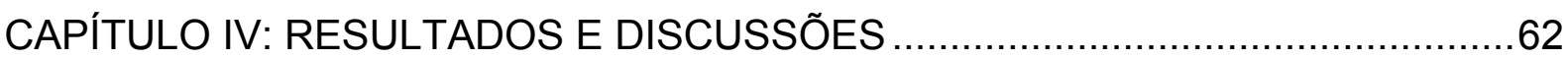

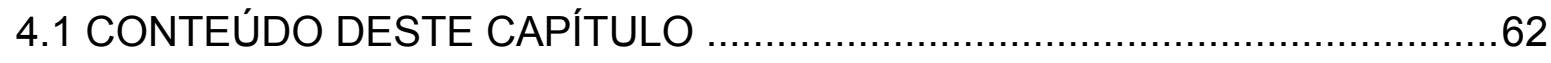

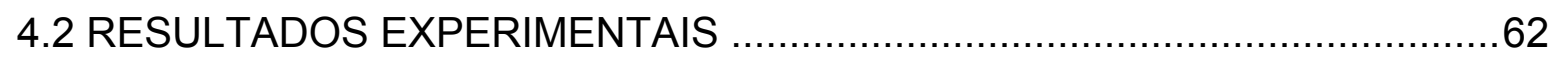

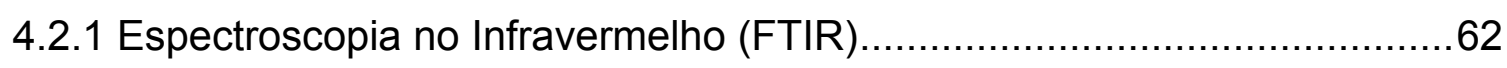

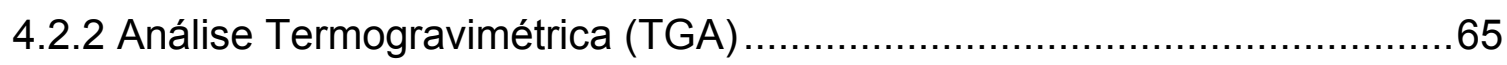

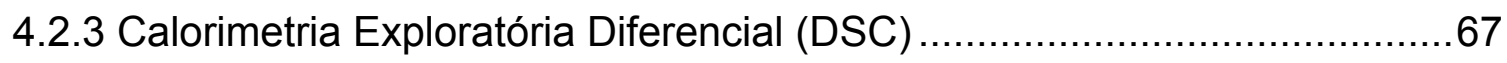

4.2.4 Análise Termodinâmico-Mecânica (DMTA) .............................................70

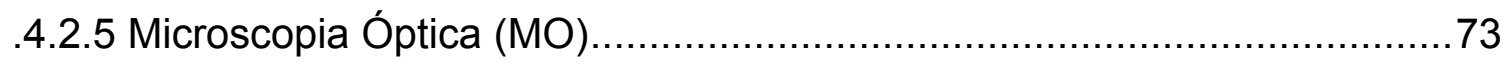

4.2.6 Microscopia Eletrônica de Varredura (MEV) ……..................................75

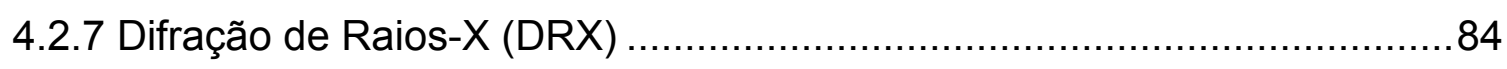

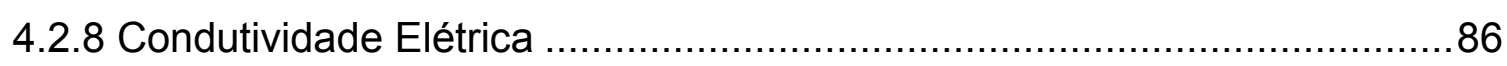

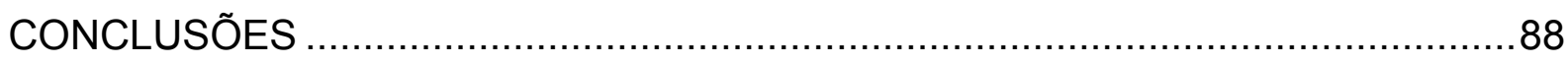

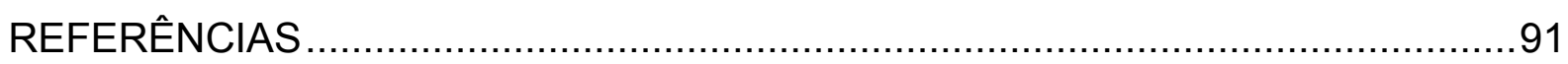




\section{LISTA DE FIGURAS}

Figura 2. 1 - Dopagem de polímeros isolantes através da inclusão de partículas de negro de fumo (a) e de metais (b) [].

Figura 2. 2. Diagrama mostrando as condutividades elétricas (em $\Omega \mathrm{m}$ ) de diferentes materiais.

Figura 2. 3 Esquema das ligações simples e duplas alternadas dos polímeros conjugados.

Figura 2. 4. Estrutura química da polianilina na forma de base (não dopada). 10

Figura 2. 5. Unidades de repetições que compõem a estrutura química da polianilina:

(a) espécie reduzida e (b) espécie oxidada.

Figura 2. 6. Representação esquemática da protonação da forma base esmeraldina da PAni por DBSA. 14

Figura 2. 7. Esquema de condução polarônica em polianilina. 19

Figura 2. 8. Conformação molecular da borracha. 22

Figura 2. 9 Variação do módulo de flexão com a temperatura para o copolímero em bloco [].

Figura 2. 10 Estrutura química do copolímero Etileno-Propileno. .25

Figura 2. 11 Tipos de monômeros diênicos utilizados em EPDM. 25

Figura 2 12. Reação com ENB durante a terpolimerização. 26

Figura 2. 13. Microestrutura do negro de fumo comparado com duas formas cristalinas regulares do carbono (diamante e grafite) [56]. 32

Figura 2. 14. Representação da polarização de Maxwell - Wagner. 36

Figura 2. 15 Separação entre cargas no momento de dipolo. 37

Figura 2. 17 Espectro de microondas obtido com borracha natural. O valor dP é a energia absorvida em relação à cavidade vazia [79].

Figura 2. 18 Energia absorvida por grama em função do tempo a $150^{\circ} \mathrm{C}$ para borracha natural com negro de fumo e sem negro de fumo [79].

Figura 2. 19. Exemplo de formação de uma rede condutora numa blenda composta por um polímero condutor e um isolante [17].

Figura 3. 1 Desenho esquemático do sistema utilizado para desvulcanização do EPDM []. 
Figura 3. 2 Imagens do filme obtido por processo mecânico (a) e sua flexibilidade (b).

Figura 3. 3. Três modos de termogravimetria. (a) TG isotérmica; (b) TG quaseisotérmica; (c) TG dinâmica.

Figura 3. 4 Arranjo para medidas de resistividade pelo método de quatro pontas (quatro terminais). A letra "a" representa a distância entre as pontas, que deve ser conhecida.

Figura 4. 1. Espectros de infravermelho da borracha dEPDM pura e de PAniDBSA/dEPDM em diferentes composições.

Figura 4. 2. Curvas termogravimétricas de dEPDM puro e blendas de PaniDBSA/dEPDM em diferentes composições.

Figura 4. 3. Curvas DSC de dEPDM puro e das blendas de PAni-DBSA/dEPDM...69 Figura 4. 4. Módulo de armazenamento em função da temperatura de dEPDM puro e blendas de PAni-DBSA/dEPDM em diferentes composições .71

Figura 4. 5. Tan $\delta$ em função da temperatura de dEPDM puro e blendas de PAniDBSA/dEPDM em diferentes composições.

Figura 4. 6. Imagens de microscopia óptica (MO) da amostra de dEPDM puro em magnitude $1.000 x-(a)$ foco na parte inferior e (b) foco na parte superior da mesma região.

Figura 4. 7. Imagens de microscopia óptica (MO) da blenda de PAni-DBSA/dEPDM 20/80 em magnitude $1.000 x$ - (a) foco na parte inferior e (b) foco na parte superior da mesma região.

Figura 4. 8. Imagens de MEV da borracha dEPDM pura em diferentes magnitudes:(a) 650x, (b) 5000x e (c) 20000x.

Figura 4. 9. Imagens de MEV da blenda de PAni-DBSA/dEPDM (02/98) em diferentes magnitudes: (a) 650x, (b) 5000x e (c) 20000x

Figura 4. 10. Imagens de MEV da blenda de PAni-DBSA/dEPDM (05/95) em diferentes magnitudes: (a) 650x, (b) 5000x e (c) 20000x.

Figura 4. 11. Imagens de MEV da blenda de PAni-DBSA/dEPDM (10/90) em diferentes magnitudes: (a) 650x, (b) 5000x e (c) 20000x.

Figura 4. 12. Imagens de MEV da blenda de PAni-DBSA/dEPDM (20/80) em diferentes magnitudes: (a) 650x, (b) 5000x e (c) 20000x. 
Figura 4. 13. Imagens de MEV da blenda de PAni-DBSA/dEPDM (30/70) em diferentes magnitudes: (a) 650x, (b) 5000x e (c) 20000x.....

Figura 4. 14. Imagens de MEV da blenda de PAni-DBSA/dEPDM (50/50) em diferentes magnitudes: (a) 650x, (b) 5000x e (c) 20000x.

Figura 4. 15. Difratograma de raios- $X$ da dEPDM pura e das blendas de PAniDBSA/dEPDM em diferentes concentrações.

Figura 4. 16. Condutividade elétrica como uma função da composição da blenda para filmes de PAni-DBSA/dEPDM preparados por processo mecânico. .86 


\section{LISTA DE TABELAS}

Tabela 2. 1. Estrutura dos principais polímeros intrinsecamente condutores [15]......7

Tabela 2. 2. Algumas aplicações dos polímeros condutores. ..................................9

Tabela 2. 3. Os estados de oxidação mais importantes da polianilina:

leucoesmeraldina, esmeraldina (isolante e condutora) e pernigranilina [15] .............11

Tabela 2. 4. Especificações Técnicas para Elastômeros Automotivos.......................29

Tabela 2. 5. Formulação da borracha - Ensaio de Lucchese [79] ..........................42

Tabela 4. 1. Picos característicos do dEPDM puro e das blendas de PAniDBSA/dEPDM em diferentes concentrações. 63

Tabela 4. 2. Valores de Tg de dEPDM puro e das blendas de PAni-DBSA/dEPDM obtidas por DSC 


\section{LISTA DE ABREVIATURAS E SIGLAS}
ABS
Terpolímero de acrilonitrila-butadieno-estireno
BC
Banda de Condução
BV
Banda de Valência
CR
Policloropreno
CSA
Ácido Canforsulfônico
DBSA
Ácido dodecilbenzeno sulfônico
DCP
Diciclopentadieno
DMTA
Análise térmica dinâmico-mecânica
DRX
Difratometria de raios- $X$
DSC
Calorimetria diferencial de varredura
dEPDM
Etileno-propileno-monômero dieno desvulcanizado
EB
Base esmeraldina
ENB
Etilideno - Norborneno
EPDM
Etileno-propileno-monômero dieno
EPM
Etileno-propileno-monômero
EPR
Ressonância paramagnética eletrônica
ES
Sal esmeraldina
FTIR
Espectroscopia no infravermelho por transformada de Fourier
$\mathrm{HCl}$
Ácido clorídrico
HIPS
Poliestireno de alto impacto
HX
Trans 1-4 Hexadieno
MDS
Espectroscopia de perda dielétrica por microondas
MEV
Microscopia eletrônica de varredura
MO
Microscopia Óptica
NBR
Borracha Nitrílica
$\mathrm{NH}_{4} \mathrm{OH}$
Hidróxido de amônia
NR
Borracha Natural
PAni
Polianilina
PAni-DBSA
Polianilina dopada com ácido dodecilbenzeno sulfônico
PE
Polietileno
phr
Partes por Cem
PMMA
Poli(metil metacrilato) 


$\begin{array}{ll}\text { PPV } & \text { Poli(p-fenileno vinileno) } \\ \text { PS } & \text { Poliestireno } \\ \text { PS-b-BR } & \text { Poliestireno- } b \text {-polibutadieno } \\ \text { PVB } & \text { Poli(vinil-butiral) } \\ \text { PVC } & \text { Cloreto de Polivinila } \\ \text { PVDF } & \text { Poli(fluoreto de vinilideno) } \\ \text { SBR } & \text { Borracha estireno-butadieno } \\ \text { SBS } & \text { Estireno-butadieno-estireno } \\ \text { SEBS } & \text { Estireno-etileno-butileno-estireno } \\ \text { Tg } & \text { Transição Vítrea } \\ \text { TGA } & \text { Análise Termogravimétrica } \\ \text { TMTDS } & \text { Disulfeto de Tetrametil tiurano }\end{array}$




\section{LISTA DE SÍMBOLOS}

\begin{tabular}{ll} 
A & Área \\
$\mathbf{C}$ & Velocidade da Luz \\
$\mathbf{d}$ & Espessura Média \\
$\mathbf{E}$ & Campo Elétrico \\
$\mathbf{f}$ & Freqüência \\
$\mathbf{F}$ & Força \\
$\mathbf{n}$ & Corrente Elétrica \\
$\mathbf{P}$ & Densidade de Carga \\
$\mathbf{q}$ & Polarização de Campo \\
$\mathbf{R}$ & Carga \\
$\mathbf{t}$ & Resistência Elétrica \\
$\mathbf{V}$ & Tempo \\
$\mathbf{x}$ & Tensão Elétrica \\
$\boldsymbol{\varepsilon}$ & Separação entre Cargas \\
$\mu$ & Constante Dielétrica \\
$\mathbf{v}$ & Mobilidade de Carga \\
$\rho$ & Velocidade de Deslocamento de Carga \\
$\sigma$ & Resistividade Elétrica \\
\hline & Condutividade Elétrica
\end{tabular}




\section{CAPÍTULO I: INTRODUÇÃO}

\subsection{INTRODUÇÃO}

O estudo de blendas poliméricas é uma área fascinante da pesquisa de materiais. A motivação inicial da fabricação de blendas foi tentar reduzir as limitações que alguns polímeros apresentam, tais como a fragilidade e a baixa resistência mecânica ao impacto. No caso de polímeros condutores intrínsecos é necessário melhorar as propriedades mecânicas e a processabilidade, preservando sua condutividade elétrica.

O desenvolvimento destes polímeros tem atraído grande atenção da comunidade científica devido seu grande potencial para aplicações tecnológicas, tais como baterias recarregáveis, coberturas de proteção contra corrosão, músculos artificiais, dentre outras [1]. No entanto, suas propriedades mecânicas pobres, baixa estabilidade térmica e insolubilidade em solventes orgânicos comuns impediram, por muitos anos, o seu uso pela indústria de polímeros [2].

O mais importante dos polímeros condutores são as blendas com polianilinas devido à sua fácil processabilidade, solubilidade, estabilidade química e térmica, dopagem e baixo custo do monômero. Blendas condutoras de polianilina (PAni) com poli(metil metacrilato) (PMMA) $[3,4]$, poliestireno (PS) $[5,6]$, polietileno (PE) $[7,8]$ e terpolímero etileno-propileno-dieno monômero (EPDM) [9] já foram obtidas, e um grande número de aplicações práticas foram propostas [10,11,12]. 


\subsection{OBJETIVOS DESTE TRABALHO}

Os objetivos deste trabalho podem ser resumidos em:

a) Preparar blendas poliméricas de PANI-DBSA (polianilina dopada com ácido dodecilbenzeno sulfônico) com o copolímero etileno-propileno-monômero dieno (EPDM) desvulcanizado por microondas proveniente do descarte da indústria de autopeças.

b) Caracterizar as blendas obtidas por técnicas tradicionais como:

espectroscopia no infravermelho (FTIR), calorimetria diferencial de varredura (DSC), análise termogravimétrica (TGA), análise térmica dinâmico mecânica (DMTA), difratometria de raios-X (DRX), microscopia óptica (MO) e microscopia eletrônica de varredura (MEV).

c) Estudar o comportamento elétrico das blendas obtidas.

\subsection{ORGANIZAÇÃO DA DISSERTAÇÃO}

O capítulo II desta Dissertação de Mestrado apresenta uma revisão bibliográfica, onde há uma breve introdução histórica dos materiais poliméricos. Uma revisão sobre a estrutura química, morfologia, processabilidade e propriedades da polianilina e do copolímero etileno-propileno-monômero dieno foram descritos. Métodos de desvulcanização de borracha foram apresentados e a desvulcanização por microondas foi descrita em detalhes. O capítulo III mostra os materiais utilizados e o processo de obtenção das blendas. As técnicas utilizadas na caracterização das blendas obtidas e a metodologia empregada estão apresentadas. O capítulo IV mostra os resultados experimentais e discussões dos ensaios de caracterização das blendas quanto à estrutura química, à morfologia e às propriedades elétricas. Por fim, as conclusões deste trabalho estão apresentadas no capítulo $V$ e as referências bibliográficas utilizadas estão reportadas no capítulo VI. 


\section{CAPÍTULO II: REVISÃO BIBLIOGRÁFICA}

\subsection{CONTEÚDO DESTE CAPÍTULO}

Neste capítulo uma breve introdução histórica sobre polímeros é apresentada. Morfologia, estrutura química e propriedades de polianilina (PAni) e seus derivados e de etileno-propileno-monômero dieno (EPDM) foram descritas em detalhes. Uma abordagem sobre blendas poliméricas foi feita. O negro de fumo (agente de reforço do EPDM) foi apresentado. Por fim, métodos de vulcanização foram citados e a desvulcanização por microondas é apresentada em detalhes.

\subsection{INTRODUÇÃO HISTÓRICA}

A ciência dos polímeros desenvolveu-se a partir do século $X X$, tendo início em 1920, quando Herman Staudinger formulou o conceito de macromoléculas como princípio estrutural para plásticos, borrachas, fibras, tintas e adesivos [13].

Posteriormente a formulação do conceito de macromoléculas, os polímeros passaram a ser estudados como uma ciência com características próprias, o que acarretou um rápido desenvolvimento nesta área. Nas décadas de 1930 e 1940, foram sintetizados e comercializados os primeiros polímeros, como o poliestireno (PS), o poli(cloreto de vinila) (PVC), poliacrilatos, polietileno de baixa densidade, borracha estireno-butadieno (SBR) e as fibras de poliamidas alifáticas (Nylon) [14].

A síntese dos polímeros vinílicos, obtidos por polimerização via radicais livres, foi a grande novidade da década de 1950. Neste período surgiram também polímeros com melhores propriedades, como: polietileno de alta densidade molar, 
policarbonatos, poliuretanos, resinas epóxi, fibras acrílicas de poliacrilonitrila, novas borrachas sintéticas e tintas em forma de látex [14].

Na década de 1960, foram desenvolvidos polímeros especiais para atender as necessidades do mercado. Estes possuíam estrutura química mais complexa, com uma elevada resistência mecânica e química, com alta temperatura de amolecimento (acima de $300^{\circ} \mathrm{C}$ ). São exemplos destes polímeros as poliimidas, poliésteres aromáticos, poliamidas aromáticas e fluorpolímeros. Dentre estes polímeros estão também os elastômeros termoplásticos, porém estes não são usados em alta temperatura [13].

Até então os polímeros eram considerados materiais eletricamente isolantes. A idéia de associar propriedades elétricas dos metais às propriedades mecânicas dos polímeros ocorreu neste período, pela incorporação de cargas condutoras (negro de fumo, fibras metálicas ou fibra de carbono) (Figura 2. 1), produzindo os chamados "polímeros condutores extrínsecos" (extrínseco, pois a carga condutora é adicionada) [15], apresentando condutividade elétrica da ordem de $10^{-15}$ a $10^{-5} \mathrm{~S} / \mathrm{cm}$, quando misturados com negro de fumo ou metais [16]. No entanto, a inclusão destas partículas em uma matriz isolante pode tornar o material mais frágil devido à grande concentração necessária para que seja alcançada uma condutividade elétrica adequada.

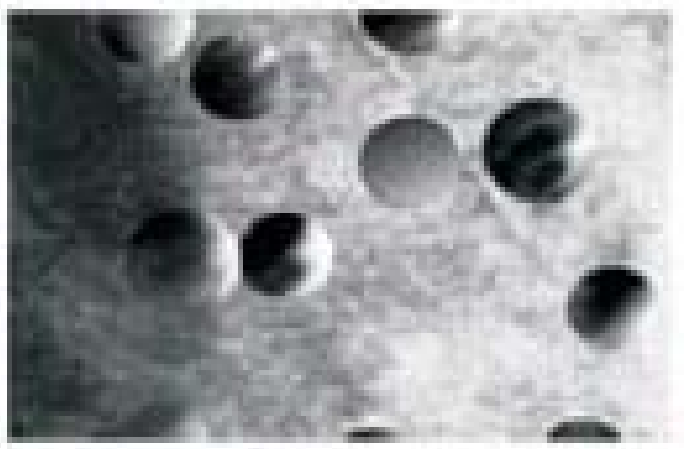

(a)

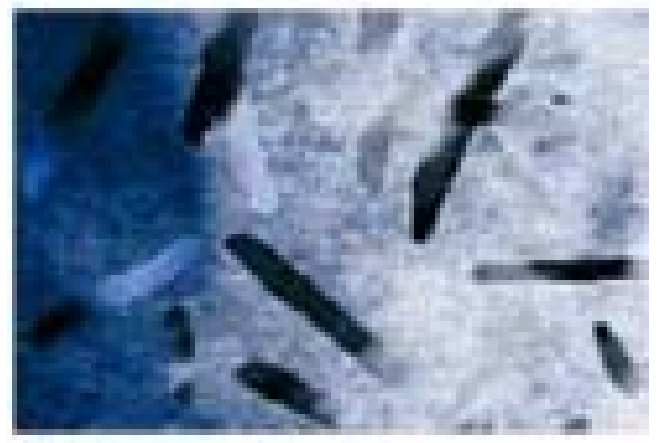

(b)

Figura 2. 1 - Dopagem de polímeros isolantes através da inclusão de partículas de negro de fumo (a) e de metais (b) [17]. 
Por volta de 1970, foi a vez da descoberta dos chamados "metais sintéticos", isto é, polímeros orgânicos que possuem propriedades elétricas, magnéticas e ópticas, semelhantes às de metais e semicondutores inorgânicos, mantendo a leveza, processabilidade e propriedades mecânicas de um polímero convencional.

\subsection{POLÍMEROS CONDUTORES INTRÍNSECOS}

Os polímeros condutores intrínsecos foram descobertos na segunda metade da década de 70, quando Shirakawa trabalhou junto com Heeger no laboratório de MacDiarmid, na Universidade da Pensilvânia. Eles produziram o primeiro "metal orgânico", ao descobrirem que a condutividade do poliacetileno poderia ser aumentada cerca de 10 ordens de grandeza, por meio de sua oxidação com cloro, bromo ou vapor de iodo; este processo, por analogia com a dopagem de semicondutores extrínsecos, foi chamado de "dopagem" [18]. Em 1977 [18], o poliacetileno na forma isolante (condutividade elétrica, $\sigma=10^{-5} \mathrm{~S} / \mathrm{cm}$ ) foi exposto a agentes dopantes tornando-se condutor elétrico (condutividade elétrica, $\sigma=10^{2}$ $\mathrm{S} / \mathrm{cm})$. A condutividade elétrica dos polímeros condutores pode ser comparada à de outros materiais conforme a Figura 2. 2.

Uma característica chave dos polímeros condutores é a presença de ligações duplas entre carbonos (-C=C-) conjugadas ao longo da cadeia polimérica (Tabela 2. 1), sendo assim, mais adequado chamá-lo de polímero conjugado. Na conjugação (Figura 2. 3), as ligações entre os átomos de carbono são, alternadamente, simples e duplas. 


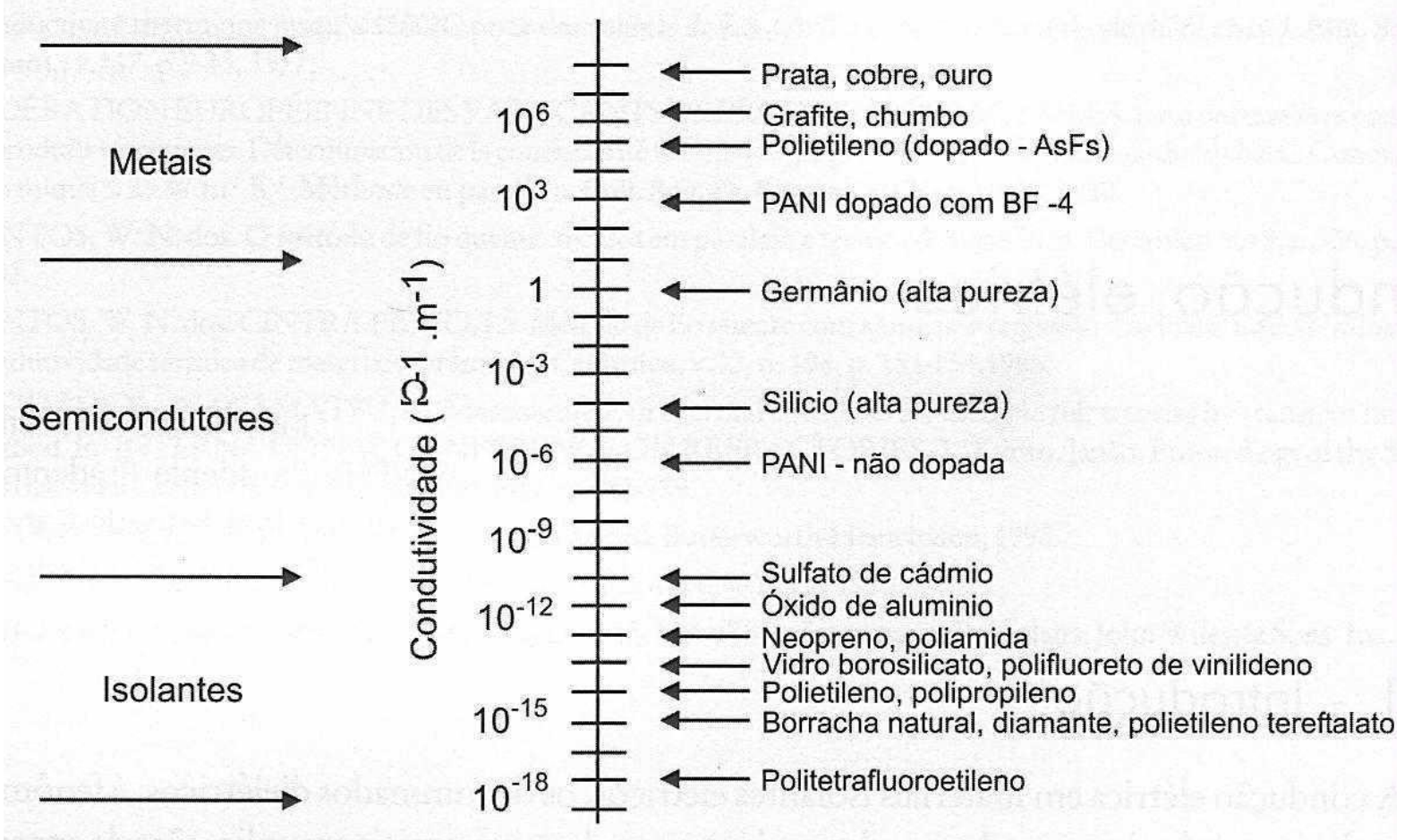

Figura 2. 2. Diagrama mostrando as condutividades elétricas (em $\Omega \mathrm{m}$ ) de diferentes materiais.<smiles>C=CC=CC=CC=C</smiles>

Figura 2. 3 Esquema das ligações simples e duplas alternadas dos polímeros conjugados. 
Tabela 2. 1. Estrutura dos principais polímeros intrinsecamente condutores [15].

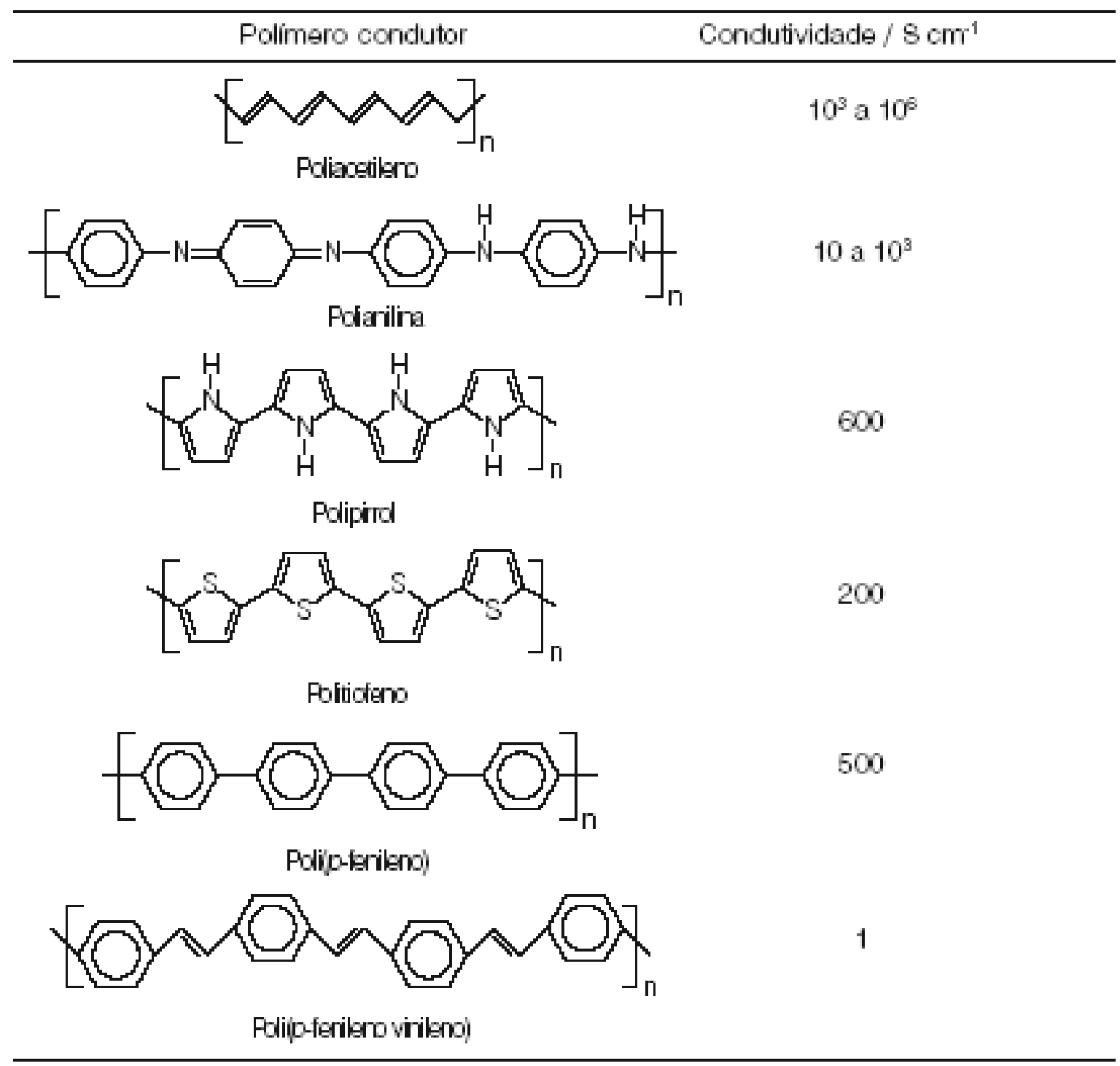

Cada ligação contém uma ligação "sigma" $(\sigma)$ que forma uma ligação quimicamente forte. Por outro lado, cada ligação dupla também contém uma ligação "pi" $(\pi)$ menos fortemente localizada e, por isso, mais fraca. Entretanto, não basta que o polímero tenha ligações duplas conjugadas. Para que ele se torne condutor elétrico, tem de ser perturbado (dopado), tanto por meio da remoção de seus elétrons (oxidação) como por meio da inserção de elétrons (redução) [18].

Os polímeros intrinsecamente condutores têm atraído a atenção de inúmeros grupos de pesquisa desde a sua descoberta [19], tanto pela importância científica em se entender este novo fenômeno como pelo seu potencial em aplicações 
tecnológicas [20,21]. Estes polímeros podem combinar as propriedades mecânicas e processabilidade dos polímeros convencionais com um comportamento elétrico, ótico e magnético semelhante ao dos metais e semicondutores inorgânicos. Esta característica faz com que estes materiais se enquadrem na categoria dos chamados metais sintéticos [22]. Um grande impulso foi dado nos últimos anos $[23,24,25,12,26]$ na aplicação tecnológica destes materiais em baterias recarregáveis, dispositivos eletrônicos, sensores químicos e térmicos, bio-sensores, janelas inteligentes, diodos emissores de luz, eliminação de carga estática, microeletrônica, proteção contra corrosão, recobrimento de materiais, etc.

Um critério importante na seleção de polímeros potencialmente condutores é a facilidade com que o sistema pode ser oxidado ou reduzido. Isto leva a escolha de polímeros com insaturações conjugadas, que possuem baixo potencial de oxidação. Os elétrons $\pi$ podem ser facilmente removidos ou adicionados, para formar um íon polimérico, sem a destruição das ligações necessárias para a estabilidade da macromolécula.

Este princípio básico tem sido aplicado com sucesso para um número crescente de polímeros condutores [20,21], tais como polifenilenos, polipirróis, politiofenos e polianilinas. O poliacetileno ainda é o polímero que tem alcançado o maior valor de condutividade [19,20], igualando-se a do cobre ( $\left.\sigma=10^{5} \mathrm{~S} / \mathrm{cm}\right)$. No entanto, pela estabilidade térmica e ambiental e difícil processamento (insolubilidade e infusibilidade) do mesmo, outros polímeros condutores têm sido extensivamente investigados com o objetivo de superar estas dificuldades.

Por esta razão, a polianilina e polímeros derivados da anilina como a poli(ortometoxianilina) têm recebido grande atenção nos últimos anos pela sua estabilidade química em condições ambientais, processabilidade, facilidade de polimerização e dopagem, com baixo custo. Estas vantagens viabilizam várias aplicações tecnológicas que já vêm sendo desenvolvidas, inclusive industrialmente [27].

As aplicações e propriedades dos polímeros condutores podem ser verificadas na Tabela 2. $2[28,15]$. 
Tabela 2. 2. Algumas aplicações dos polímeros condutores.

\begin{tabular}{|c|c|c|}
\hline Aplicação & Fenômeno & Uso \\
\hline Eletrodos & Transferência de carga & $\begin{array}{l}\text { Baterias recarregáveis, } \\
\text { sensores e capacitores }\end{array}$ \\
\hline $\begin{array}{c}\text { Dispositivos } \\
\text { eletrocrômicos }\end{array}$ & $\begin{array}{c}\text { Variação de cor com aplicação } \\
\text { de potencial elétrico }\end{array}$ & Janelas inteligentes \\
\hline $\begin{array}{l}\text { Músculos } \\
\text { artificiais }\end{array}$ & $\begin{array}{l}\text { Movimentação mecânica de } \\
\text { um filme pela aplicação de } \\
\text { potencial elétrico }\end{array}$ & $\begin{array}{c}\text { Transdutor mecânico para } \\
\text { robótica }\end{array}$ \\
\hline LEDs & Emissão de luz & Monitores e mostradores \\
\hline $\begin{array}{l}\text { Protetor anti- } \\
\text { estático }\end{array}$ & Eliminação de carga estática & Microeletrônica \\
\hline Anti-corrosivos & Proteção contra corrosão & Tintas \\
\hline Células solares & $\begin{array}{l}\text { Transformação de energia } \\
\text { luminosa em energia elétrica }\end{array}$ & $\begin{array}{c}\text { Fonte alternativa de } \\
\text { energia }\end{array}$ \\
\hline $\begin{array}{c}\text { Blindagem } \\
\text { eletromagnética }\end{array}$ & $\begin{array}{l}\text { Absorção de radiação (diminui } \\
\text { interferência eletromagnética } \\
\text { nos equipamentos eletrônicos) }\end{array}$ & $\begin{array}{l}\text { Marinha, aeronáutica e } \\
\text { telecomunicações }\end{array}$ \\
\hline
\end{tabular}

Associados aos polímeros condutores, surgiram os chamados polímeros conjugados de segunda geração, os quais possuem propriedades eletro-ópticas, tendo particular interesse os polímeros eletroluminescentes. Isto aconteceu em 1990, com a descoberta da possibilidade de emissão de luz do poli(p-fenileno vinileno), PPV [29]. 


\subsection{POLIANILINA}

As polianilinas representam uma classe de polímeros, cuja composição química na forma de base (não dopada) é dada por uma estrutura química conforme ilustra a Figura 2. 4.

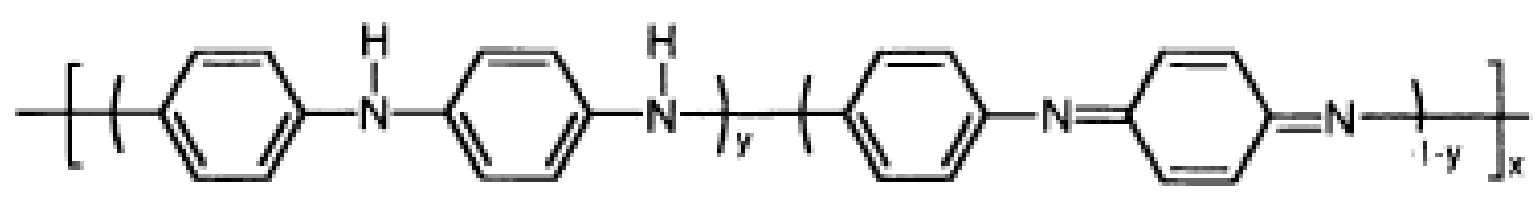

Figura 2. 4. Estrutura química da polianilina na forma de base (não dopada).

Esta estrutura química é composta por unidades repetidas [30,31,32] das espécies reduzidas (y) e oxidadas (1-y), conforme mostradas na Figura 2. 5.

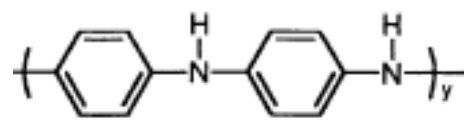

$(y)=$ reduzida

(a)

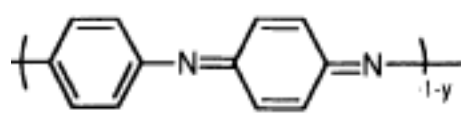

$(1-y)=$ oxidada

(b)

Figura 2. 5. Unidades de repetições que compõem a estrutura química da polianilina: (a) espécie reduzida e (b) espécie oxidada.

O valor de y pode variar continuamente entre 1 (um) para o polímero completamente reduzido (contendo somente nitrogênios amina) e 0 (zero), no caso do polímero completamente oxidado (contendo somente nitrogênios imina) [33]. Os diferentes graus de oxidação da polianilina (Tabela 2. 3) são designados pelos termos leucoesmeraldina, protoesmeraldina, esmeraldina, nigranilina e pernigranilina, quando y for igual a $1 ; 0,75 ; 0,5 ; 0,25$; e 0 respectivamente. 
Tabela 2. 3. Os estados de oxidação mais importantes da polianilina: leucoesmeraldina, esmeraldina (isolante e condutora) e pernigranilina [15].

Estado de oxidaçáo

* Os valores numéricos referem-se ao comprimento de onda (em nanometros) onde a absorçáo é máxima.

As propriedades condutoras da PAni foram descobertas quando se aplicou o conceito de dopagem estabelecido para semicondutores inorgânicos aos polímeros. A dopagem de polímeros como poliacetileno, polipirrol e politiofeno é feita através de redução e oxidação da cadeia polimérica (dopagem do tipo n ou p); no entanto, a PAni possui uma dopagem diferenciada, do tipo não-redox, obtida através da protonação da cadeia. Este processo coloca a PAni num lugar de destaque entre os polímeros condutores, aliados à facilidade de síntese, estabilidade química e térmica [26], sendo, por isso, o polímero condutor mais explorado.

A polianilina forma outra classe de polímeros condutores porque pode ser dopada por protonação, isto é, sem que ocorra alteração do número de elétrons (oxidação ou redução associados à cadeia polimérica) [33]. Logo os nitrogênios desta espécie podem estar, total ou parcialmente, protonados para se obter o polímero na forma de sal (forma dopada). O estado de oxidação esmeraldina é a forma na qual após dopagem, a polianilina alcança os maiores valores de condutividade e dopagem química da polianilina no estado esmeraldina é feita por protonação em solução ácida aquosa. O grau de protonação da base depende do grau de oxidação que o polímero foi sintetizado, e do pH da solução dopante. 


\subsubsection{SÍNTESE DE POLIANILINAS}

A polianilina (PAni) pode ser sintetizada na forma de pó utilizando-se um oxidante químico apropriado, ou na forma de filmes finos pela oxidação eletroquímica do monômero sobre eletrodos de diferentes materiais inertes. $\mathrm{O}$ baixo custo do monômero aliado à facilidade de síntese e de dopagem da polianilina faz com que esse polímero seja economicamente viável, já sendo inclusive comercializada por algumas indústrias [13,27,34], para aplicações especiais em um primeiro estágio.

A síntese convencional $[35,36]$ da PAni tem grande vantagem de produzir um polímero de alta massa molar e de elevada pureza, que pode ser obtido diretamente no estado dopado, em grandes quantidades, na forma de um pó verde.

Por outro lado, a síntese eletroquímica [37] da PAni possui algumas vantagens sobre a síntese química: não necessita de agente oxidante e catalisador, facilidade de caracterização "in situ" por técnicas espectroscópicas, e o polímero é obtido diretamente na forma de filmes finos. No entanto, para o estudo das propriedades físicas e aplicações tecnológicas, a síntese química tem sido mais indicada.

A obtenção de materiais com massas molares altas e controláveis, é extremamente desejável em tecnologia de polímeros, pois com isso várias propriedades desses materiais podem ser melhoradas. Para polímeros condutores, em particular, a condutividade elétrica e a resistência mecânica aumentam significativamente com o aumento da massa molar. É interessante observar que, ao contrário do que ocorre com outros polímeros condutores, para a PAni foi desenvolvido um método de síntese para a obtenção de polímeros de alta massa molar e controlável numa grande faixa $[38,39]$. 


\subsubsection{DOPAGEM DA POLIANILINA}

A condução elétrica na polianilina envolve um novo conceito $[40,32,41]$ em polímeros condutores. A polianilina forma uma nova classe de polímeros condutores, pela possibilidade de ser facilmente dopada por protonação [32,33]. De acordo com este processo, a base esmeraldina - EB (azul) é tratada com um ácido forte $\left(\mathrm{H}^{+} \mathrm{A}\right)$, por exemplo, o ácido dodecilbenzenosulfônico (DBSA), como mostrado na Figura 2. 6, ou ácido canforsulfônico (CSA) [42,43,31]. Este processo transforma a base esmeraldina (isolante) em sal esmeraldina - ES (verde, forma dopada) (eletricamente condutor). A condutividade deste material protonado não se altera durante longos períodos de exposição ao ar. A desprotonação ocorre reversivelmente por tratamento semelhante com solução aquosa básica. A base de esmeraldina pode ser dopada com um ácido protônico não oxidante, diferindo de todos os outros polímeros condutores [44], por não ocorrer mudança no número de elétrons associados à cadeia polimérica.

Os demais polímeros condutores [44] possuem, em geral, íons de carbono, porém o sal de esmeraldina difere destes apresentando-se como um polímero, no qual a carga positiva reside primordialmente no nitrogênio.

Estudos sugerem que a protonação da polianilina não é homogênea [41], mas que ocorre a formação de domínios completamente protonados, que originam ilhas metálicas embebidas em regiões não protonadas isolantes. Foi proposto que estas ilhas condutoras possuem a característica especial de serem simples cadeias poliméricas protonadas e condutoras, onde os polarons são formados por injeção de carga.

O tipo de dopante utilizado (inorgânico, orgânico ou poliácido) influencia decisivamente nas estruturas e propriedades das polianilinas (solubilidade, cristalinidade, condutividade elétrica, resistência mecânica, etc.) [26].

A polianilina pode sofrer um efeito de auto-dopagem quando o estado esmeraldina reage com ácido sulfúrico concentrado. Neste caso, um átomo de 
hidrogênio do anel benzênico é substituído pelo grupo $-\mathrm{SO}_{3} \mathrm{H}$, resultando em uma polianilina sulfonada dopada $(\sigma=0,1 \mathrm{~S} / \mathrm{cm})$ [45]. O próton dopante não consegue se difundir para longe da cadeia polimérica, devido ao contra-íon ao qual está quimicamente ligado, e a PAni se mantém dopada mesmo para meios neutros ou levemente básicos, o que não ocorre para a PAni convencionalmente dopada [26].

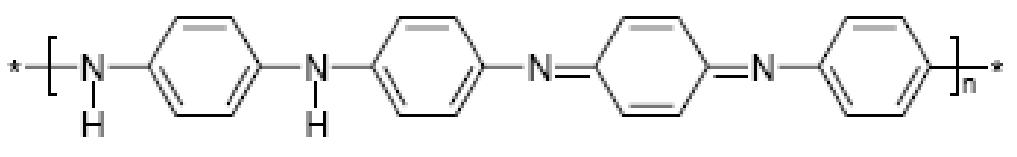

Polianilina - Base Esmeraldina
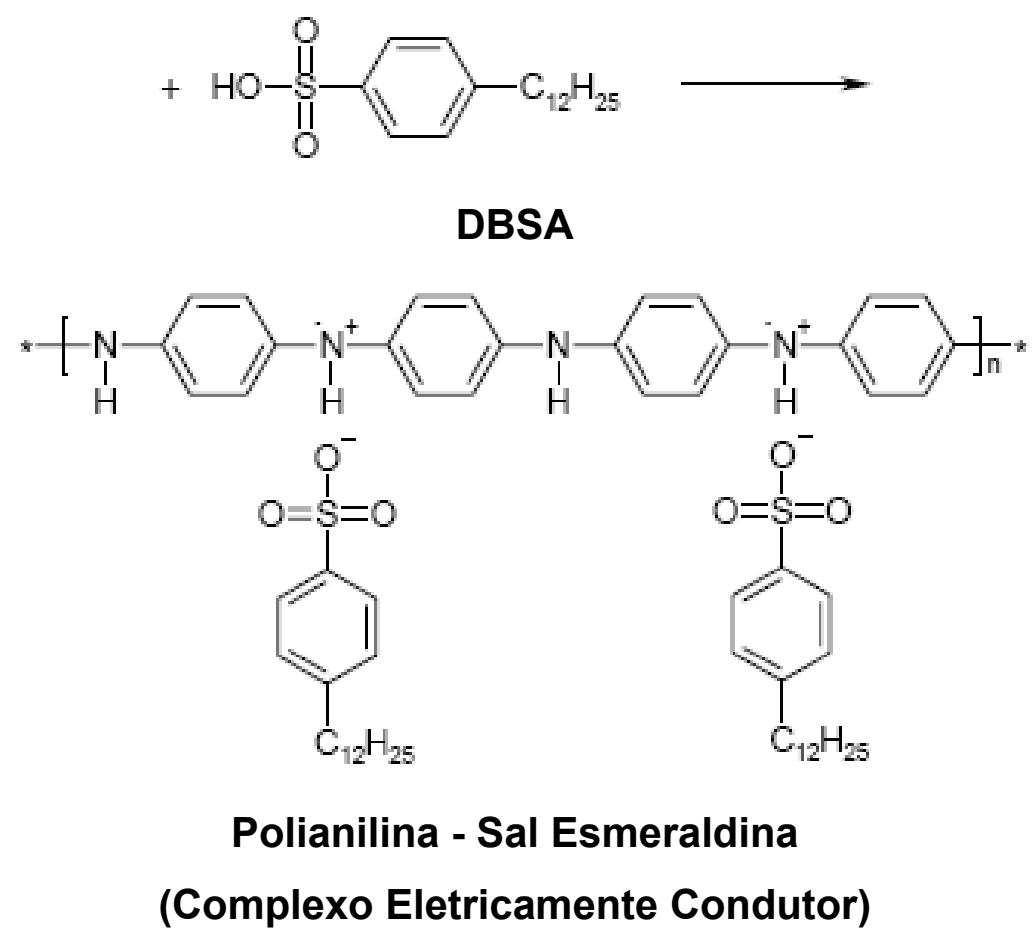

Figura 2. 6. Representação esquemática da protonação da forma base esmeraldina da PAni por DBSA.

Outro fenômeno importante do dopante se refere à dopagem secundária [46,47,48], na qual a combinação de um ácido orgânico funcionalizado e um solvente apropriado promove uma mudança conformacional das cadeias poliméricas 
de enoveladas para estendidas, efeito este acompanhado por um aumento adicional da condutividade da PAni, atingindo $\sim 200$ S/cm.

\subsubsection{ESTRUTURA E MORFOLOGIA DE POLIANILINAS}

A estrutura e morfologia da PAni dependem não só do método de síntese que determina a pureza e linearidade da cadeia principal do polímero, mas também da dopagem (natureza do dopante e nível de dopagem) e das condições de processamento do polímero. Desta forma, um número grande de estruturas amorfas e cristalinas, e morfologias podem ser obtidos devido à variedade de métodos de sínteses e dopantes existentes.

A polianilina foi considerada durante muito tempo como um material amorfo [49], porém, detectou-se por medidas de difração de raios- $X$ um grau de cristalinidade de até $50 \%$ [50]. Isto é muito interessante, pois é conhecido o fato de que os polímeros condutores, em geral, (por exemplo, poliacetileno) apresentam aumento da condutividade elétrica com o aumento do grau de orientação e da cristalinidade do polímero $[20,22]$.

Os primeiros estudos nesta área, foram realizados por Wang e colaboradores. [51] que demonstraram que a polianilina não dopada apresentava espectros de raios-X característicos de uma amostra amorfa. Porém, quando o polímero é dopado em $\mathrm{HCl}$ a cristalinidade aumenta de $5 \%(\mathrm{pH}=6)$ para até $30 \%(\mathrm{pH}=0-1)$. Observouse que a cristalinidade também depende das condições de polimerização, sendo os maiores valores de cristalinidade obtidos para a síntese com persulfato de amônio e ácido clorídrico.

É necessário ressaltar que os altíssimos valores de condutividade observados [52] para a PAni de alta massa molar e orientada ( 7.000 S/cm), foram obtidos para um polímero basicamente amorfo. Isto expõe a controvérsia quanto ao efeito de cristalinidade e confirma a grande influência da microestrutura apresentada pelo 
polímero, que é uma função das condições de síntese, dopagem e processamento na estrutura da PAni.

A investigação da morfologia superficial da polianilina tem sido realizada através da técnica de microscopia eletrônica de varredura, mostrando ser dependente das condições de síntese, dopagem e processamento [53,54]. Estudos [51] em polianilina sintetizada por via química (em pó) apresentaram uma morfologia granular para amostras dopadas e não dopadas. Contudo, o tamanho de grão apresentou-se maior para o polímero dopado. Mais tarde uma morfologia fibrilar para o polímero foi obtida para filmes de PAni e derivados.

\subsection{CONDUTIVIDADE ELÉTRICA}

A descoberta de que polímeros orgânicos podem conduzir carga elétrica [55] criou esta nova classe de materiais: os polímeros intrinsecamente condutores. Desde então, não cessam os estudos visando à otimização de sua condutividade elétrica, sem que haja prejuízo das propriedades típicas dos materiais poliméricos. Os polímeros condutores podem ter valores de condutividade que vão desde isolante até condutor dependendo do grau de dopagem $[55,20]$.

A condutividade elétrica dos polímeros foi primeiramente explicada com base no "modelo de bandas", semelhante aos semicondutores inorgânicos. Em um cristal, como em um polímero, a interação da cela unitária com todos os seus vizinhos leva à formação de bandas eletrônicas. Os níveis eletrônicos ocupados de mais alta energia constituem a banda de valência (BV) e os níveis eletrônicos vazios de mais baixa energia, a banda de condução (BC). Estes são separados por uma faixa de energia proibida chamada de "band-gap", cuja largura determina as propriedades elétricas intrínsecas do material [15].

No caso do poliacetileno, uma oxidação remove elétrons do topo da banda de valência e uma redução adiciona elétrons na banda de condução. Isso forma bandas 
semi-preenchidas, como no caso dos metais. No entanto, esse modelo não explica o fato de que a condutividade está associada a portadores de carga de spin zero e não a elétrons deslocalizados.

Da mesma forma que em qualquer sólido semicondutor, em um polímero o processo de ionização resulta na criação de uma lacuna no topo da banda de valência. Neste caso, três observações podem ser feitas:

1. Pela definição exata do processo, nenhuma relação geométrica (distorção do retículo) ocorre na cadeia polimérica.

2. A carga positiva gerada permanece deslocalizada sobre toda a cadeia polimérica.

3. A presença da lacuna (nível desocupado) no topo da banda de valência confere um caráter metálico ao processo.

Contudo, em sólidos unidimensionais, dos quais os polímeros condutores fazem parte, pode ser energeticamente favorável localizar a carga que aparece sobre a cadeia (criando um defeito) e ter ao redor desta carga uma distorção local do retículo (relaxação). Esse processo resulta no aparecimento de estados eletrônicos localizados no interior da banda proibida.

Considerando-se o caso da oxidação, isto é, a remoção de um elétron da cadeia, há a formação de um cátion radical (também chamado de polaron em química dos sólidos). Isto pode ser interpretado como uma redistribuição de elétrons $\pi$, que polariza a cadeia polimérica apenas localmente, produzindo uma modificação de curto alcance na distribuição espacial dos átomos. No processo de formação do polaron, a banda de valência permanece cheia e a banda de condução vazia, e não há o aparecimento do caráter metálico, uma vez que o nível parcialmente ocupado está localizado na banda proibida.

Quando um segundo elétron é removido da cadeia, podem-se ter duas situações: ou o elétron é removido da cadeia polimérica, ocasionando a criação de mais um estado polaron, ou é removido do estado polaron já existente; neste caso, ocorre a formação de um bipolaron, que é definido como um par de cargas iguais. A 
formação de um bipolaron é mais provável em relação à formação de dois polarons, uma vez que o ganho de energia decorrente da interação de duas cargas com o retículo é maior do que a repulsão coulômbica entre as cargas de mesmo sinal.

Portanto, assim como nos semicondutores inorgânicos, os polímeros condutores devem ser dopados para apresentar maior condutividade. Entretanto, de forma diferente dos semicondutores inorgânicos, os portadores de carga não são elétrons ou buracos localizados no interior de bandas e sim defeitos carregados, os polarons e bipolarons, localizados ao longo da cadeia polimérica. Essa particularidade influencia diretamente o mecanismo de transporte no interior da cadeia do polímero [15].

A condutividade intrínseca $(\sigma)$ pode ser expressa como o produto da carga (q), da densidade de carga dos portadores ( $n$ ) e da mobilidade de carga $(\mu)$ :

\section{Equação 2. $1 \quad \sigma=q n \mu(\mathrm{S} / \mathrm{cm})$}

Portanto, qualquer variação de densidade ou mobilidade de carga, alterará a condutividade intrínseca. A variação inclui a mudança de estrutura cristalina, tipos de dopantes, etc.. A densidade de carga depende do número de polarons deslocalizados que vem dos bipolarons ou polarons em condução. Isto pode ser postulado conforme a Figura 2. 7: 


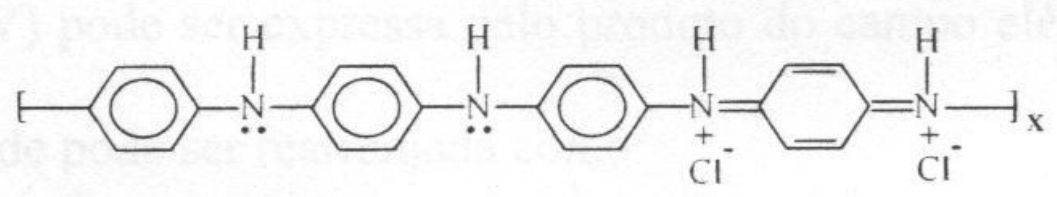

Bipolaron (pobre mobilidade de carga)

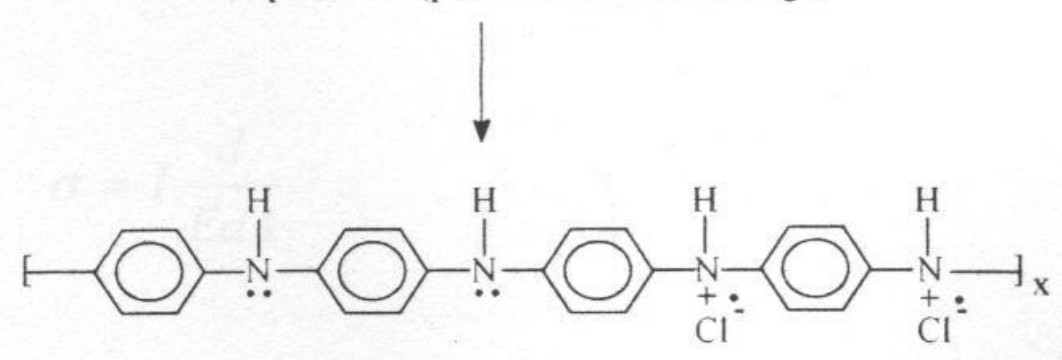

Polaron (localizado)

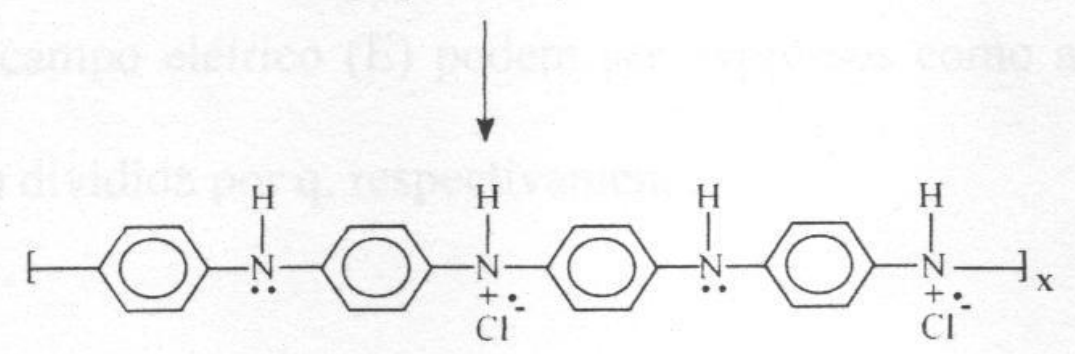

Polaron (delocalizado com boa mobilidade de carga)

Figura 2. 7. Esquema de condução polarônica em polianilina.

A Equação 2. 2 é derivada da Lei de Ohm, e a mobilidade de carga ( $\mu$ ) é definida como a razão da velocidade de deslocamento de carga sobre a força $(F)$.

$$
\text { Equação 2. } 2 \quad R=\frac{V}{I}(\Omega) \text { Lei de Ohm e } \mu=\frac{V}{F} \quad \text { (V/cm.s) }
$$

mas $\sigma$ é definida como a resistividade recíproca que pode ser expressa por:

$$
\text { Equação 2. } 3 \quad \sigma=\frac{1}{\rho}=\frac{d}{R \cdot A}(\mathbf{S} / \mathbf{c m})
$$

Onde d e A são a espessura média e a área da secção reta da amostra, respectivamente. Como $\mathrm{R}=\mathrm{V} / \mathrm{I}$, temos: 


$$
\text { Equação 2. } 4 \quad \sigma=I\left(\frac{d}{V . A}\right) \quad(\mathbf{S} / \mathbf{c m})
$$

mas a tensão elétrica $(V)$ pode ser expressa pelo produto do campo elétrico $(E)$ e espessura (d). A condutividade pode ser reescrita como:

$$
\text { Equação 2.5 } \quad \sigma=I\left(\frac{d}{E . d . A}\right) \quad(\mathbf{S} / \mathbf{c m})
$$

A corrente elétrica (I) e o campo elétrico (E) podem ser expressos como a carga dividida por tempo e a força $(F)$ dividida por $\mathrm{q}$, respectivamente.

A nova expressão de condutividade elétrica é:

$$
\text { Equação 2. } 6 \quad \sigma=\frac{q . q . d}{t . F . d . A} \quad(\mathbf{S} / \mathbf{c m})
$$

onde $\mathrm{q} / \mathrm{dA}$ e d/t são iguais a densidade de carga (n) e velocidade de deslocamento de carga $(v)$, respectivamente. Então, a condutividade elétrica $(\sigma)$ pode ser expressa por:

$$
\text { Equação 2. } 7 \quad \sigma=\frac{q . n . v}{F} \quad(\mathbf{S} / \mathrm{cm})
$$

onde v/F é a definição de mobilidade ( $\mu$ ). Portanto, temos:

$$
\text { Equação 2. } 8 \quad \sigma=q . n . \mu \quad(\mathrm{S} / \mathrm{cm})
$$

Basicamente, a carga (q) e a densidade de carga (n) podem aumentar para elevados graus de dopagem. Entretanto, a alta ionização da cadeia principal pode impedir o movimento de cargas $(\mu)$ devido à forte atração dos contra-íons. Conseqüentemente, q, n e $\mu$ não são independentes um dos outros. 


\subsection{ELASTÔMEROS}

Já na época do descobrimento da América em 1492, foi constatado que os habitantes do que é hoje a Amazônia, Guatemala e México, utilizavam um objeto estranho para fabricar sandálias e ao mesmo tempo impermeabilizavam tecidos. $\mathrm{O}$ problema era que este material ficava pegajoso em épocas quentes e rígidos em épocas frias [56].

Surgiu então, a preocupação de se estabilizar e secar estes materiais; muitos cientistas pesquisaram maneiras de desenvolver este processo de secagem, e o mérito de Charles Goodyear descobrir em 1839 um feito que iria revolucionar a indústria da borracha: que o enxofre acima do seu ponto de fusão transformaria a borracha de seu estado original plástico em elástico, estável, e com capacidade de suportar variações de temperatura [56].

A indústria de borracha, embora esteja entre as indústrias mais antigas, as quais são geralmente conservadoras, tem mostrado um desenvolvimento visivelmente progressivo nas últimas décadas (1990 e 2000). Os desenvolvimentos no campo de elastômeros sintéticos têm progredido tão rapidamente que novos conceitos de tecnologia de borracha têm surgido [57].

Uma variedade de tipos de borracha, borrachas sintéticas, tecnologias de processamento, técnicas analíticas e métodos de teste foram desenvolvidos e melhorados desde então. Muitos conceitos antigos tiveram de ser modificados em face às novas descobertas, ou completamente abandonados. As definições de terminologia de borracha e elastômeros estão tornando-se, progressivamente, mais ambíguas desde que os limites entre elastômeros e termoplásticos têm caído [57].

Elastômeros ou borrachas são classes de materiais como metais, fibras, concreto, madeira, plásticos ou vidro, sem os quais a tecnologia moderna seria inconcebível. Atualmente o consumo anual de borracha eleva-se para mais de 13 milhões de toneladas. Cerca de um terço da borracha global total usada é a borracha natural, produzida em plantações ou por pequenos produtores na Malásia, 
Indonésia ou outros países do sudeste da Ásia, bem como no oeste da África, América do Sul e América Central. Os dois terços remanescentes de borracha requerida são produzidos sinteticamente por um grande número de países industriais, bem distribuídos através do mundo. Hoje a matéria-prima para a produção de borracha sintética ainda é, na maior parte, petróleo [57].

Elastômero é um polímero constituído de macromoléculas lineares de elevado peso molecular, com a temperatura de transição vítrea $(\mathrm{Tg})$ abaixo da temperatura ambiente, o que the confere a flexibilidade característica. As macromoléculas são ligadas entre si por ligações químicas realizadas na presença de enxofre, na maioria das vezes, mas também através de peróxidos orgânicos. Tem a capacidade de atingir elevadas deformações (maiores que 500\%) durante o estiramento e recuperar a deformação original após a retirada da tensão. Os elastômeros apresentam baixos módulos elásticos a baixas deformações e altos módulos a altas deformações [56]. A Figura 2. 8. Conformação molecular da borracha.Figura 2. 8 ilustra a capacidade de estiramento das moléculas de borracha.

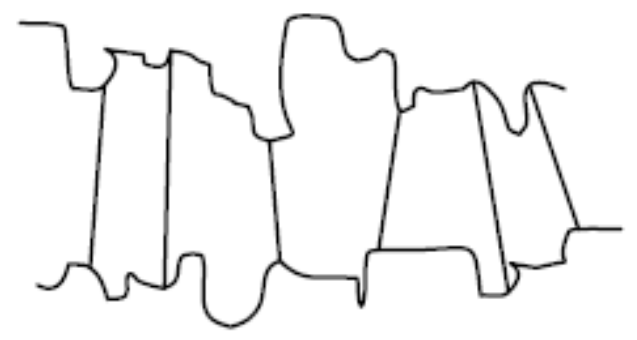

Livre de tensão

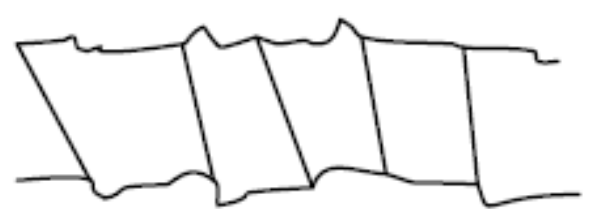

Sob tensão

Figura 2. 8. Conformação molecular da borracha.

A propriedade predominante dos elastômeros é o comportamento elástico após deformação na compressão ou tensão. É, por exemplo, possível estirar um elastômero dez vezes o seu comprimento original, e depois de retirar a tensão, este retornará, sob circunstâncias ideais, à sua forma e comprimento original. Além disso, 
os elastômeros são caracterizados por sua grande resistência a tensões estáticas e dinâmicas, resistência à abrasão (a qual, em vários casos, é maior do que a do aço), pela impermeabilidade ao ar e à água, e em muitos casos, pela resistência a inchar em solventes, e ao ataque químico [57]. Estas propriedades são observadas à temperatura ambiente e temperaturas maiores, e são, em certas condições, conservadas à maioria das condições climáticas e a atmosferas ricas em ozônio.

Borrachas são, também, capazes de aderir a fibras têxteis e a metais. $\mathrm{Na}$ combinação com fibras, poliamida, poliéster, vidro ou cordão de aço e, dependendo das propriedades do agente de reforço, a resistência à tensão aumenta consideravelmente com a redução da extensão. Pela mistura de elastômeros com metais obtém-se, por exemplo, componentes que combinam a elasticidade dos elastômeros com a rigidez dos metais [57].

As composições elastoméricas fazem uso de grande variedade de aditivos para modificar ou alterar algumas propriedades específicas da borracha. Entre esses aditivos podem ser citados, por exemplo, os agentes de reforço, formadores de espuma, odorantes, fungicidas e retardantes de chama [58,59,60]. Um desses aditivos é o negro de fumo ("carbon black", termo em inglês) ${ }^{1}$.

\subsection{PROPRIEDADES DOS ELASTÔMEROS TERMOPLÁSTICOS}

Os elastômeros termoplásticos apresentam sistemas de duas fases, os quais mostram muitas características individuais dos polímeros que compõe as fases. Por exemplo, o copolímero em bloco de poliestireno-b-polibutadieno (PS-b-BR) apresenta duas transições vítreas, uma do polibutadieno e a outra do poliestireno.

\footnotetext{
${ }^{1}$ O negro de fumo está descrito na seção 2.9 NEGRO DE FUMO.
} 


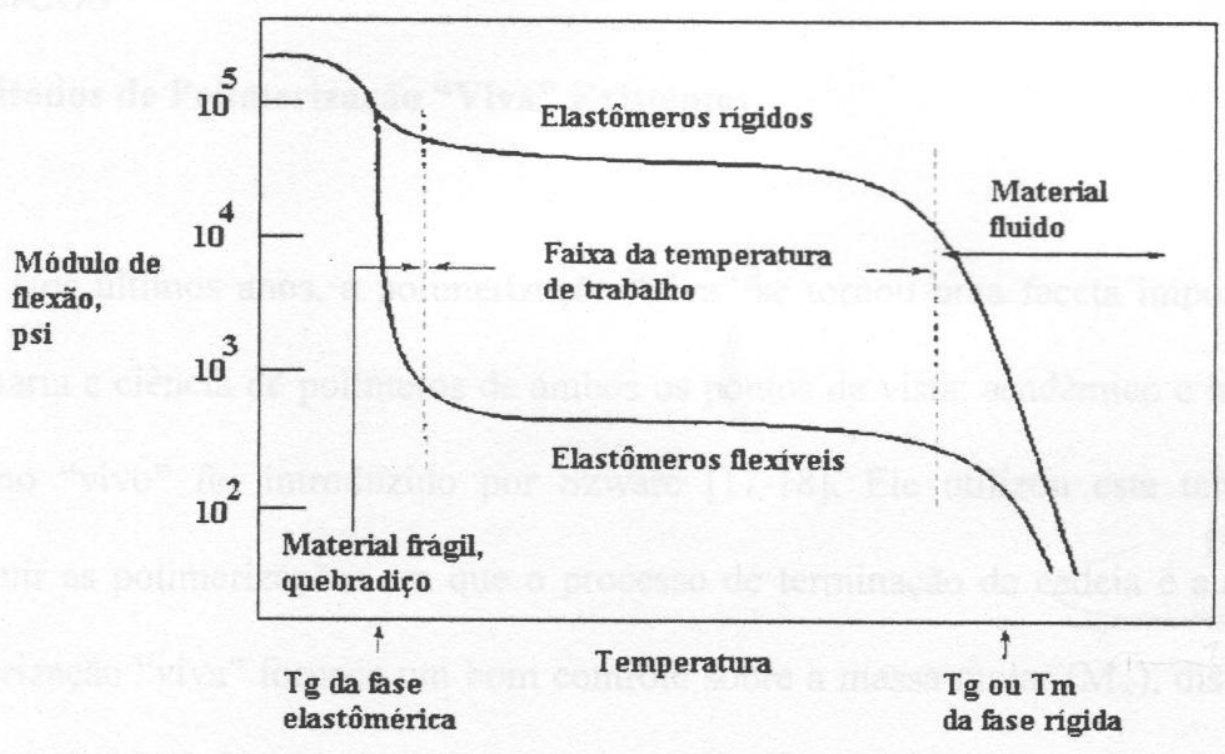

Figura 2. 9 Variação do módulo de flexão com a temperatura para o copolímero em bloco [61].

Em temperaturas muito baixas, ambas as fases do copolímero são rígidas e frágeis, entretanto, com o aumento da temperatura a fase elastomérica torna-se flexível. Nesta etapa, tem-se início uma faixa de temperatura em que os módulos de perda e de elasticidade ficam praticamente constantes e esta região é conhecida como platô borrachoso [62]. Finalmente, com o aumento da temperatura, a fase rígida também se torna flexível e a partir deste ponto o elastômero termoplástico torna-se fluido, como pode ser observado na Figura 2. 9.

\subsection{EPDM (Etileno-Propileno-Monômero Dieno) [56,63]}

À temperatura ambiente, o polietileno é um termoplástico cristalino, mas sob aquecimento passa através de uma fase "elastomérica". Pela interferência com a cristalização do polietileno, isto é, pela incorporação nos elementos da cadeia polimérica, o que inibe a cristalização, a temperatura de fusão e, por conseguinte a fase elastomérica pode ser obtida abaixo da temperatura ambiente [57]. 
Durante a copolimerização aleatória do etileno com propileno poderemos ter como resultado um polímero amorfo (EPM) ou copolímero de etileno - propileno que não contém insaturação, motivo pelo qual esta borracha somente poderá ser curada com peróxidos. A Figura 2. 10 representa a estrutura química da borracha de Etileno Propileno (EPM).

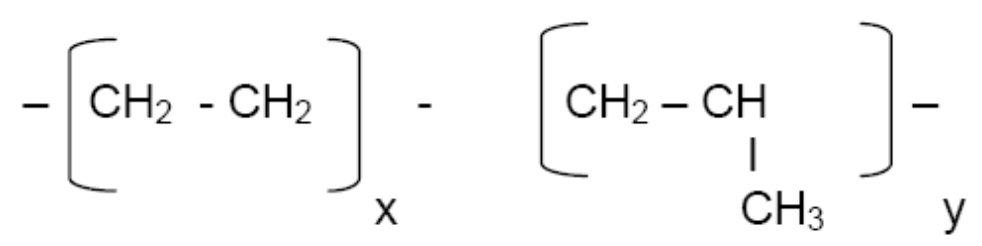

Figura 2. 10 Estrutura química do copolímero Etileno-Propileno.

Se, durante a copolimerização do etileno e propileno, um terceiro monômero (um dieno), é adicionado, a borracha resultante terá insaturação, e pode ser vulcanizada com enxofre. Estas borrachas são chamadas EPDMs. A maioria dos EPDMs comerciais contém cerca de $40 \%$ e $80 \%$ em massa de etileno[57].

Em escala comercial somente três tipos de monômeros diênicos são utilizados e em todos eles, a insaturação se dará em ramificações da cadeia principal. São eles (Figura 2. 11):

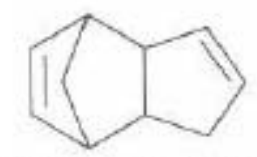

Diciclopentadieno (DCP)

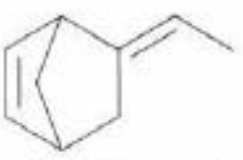

Etilideno-Norborneno (ENB)

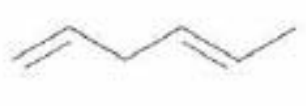

Trans 1-4 Hexadieno

$(\mathrm{HX})$

Figura 2. 11 Tipos de monômeros diênicos utilizados em EPDM.

A reação do ENB durante a terpolimerização resulta na estrutura mostrada na Figura 212. 


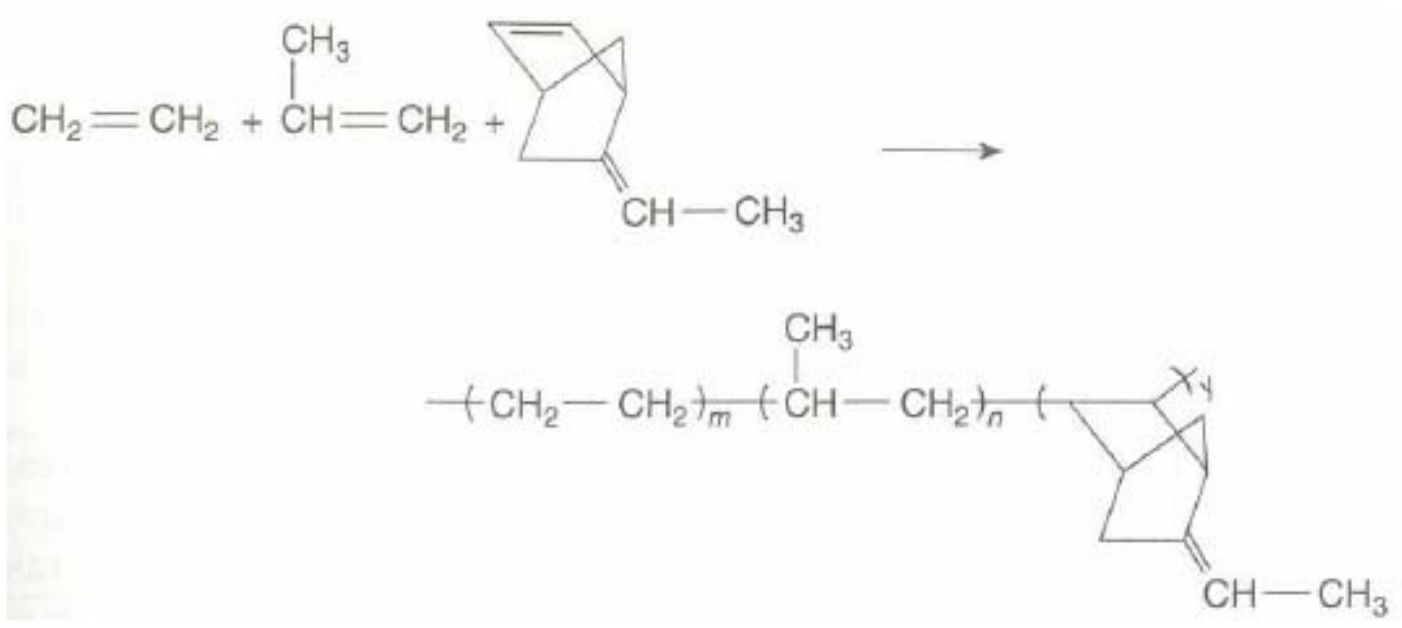

Figura 2 12. Reação com ENB durante a terpolimerização.

A copolimerização com o terceiro monômero não é fácil porque as duas insaturações do termonômero devem ter reatividades diferentes, para que uma reaja com a cadeia principal, e a outra fique livre na ramificação para reagir depois com o enxofre. Além disso, esta insaturação deve ser extremamente reativa com enxofre.

As insaturações estão nos grupos laterais localizados nas ramificações da cadeia principal, que por sua vez é completamente saturada. Isso confere ao EPDM uma excelente resistência à degradação na presença de oxigênio e ozônio, porque qualquer reação indesejada de oxidação ou ozonização se dará em algum grupo lateral insaturado, e se acontecer, o prejuízo às propriedades da borracha será menor.

É comum a adição de Etileno Propileno Dieno Monômero (EPDM), à razão de até $30 \%$ em peso a outros polímeros que têm insaturação na cadeia principal (NR, SBR), para melhorar a resistência ao ozônio e à degradação termoxidativa.

Blendas de EPDM com borracha nitrílica (NBR) são de interesse econômico para substituir a borracha de policloropreno (CR) em aplicações onde se requer resistência a óleos e ao envelhecimento sob intempéries. 
A pesquisa sobre EPDM ainda continua objetivando produtos de maior qualidade e menor preço. É o elastômero de crescimento mais rápido entre as borrachas sintéticas desde a sua introdução em 1963. Representa $7 \%$ do consumo de borracha mundial e é a borracha mais utilizada quando não se trata de pneus. Isto se deve a sua excelente resistência ao ozônio quando comparada à borracha natural e seus similares sintéticos (Borracha Isopreno, Borracha Butadieno e Borracha Butadieno Estireno) [63].

\subsubsection{PROPRIEDADES DO EPDM VULCANIZADO}

O nível das propriedades mecânicas depende, consideravelmente, do tipo e da quantidade de cargas de preenchimento (como negro de fumo) no componente. A tensão mecânica da borracha EPDM a altas temperaturas e a flexibilidade à baixa temperatura, comparam-se às alcançadas pela borracha natural (NR) vulcanizada. No entanto, suas propriedades elásticas são melhores que a borracha estireno butadieno (SBR), mas não alcançam o nível obtido pela borracha natural vulcanizada [57].

A borracha EPDM tem uma excelente resistência às intempéries climáticas e também ao ozônio.

Quanto à resistência química, a EPDM não é atacada por ácidos diluídos, acetona, álcool e fluidos hidráulicos. Porém, ácidos inorgânicos concentrados endurecem ou destroem as borrachas vulcanizadas [57].

A borracha EPDM possui também excelentes propriedades de isolações elétricas e dielétricas, mesmo a altas temperaturas e após ação de calor. 


\subsubsection{USOS DE EPM E EPDM}

Os principais usos são em aplicações automotivas, tais como na produção de perfis de portas, mangueiras, lacres, cabos isolantes e encapsulamento, tão bem como em produtos que tenham de ser resistentes ao calor, clima e água salgada. Em 1978, das 150.000 toneladas de EPM e EPDM que eram produzidas nos Estados Unidos, 11\% foram usadas para pneus, 42\% produtos automotivos, exceto pneus, como radiador, molduras de portas e janelas, e pára-choques, $7 \%$ para produtos não automotivos, como máquina de lavar, $6 \%$ para cabos elétricos, $20 \%$ para modificadores plásticos, e 14\% para aplicações diversas como perfis de janelas e arquiteturas ou lacres [57].

\subsubsection{RECICLAGEM DE EPDM}

$\mathrm{Na}$ história da química, os estudiosos sempre se sentiram desafiados a entender o enigma sobre a postura do ser humano, observada a partir do desenvolvimento da ciência dos polímeros. Se, por um lado, o homem mostrou genialidade e capacidade realizadora ao criar, desenvolver e consolidar a tecnologia e o mercado dos polímeros, tornando o negócio de plásticos, elastômeros e resinas em um negócio global, amplo, atraente e dinâmico em apenas 60 anos considerando que o maior impulso e a concentração dos investimentos no setor petroquímico ocorreram após o final da II Guerra Mundial (1945). Por outro lado, a sociedade, nesse mesmo tempo, não investiu esforço equivalente, nem mostrou similar criatividade ou capacidade de usar racionalmente seus recursos na pesquisa de soluções para dois dos problemas e efeitos colaterais mais evidentes resultantes do crescente uso de polímeros sintéticos no mundo: a necessidade de desenvolver novas fontes de energia renovável e síntese dos polímeros, devido a fato de que as reservas de petróleo e gás são finitas. Também deveria se dar mais ênfase à valorização e reciclagem dos resíduos dos polímeros, uma vez que seu processo de decomposição natural é longo (acima de 100 anos) e crítico ao equilíbrio ecológico 
[64]. No caso da borracha vulcanizada, mais resistente que a borracha natural, quando queimada a céu aberto, contamina o meio ambiente com carbono, enxofre e outros poluentes.

Desde os anos 1980 houve um aumento do uso da borracha em automóveis, onde dentre as muitas aplicações, a maior parte destina-se aos pneus. Muitos tipos diferentes de elastômeros são usados para reunir as várias exigências térmicas, químicas e físicas destas aplicações. O ambiente automotivo fornece extremos em temperaturas, exposição a uma variedade de fluidos agressivos, fatiga, abrasão, e componentes químicos.

A escolha de um elastômero para o uso em uma aplicação particular é influenciada por muitos fatores (Tabela 2. 4) incluindo o ambiente de operação, desenho do componente, durabilidade, reciclabilidade, uso de conteúdo reciclado no componente, manufaturabilidade, qualidade, regulamentos governamentais e econômicos.

Tabela 2. 4. Especificações Técnicas para Elastômeros Automotivos.

- resistência ao calor

- resistência a fluidos

- flexibilidade à baixa temperatura

- comportamento de fratura

- características de fatiga

- estabilidade química por longo período

- permeabilidade

- capacidades de reciclagem

Além disto, os elastômeros devem durar um longo tempo e devem ser compatíveis com sistemas multi-materiais. A maioria dos componentes de borracha contém apenas $30-50 \%$ de base elastomérica misturada com a variedade de outros materiais (preenchimentos, plastificantes, extensores, estabilizantes, e materiais curáveis) para alcançar o desempenho específico requerido, tornando assim uma 
borracha vulcanizada. Devido aos compostos elastoméricos serem designados a maximizar o desempenho, a vida e estabilidade dos componentes, estes materiais não deterioram rapidamente e se acumulam nas áreas de eliminação [65].

Os destinos convencionais da borracha descartada são os depósitos a céu aberto e aterros; no entanto, existem algumas maneiras de reaproveitar este material que precisam ser mais difundidos como: reaproveitamento em materiais não poliméricos (asfalto e cimento); reciclagem do material na forma de pó; reciclagem por desvulcanização; mistura com outros materiais poliméricos; e mistura com elastômeros virgens.

No entanto, é muito difícil reciclar borrachas vulcanizadas, pois o processo de vulcanização implica na formação de ligações cruzadas, as quais de maneira positiva conferem boas propriedades mecânicas aos elastômeros, porém, por outro lado, fornecem características termorrígidas que dificultam a reciclagem do material. Por isso, dentre as várias maneiras de reaproveitamento da borracha, a reciclagem por desvulcanização é a alternativa mais promissora resultando em materiais de alto desempenho.

A reciclagem de EPDM consiste na reutilização do material desperdiçado [66] e no reprocessamento da sua forma virgem pela quebra de retículas entre as cadeias poliméricas (desvulcanização) [67].

Esforços para desvulcanizar a borracha EPDM são, principalmente, derivados de processos de reciclagem de pneus de borracha natural. No entanto, os métodos usados para reciclar pneus não podem, simplesmente, ser transferidos para a reciclagem de EPDM devido à diferença na estrutura (tipo de reticulação, grau de insaturação) entre as duas borrachas [68]. (Maiores detalhes sobre processo de desvulcanização estão escritos na seção 2.10 DESVULCANIZAÇÃO.) 


\subsection{NEGRO DE FUMO}

O carbono é o nono elemento químico mais abundante na natureza e se encontra combinado em centena de milhares de compostos, entre os quais se inclui a totalidade das substâncias orgânicas. Na forma não-combinada, o carbono elementar ou livre, constitui o componente predominante de alguns produtos com grande importância industrial, dentre eles o coque, o carvão vegetal, a grafite, o carvão ativo e o negro de fumo [69].

Negro de Fumo é um termo genérico usado para identificar uma ampla variedade de materiais carbonáceos finamente divididos, produzidos através da decomposição térmica controlada de hidrocarbonetos aromáticos. É largamente utilizado como agente reforçante para compostos de borracha, pigmentos para indústrias de tintas e de plásticos, protetor contra degradação por raios ultravioleta (U.V.) em certos polímeros e aplicações onde se requer condutividade elétrica, entre outras [70].

O negro de fumo é uma forma particulada de carbono elementar ou também conhecido como carbono industrial. Embora este seja constituído de carbono elementar, como as duas formas cristalinas do carbono - diamante e grafite existentes na natureza, o negro de fumo difere química e fisicamente destas formas puras e mais cristalinas do carbono.

A microscopia eletrônica mostra que as partículas de negro de fumo são constituídas por redes hexagonais planares de átomos de carbono. Estas redes ou camadas hexagonais são similares às encontradas na grafite, porém no negro de fumo são mais afastadas, são menores e menos extensas, e não têm nenhuma orientação vertical. Por isso, o negro de fumo é dito ter uma estrutura semi-grafítica.

A Figura 2. 13 apresenta a microestrutura semi-grafítica do negro de fumo comparada às outras duas microestruturas regulares do carbono - diamante e grafite. 


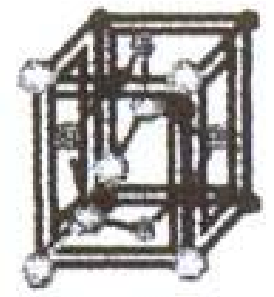

Diamante

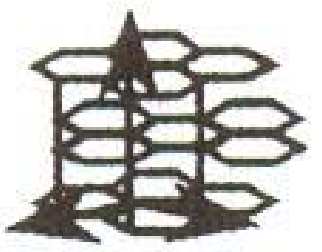

Grafite

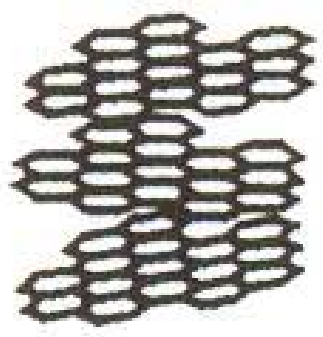

Negro de Fumo

Figura 2. 13. Microestrutura do negro de fumo comparado com duas formas cristalinas regulares do carbono (diamante e grafite) [56].

O negro de fumo é a carga de reforço mais utilizada nas composições elastoméricas, não só pelas excelentes propriedades que confere ao artefato, mas também pelo baixo custo e facilidade de processamento [71]. É conhecido que a incorporação de cargas particuladas, como negro de fumo, aumenta o desempenho mecânico de elastômeros vulcanizados. O termo reforço, em tecnologia de polímeros, significa aumento do desempenho mecânico, principalmente em resistências ao rasgamento, à tração e à abrasão. Uma conseqüência prática do reforço é o aumento na vida útil do artefato final de borracha. As cargas também aumentam o módulo de elasticidade e são freqüentemente usadas para este propósito, sendo o negro de fumo seu principal representante [72,73]. 


\subsection{DESVULCANIZAÇÃO}

Um material borrachoso é composto de macromoléculas (polímeros), e seu comportamento é influenciado por suas longas cadeias. As cadeias são flexíveis, os átomos de carbono são capazes de rotacionar sobre seus eixos, permitindo que as cadeias macromoleculares moldem-se em várias conformações. Conseqüentemente, podem ocorrer emaranhados entre estas cadeias.

A vulcanização ${ }^{2}$ é um processo de formar uma rede entre as cadeias macromoleculares pela reticulação. Depois da vulcanização, a borracha tem uma forma fixa e não pode mais fluir, devido à reticulação, o que prende as cadeias poliméricas umas às outras, e não permite que deslize. Portanto, ao contrário do que acontece em processos de reciclagem de termoplásticos, não é possível processar a borracha vulcanizada somente por aquecimento e dá-la uma nova forma geométrica [63].

A maior dificuldade para a reciclagem de produtos à base de elastômeros vulcanizados decorre das reticulações presentes em sua estrutura molecular. Essas reticulações geram uma estrutura na forma de rede tridimensional, que restringe a mobilidade das macromoléculas, dificultando e inviabilizando o reprocessamento [74].

Além disso, o descarte inadequado desses materiais provoca danos ao meio ambiente e à saúde do homem. Quando queimados, esses produtos ainda emanam, para a atmosfera, efluentes tóxicos e ainda possibilitam a migração de alguns

\footnotetext{
${ }^{2}$ Vulcanização é um processo termo-químico que incorpora enxofre e reticulações de enxofre em uma mistura de moléculas de borracha para melhorar a elasticidade e outras propriedades que são desejáveis na fabricação de produtos de borracha. no processo, átomos de enxofre são quimicamente ligados aos átomos de carbono das moléculas de borracha e servem como retilculações (ligações químicas) entre as moléculas de borracha sulfídica. $O$ processo de desvulcanização é irreversível sob condições atmosféricas padrão de temperatura e pressão.
} 
aditivos normalmente incorporados aos compostos elastoméricos, tais como estabilizantes, retardantes de chamas, pigmentos, plastificantes, etc., para o meio ambiente sob condições de intempéries [74].

A estrutura da borracha vulcanizada pode sofrer grandes modificações por meio da aplicação de uma quantidade de energia que seja capaz de romper, preferencialmente, as reticulações. Com base nesse princípio, vários métodos de desvulcanização (química, ultra-sônica, microondas, mecânica, biológica e outras) foram desenvolvidos.

A desvulcanização consiste na quebra das ligações carbono-enxofre, enxofreenxofre e carbono-carbono, gerando uma massa elastomérica degradada [75]. A quebra dessas ligações aumenta a plasticidade desses materiais, tornando-os adequados ao reprocessamento [76]. Os diferentes tipos de processos de desvulcanização modificam algumas propriedades da borracha que, idealmente, renderia um produto que poderia servir como um substituto para a borracha virgem, em termos de propriedades e em termos de custo de manufatura.

O processo de desvulcanização é um método potencial de reciclagem de borracha e o material resultante pode ser revulcanizado ou transformado em produtos úteis.

São métodos de desvulcanização [74]:

a) Desvulcanização química: são utilizados compostos químicos como agentes de regeneração. Esse processo apresenta a vantagem de possibilitar a quebra seletiva das reticulações sem que ocorra uma ruptura significativa da cadeia principal.

b) Desvulcanização por ultra-som: consiste na produção de ondas sonoras transversais, longitudinais e superficiais, de freqüências superiores a $20 \mathrm{kHz}$. Essas ondas são capazes de gerar vibrações nas moléculas da borracha, convertendo energia cinética em calor. O calor dosado adequadamente é capaz de promover a degradação controlada do elastômero. 
c) Desvulcanização mecânica: envolve a quebra das ligações químicas dos elastômeros através do cisalhamento intenso em moinhos, misturadores internos ou extrusoras. A borracha vulcanizada é degradada pela ação mecânica, que provoca o alongamento e a ruptura das macromoléculas.

d) Desvulcanização por microondas: este processo utiliza freqüências de 915 a 2.450 $\mathrm{MHz}$ e a borracha é exposta à energia das microondas sob condições controladas usando impulsos que podem romper ligações moleculares e atômicas produzindo borracha desvulcanizada. Este foi o método utilizado neste trabalho e será descrito na seção 3.4.1 DESVULCANIZAÇÃO DA BORRACHA EPDM POR MICROONDAS.

\subsubsection{INTERAÇÃO ENTRE MICROONDAS E MATERIAIS}

Em processamentos térmicos convencionais, a energia é transmitida ao material através de convecção, condução e irradiação de calor, a partir da superfície do material. $\mathrm{O}$ aquecimento através de microondas é possível porque existe uma interação molecular com o campo eletromagnético aplicado. A conversão de energia térmica é maior com microondas do que com o aquecimento convencional [77].

A origem do aquecimento com microondas está na habilidade do campo elétrico aplicado polarizar as cargas elétricas em parâmetro molecular, e no atraso do material em recuperar esta polarização inicial quando o campo elétrico é retirado (tempo de relaxação). Esse tempo de relaxação dielétrica é responsável pela dissipação de energia na forma de calor [77].

Esse deslocamento das cargas em relação à sua posição de equilíbrio forma um dipolo induzido, que se origina de uma polarização eletrônica quando o deslocamento ocorre nos elétrons que estão ao redor do núcleo, ou ainda de uma 
polarização atômica em função de uma distribuição desbalanceada de cargas na formação da molécula [78].

Em adição aos dipolos induzidos existem os dipolos permanentes, que vão se orientar também quando um campo elétrico for aplicado.

Finalmente, existe ainda a polarização de Maxwell - Wagner (Figura 2. 14) presente em sistemas heterogêneos e que se forma na interface entre os componentes [78].

A polarização orientada e a polarização de Maxwell - Wagner juntas, são a base para o aquecimento com alta freqüência [78].

\section{REDISTRIBUIÇÃO DE CARGA REDISTRIBUIÇÃO DO DIPOLO}
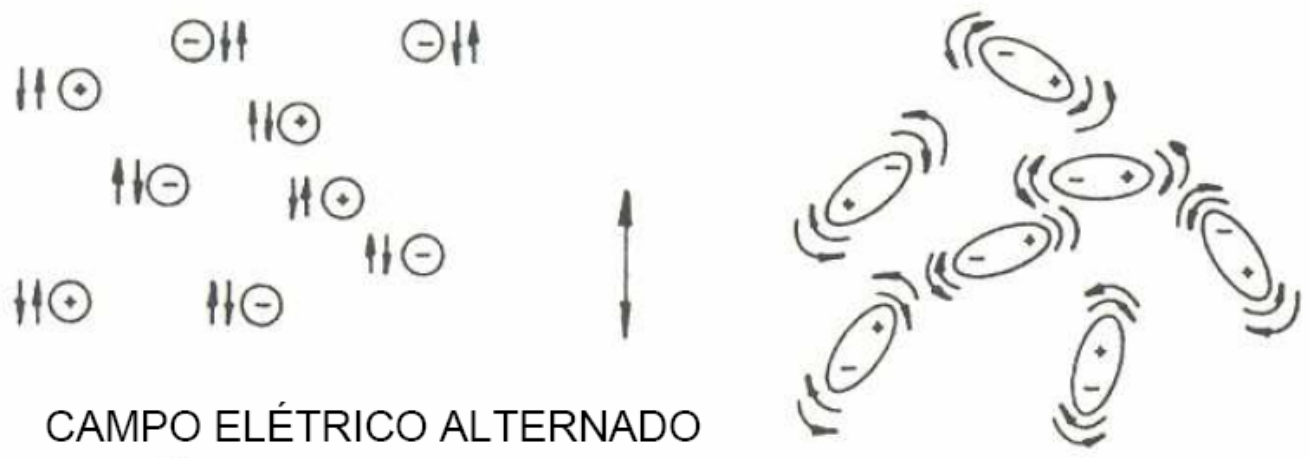

Figura 2. 14. Representação da polarização de Maxwell - Wagner.

O momento de dipolo médio de qualquer dipolo no material é dado pela Equação 2. 9

\section{Equação 2. $9 \quad \mu=q x_{i}$}

onde q é a carga e $x_{i}$ é a separação entre as cargas como ilustra a Figura 2. 15. 


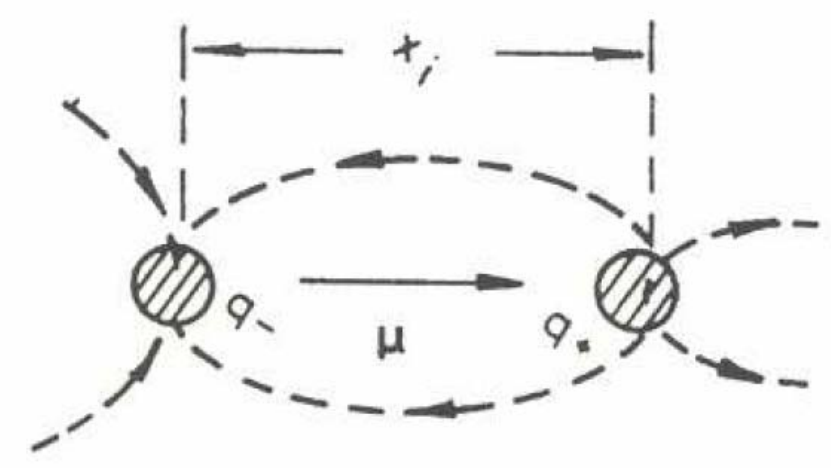

Figura 2. 15 Separação entre cargas no momento de dipolo.

A soma de todos os momentos de dipolo dentro de um volume, $\delta \mathrm{v}$, contendo $\mathrm{N}$ dipolos, resulta no tempo $\mathrm{P}$, chamado de polarização de campo (Equação 2. 10), que leva em consideração as cargas ligadas do sistema:

$$
\text { Equação 2.10 } \quad P=\sum_{i=1}^{n} \frac{q x_{i}}{\delta v}
$$

A carga total do sistema é dada por um vetor $D$ chamado de densidade de carga elétrica (Equação 2. 11), e a diferença entre os dois vetores resulta no total de cargas livres remanescentes do sistema, quando um campo elétrico externo E é aplicado:

$$
\text { Equação 2. } 11 D=\varepsilon_{0} E+P
$$

sendo que $\varepsilon_{0}$ é a constante dielétrica no espaço.

A razão entre as cargas ligadas e as cargas livres é chamada de susceptibilidade elétrica e é dada pela Equação 2. 12:

$$
\text { Equação 2. } 12 \quad X=\frac{P}{\varepsilon_{0} E}=\left(\varepsilon^{\prime}-1\right)
$$


sendo que $\varepsilon^{\prime}$ é a constante dielétrica relativa.

A polarização P para um dipolo individual N resulta em (Equação 2. 13):

\section{Equação 2. $13 \quad P=\mu N$}

Se um campo elétrico local E é aplicado a um dipolo individual, o momento de dipolo $\mu$ (Equação 2. 14) torna-se uma simples função do campo aplicado, assumindo ser linear [78]:

\section{Equação 2. $14 \quad \mu=\alpha_{t} E^{\prime}$}

onde a polarizabilidade total $\alpha_{t}$ é dada pela Equação 2. 15:

$$
\text { Equação 2. } 15 \quad \alpha_{t}=\alpha_{e}+\alpha_{a}+\alpha_{d}+\alpha_{M W}
$$

e os subscritos referem-se a eletrônico, atômico, dipolar e Maxwell-Wagner, respectivamente.

Combinando as equações Equação 2. 13 e Equação 2. 14 e considerando $D=\varepsilon_{0} \varepsilon^{\prime} E$ [78], chega-se à relação (Equação 2. 16):

\section{Equação 2. $16 \quad\left(\varepsilon^{\prime}-1\right) \varepsilon_{0} E=\alpha_{t} N^{\prime} E^{\prime}$}

A Equação 2. 16 faz uma ligação entre grandezas macroscópicas $\varepsilon^{\prime}$ e $E$ e as grandezas moleculares $N^{\prime}$ e $E^{\prime}$ e mostra que o campo elétrico $E^{\prime}$ experimentado pelos dipolos é diferente do campo elétrico aplicado $E$. Considerando que o processo microscópico envolve um volume esférico muito maior comparado às distâncias interatômicas e muito menor quando comparado às não homogeneidades atômicas, Mosotti derivou uma relação simples entre os dois campos (Equação 2. 17) [78]: 
Equação 2. $17 \quad E^{\prime}=(E / 3) \times\left(\varepsilon^{\prime}+2\right)$

\subsubsection{Constante Dielétrica Complexa}

A constante dielétrica $\varepsilon^{\prime}$ e a constante de perda $\varepsilon$ " quantificam as componentes capacitiva e condutiva da resposta dielétrica. Essas componentes são freqüentemente expressas em termos da constante dielétrica complexa $\varepsilon^{*}$ (Equação 2. 18) [77]:

Equação 2. $18 \varepsilon^{*}=\varepsilon^{\prime}-i \varepsilon^{\prime \prime}$

ou ainda do amortecimento elétrico (Equação 2. $19 \tan \delta=\left(\varepsilon^{\prime \prime}\right) /\left(\varepsilon^{\prime}\right)$ ):

Equação 2. $19 \tan \delta=\left(\varepsilon^{\prime \prime}\right) /\left(\varepsilon^{\prime}\right)$

\subsubsection{Conversão de Energia}

Assumindo-se ser uniforme um campo elétrico $E$ aplicado a um volume de material, a energia absorvida $\mathrm{P}$, por volume de material é dada pela Equação 2. 20 [77]:

\section{Equação 2. $20 \quad P=2 \pi f \varepsilon^{\prime \prime} E^{2}$}

sendo f a freqüência de operação do microondas.

A profundidade de penetração d da energia das microondas é dada pela Equação 2. 21: 


\section{Equação 2. $21 \quad d=\left(c \varepsilon_{0}\right) /\left(2 \pi f \varepsilon^{\prime \prime}\right)$}

sendo c a velocidade da luz.

A profundidade de penetração e o conhecimento de como o campo elétrico diminuem a partir da superfície, é importante no processamento dos materiais com a energia das microondas. Como a profundidade de penetração é muito menor do que a espessura do material, somente a superfície será aquecida e o restante do material será aquecido somente por condução [77]. Materiais com alta condutância e baixa capacitância (metais) têm altos valores de $\varepsilon^{\prime \prime}$ e pela Equação 2. 21 observase que a profundidade de penetração tende a zero; por este motivo são considerados refletores.

Materiais com baixos valores de $\varepsilon^{\prime \prime}$ terão grandes profundidades de penetração e absorvem pouca energia; por este motivo são considerados como transparentes. O limite para aquecimento de materiais com energia de microondas será então: $10^{-2}<\varepsilon^{\prime \prime}<5$ [78]. Muitos materiais em seu estado natural são virtualmente transparentes às microondas, exibindo $\varepsilon$ " abaixo de $10^{-3}$, e muito difíceis de serem aquecidos por microondas. É o caso das borrachas tais como SBR, NR, EPDM, silicone, etc.

Assim, nota-se que as propriedades mecânicas finais dos compostos são determinadas pelo tipo de elastômero, cargas, agentes de vulcanização, processo de mistura, etc. A quantidade de insaturações presentes no elastômero também vai determinar a quantidade de ligações formadas durante a vulcanização e a quantidade de ligações que deverão ser quebradas durante a irradiação com microondas.

Pela Equação 2. 21 e pela Erro! Fonte de referência não encontrada. vemos que a borracha de silicone, aqui representando as demais, tem a baixa capacidade de absorção em seu estado natural, o que impossibilitaria a desvulcanização por este processo. No entanto, a presença de negro de fumo 
(2.10.2 INFLUÊNCIA DO NEGRO DE FUMO NA ABSORÇÃO DE MICROONDAS) aumenta a capacidade de absorção porque introduz a polaridade necessária que originalmente as borrachas não têm.

Além da necessidade de introdução de uma carga que auxilie a borracha na capacidade de absorção, há que se preocupar com a quantidade de energia que será fornecida, porque o EPDM vulcanizado com enxofre tem ligações do tipo C-C, C-S e S-S principalmente, cujas energias de dissociação são respectivamente: $83 \mathrm{kcal} / \mathrm{mol}$ e $72 \mathrm{kcal} / \mathrm{mol}$. Por este motivo, durante a desvulcanização existe o risco de quebrar as ligações do tipo C-C e, não somente as ligações do tipo C-S ou S-S, o que levaria à perda de importantes propriedades mecânicas e limitaria a reutilização da borracha desvulcanizada [79].

\subsubsection{INFLUÊNCIA DO NEGRO DE FUMO NA ABSORÇÃO DE MICROONDAS}

A adição de negro de fumo em componentes elastoméricos é uma prática convencional, em virtude de sua capacidade de reforço. Após a sua adição, há a criação de uma interface com a fase borracha, que se estende até poucos nanômetros além da superfície das partículas de negro de fumo [80]. Além disso, a capacidade dos materiais como borrachas do tipo NR (borracha natural), SBR (Copolímero Butadieno - Estireno) e EPDM (Copolímero Etileno - Propileno) absorverem microondas, pode ser aumentada pela introdução controlada de impurezas ou aditivos, tais como negro de fumo [78].

Younan e colaboradores [81] estudaram as propriedades físicas e elétricas da borracha EPDM combinada com um tipo de negro de fumo a freqüências de microondas de $100 \mathrm{~Hz}$ até $10 \mathrm{MHz}$ e concluíram que o aumento nas propriedades dielétricas está relacionado com as interações entre a borracha e o aditivo.

Lucchese e colaboradores [80] utilizando a técnica MDS (Espectroscopia de perda dielétrica por microondas) mediram a perda dielétrica em matrizes de borracha 
com negro de fumo e sem negro de fumo. Utilizaram borracha natural (SMR5) e o negro de fumo Sterling SO (N550) e como agentes de cura utilizaram óxido de zinco, ácido esteárico e Disulfeto de Tetrametil tiurano (TMTDS) como estabilizantes, Agerite Resin D e Santoflex 13. Os compostos foram feitos conforme Tabela 2. 5.

Tabela 2. 5. Formulação da borracha - Ensaio de Lucchese [80]

\begin{tabular}{|c|c|c|c|c|}
\hline Ingredientes & $\begin{array}{c}\text { NR / SSO } \\
\text { (phr) }\end{array}$ & $\begin{array}{c}\text { NR } \\
\text { (phr) }\end{array}$ & $\begin{array}{c}\text { NRSSO } \\
\text { (phr) }\end{array}$ & $\begin{array}{c}\text { NES9 } \\
\text { (phr) }\end{array}$ \\
\hline SMR5 & 100 & 100 & 100 & 100 \\
\hline Sterling SO & 50 & - & 50 & 50 \\
\hline Óxido de zinco & - & 5 & 5 & 5 \\
\hline Ácido Esteárico & - & 1 & 1 & 1 \\
\hline TMTDS & - & 5 & 5 & 5 \\
\hline Santoflex 13 & - & - & - & 2 \\
\hline Agerite Resin D & - & - & - & 1 \\
\hline
\end{tabular}

Lucchese e colaboradores [80], a partir dessas formulações, vulcanizaram corpos de prova de $20 \mathrm{~mm} \times 4 \mathrm{~mm} \times 2 \mathrm{~mm}$, mediram o seu peso com precisão e os introduziram em um tubo de vidro de $75 \mathrm{~mm} \times 10 \mathrm{~mm} \times 10 \mathrm{~mm}$ (chamado de cavidade vazia). Uilizaram um equipamento marca MARCONI 10MHz - 20GHz 6200 e a técnica de Espectroscopia de Perda Dielétrica com microondas, no intervalo de 4,7 $4,9 \mathrm{GHz}$, que é a faixa característica para a absorção da energia de microondas com o negro de fumo Sterling SO [80]. A Figura 2. 16 ilustra o equipamento utilizado e as medidas resultantes para a determinação da perda de energia dP da borracha em relação à cavidade vazia. 

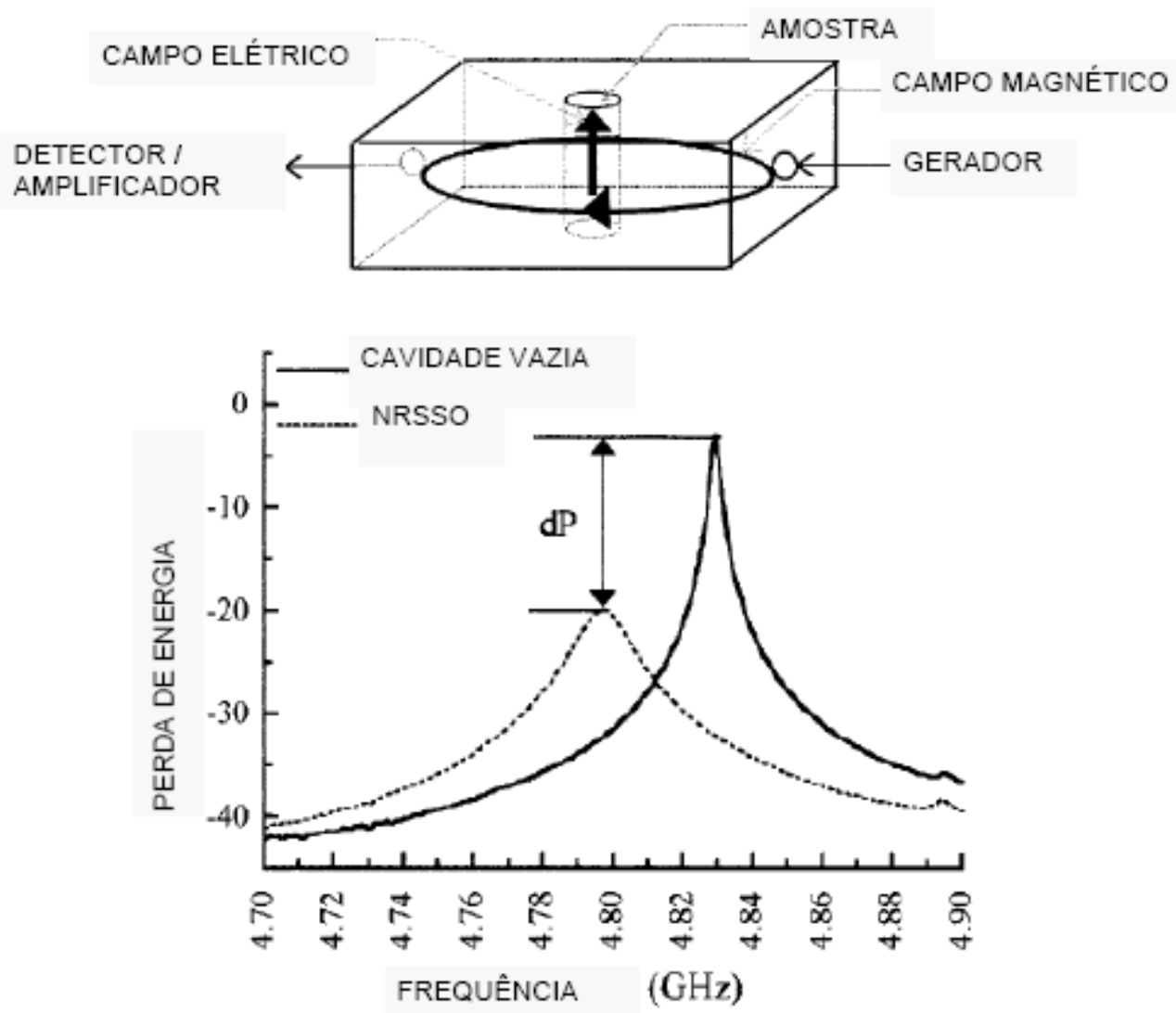

Figura 2. 16 Espectro de microondas obtido com borracha natural. $\mathrm{O}$ valor dP é a energia absorvida em relação à cavidade vazia [80].

Os valores de dP foram normalizados em função da massa do elastômero (dP/massa) e plotados em função da variação no tempo de envelhecimento da borracha a $150^{\circ} \mathrm{C}$, ilustrado na Figura 2. 17.

Na Figura 2. 17 fica evidenciada a importância da presença do negro de fumo para absorver a energia das microondas, uma vez que a borracha natura (NR) sem carga alguma, praticamente não sofre nenhuma variação na absorção da energia ao longo do tempo de envelhecimento. Por outro lado, a borracha NRSSO (com negro de fumo) apresenta inicialmente um valor mais elevado de absorção (dP/massa), e depois, no decorrer do tempo esta energia cai. Os autores [80] atribuíram este fato à destruição da interface entre a borracha e as partículas de negro de fumo. 


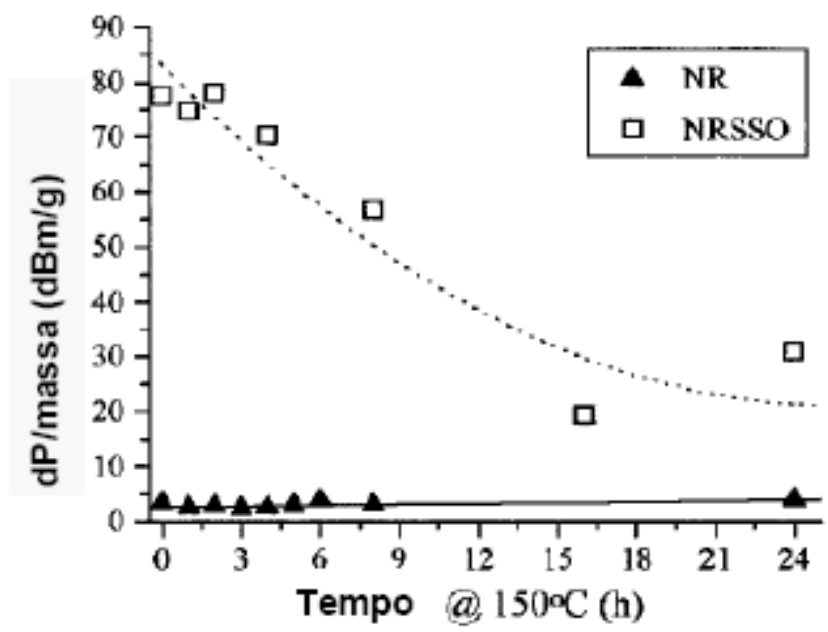

Figura 2. 17 Energia absorvida por grama em função do tempo a $150^{\circ} \mathrm{C}$ para borracha natural com negro de fumo e sem negro de fumo [80]. 


\subsection{BLENDAS POLIMÉRICAS}

Blendas poliméricas são produzidas para melhorar as propriedades físicas sem a necessidade de sintetizar sistemas poliméricos especializados. A motivação inicial da fabricação de blendas foi tentar reduzir as limitações apresentadas por alguns polímeros, como fragilidade e baixa resistência mecânica.

No campo de polímeros condutores, a blenda é uma ótima estratégia para tirar vantagem das boas propriedades mecânicas e elétricas, e da processabilidade de polímeros convencionais. Neste caso, pequenas quantidades de polímero condutor (cerca de 5\%) são suficientes para alcançar valores de condutividade elétrica satisfatórios, devido à formação de redes condutoras dentro da matriz isolante (Figura 2. 18).

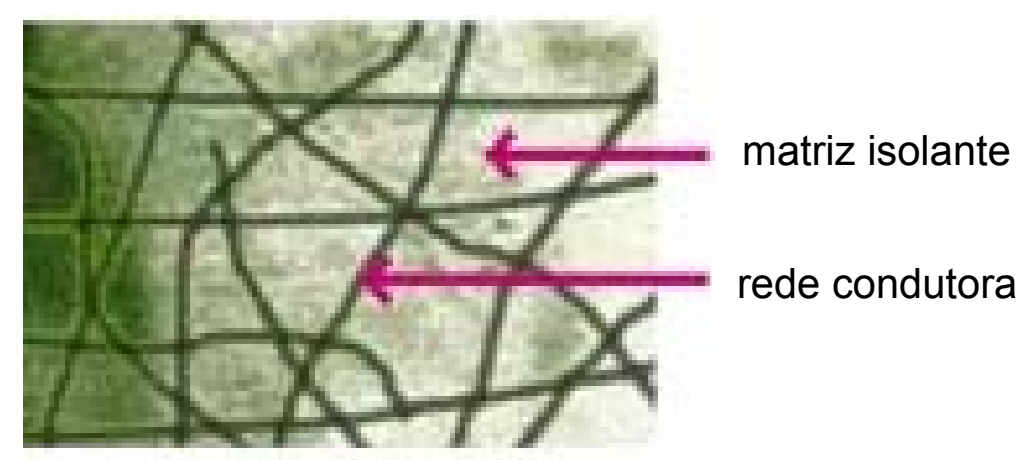

Figura 2. 18. Exemplo de formação de uma rede condutora numa blenda composta por um polímero condutor e um isolante [17].

Outra razão é assegurar os custos por misturar um polímero de alto desempenho com um material barato. Uma utilidade muito importante da blenda é a combinação de um elastômero com um polímero rígido para reduzir sua fragilidade [82].

Blendas com polianilinas são largamente estudadas devido a sua fácil processabilidade, solubilidade, estabilidade e dopagem. Uma grande variedade de 
blendas de polianilina já foi obtida com sucesso, dentre as quais se destacam as produzidas com os seguintes polímeros: polietileno (PE) [83], polipropileno [84], poliestireno [84], poliestireno de alto impacto (HIPS) [85], poli(metacrilato de metila) [86], náilon [84], policarbonato [84], poli(vinil-butiral) (PVB) [84], terpolímero de acrilonitrila-butadieno-estireno (ABS) [84], poli (cloreto de vinila) (PVC) [85], poli(fluoreto de vinilideno) (PVDF) [87], copolímero de vinilideno e tetrafluoretileno [88] e elastômeros de estireno-etileno-butileno-estireno (SEBS) [85] e de estirenobutadieno-estireno (SBS) [89].

Análises em termos do comportamento térmico da PAni dopada com ácido dodecilbenzeno sulfônico [complexo de PAni-DBSA] [90,91,92,93] e de borracha EPDM $[93,94,95,96,97,98]$ conduziram estudos para a preparação de blendas deste dois componentes.

Blendas de PAni dopada com ácido p-tolueno sulfônico e um terpolímero de etileno-propileno-5-etilideno-2-norborneno (EPDM) obtidas por processo mecânico foram relatadas [9]. No entanto, a eficiência da reação da reticulação foi prejudicada pela decomposição do peróxido de dicumila (agente reticulador) pelo ácido sulfônico. Outras tentativas [99] para obter blendas reticuladas foram testadas por processo de mistura mecânico de uma resina fenólica em estado sólido com sistemas laminados de EPDM/PAni em um moinho de rolo aberto. Neste caso, a presença de grupos ácidos diminuiu a eficiência da resina fenólica no processo de reticulação. Em todos os casos, as blendas resultantes foram imiscíveis e apresentaram condutividades dc acima de $10^{-6} \mathrm{~S} / \mathrm{cm}$ para as blendas contendo mais de $50 \%$ em massa de PAni. 


\section{CAPÍTULO III: MATERIAIS E MÉTODOS EXPERIMENTAIS}

\subsection{CONTEÚDO DESTE CAPÍTULO}

Neste capítulo, os materiais e equipamentos utilizados no presente trabalho estão apresentados. Os procedimentos de desvulcanização da EPDM por microondas e da obtenção das blendas de PAni/dEPDM estão descritos. Por fim, é feita uma abordagem das técnicas utilizadas para caracterizar os filmes de dEPDM puro e PAni-DBSA/dEPDM em diferentes concentrações.

\subsection{MATERIAIS UTILIZADOS}

Neste trabalho foram utilizados polianilina dopada com ácido dodecilbenzeno sulfônico (PAni-DBSA) e o copolímero de etileno-propileno-monômero dieno (EPDM).

A PAni-DBSA foi fornecida pela Dra. Débora Balogh do Grupo de Polímeros Bernard Gloss do Instituto de Física de São Carlos - USP.

O EPDM desvulcanizado por microondas, proveniente do descarte da indústria de autopeças, foi fornecida pelo Profo. Dr. Carlos Henrique Scuracchio do Departamento de Engenharia de Materiais da Faculdade de Engenharia Química de Lorena (DEMAR-FAENQUIL). O EPDM fornecido tinha $140 \mathrm{phr}$ de negro de fumo. 


\subsection{EQUIPAMENTOS UTILIZADOS}

Para a caracterização dos materiais foram utilizados os seguintes equipamentos:

- Microscópio Óptico acoplado à estação de trabalho "Went Worth modelo 900" do Laboratório de Microeletrônica do Departamento de Engenharia Elétrica da Escola Politécnica da USP.

- Microscópio Eletrônico de Varredura Philips, modelo XL30 do Departamento de Engenharia Metalúrgica e de Materiais da Escola Politécnica da USP.

- Difratômetro de Raios-X RIGAKU modelo RINT 2100 do Departamento de Cristalografia do Instituto de Física da USP.

- $\quad$ DSC Q10 da TA Instruments do Departamento de Engenharia de Materiais da USP Campus Lorena.

- $\quad$ Espectrôfotometro de Infravermelho modelo Nicolet 380 da empresa Nicolet.

- $\quad$ Shimadzu TGA-50H do Departamento de Engenharia de Materiais da USP Campus Lorena.

- Netzsch DMA 242 do Grupo de Polímeros do Instituto de Física da USP, Campus São Carlos.

- $\quad$ Medidor de Resistividade de Quatro Pontas LCR Meter HP4284A. 


\subsection{MÉTODOS EXPERIMENTAIS}

Nesta seção estão descritos os métodos de desvulcanização da borracha EPDM por microondas e da obtenção dos filmes de dEPDM puro e de PANIDBSA/dEPDM.

\subsubsection{DESVULCANIZAÇÃO DA BORRACHA EPDM POR MICROONDAS}

Dentre as técnicas de desvulcanização descritas na literatura [63], uma das mais promissoras é a desvulcanização através de microondas [76]. Este tipo de processo de desvulcanização tem natureza física, ou seja, não envolve reagentes químicos durante o processo, permitindo a aplicação de alta quantidade de energia ao material em um curto tempo (entre 5 ou 10 minutos), resultando em alta produtividade. Apesar do processo de desvulcanização por microondas ser conhecido desde o final da década de 1970 [100], a literatura que descreve as propriedades do material desvulcanizado ainda é bastante limitada. Isso tem reduzido tanto o campo de aplicação destes materiais quanto o entendimento do processo de desvulcanização em si [102].

De uma forma geral, a desvulcanização através de microondas se dá devido ao aquecimento da borracha, que provoca a quebra das ligações cruzadas em um processo ativado termicamente [101] (conforme explicado na seção 2.10 DESVULCANIZAÇÃO). A situação ideal é que a quantidade de energia absorvida das microondas pela amostra seja elevada o suficiente para quebrar as ligações S-S e C-S das ligações cruzadas, porém não o suficiente para quebrar as ligações C-C da cadeia principal do polímero. De acordo com a literatura [100], a energia necessária para a desvulcanização da borracha é de aproximadamente 180 Watt.hora por quilo de borracha. No entanto, para que o material tenha uma boa interação com as microondas e, portanto, um aquecimento eficiente é necessário 
que o mesmo apresente uma determinada polaridade. O EPDM é apolar [63], e apresenta quase nenhuma interação com as microondas. Esta dificuldade é contornada pela utilização de cargas condutoras de eletricidade, como o negro de fumo [102]. A energia das microondas é, então, absorvida pelo negro de fumo contido no EPDM, que faz com que as moléculas da borracha ao redor se aqueçam por condução num processo indireto.

O EPDM utilizado, que continha negro de fumo, foi previamente triturado e desvulcanizado em um forno de microondas Electrolux modelo 27E, com um magnetron de potência nominal $700 \mathrm{~W}$. De forma a tornar o material tratado mais homogêneo e minimizar o efeito de regiões com alta concentração de onda ("hot spots"), este forno foi adaptado com um sistema de agitação, constituído de uma haste principal e oito hastes secundárias, perpendiculares à haste principal. As hastes foram feitas de aço inoxidável. Este sistema de agitação foi acoplado a um motor com controlador de velocidade. A Figura 3. 1 mostra esquematicamente o sistema utilizado para a desvulcanização do EPDM [102].

O EPDM em pó foi submetido ao tratamento pelas microondas por um tempo de 300 s à uma potência de 700W.

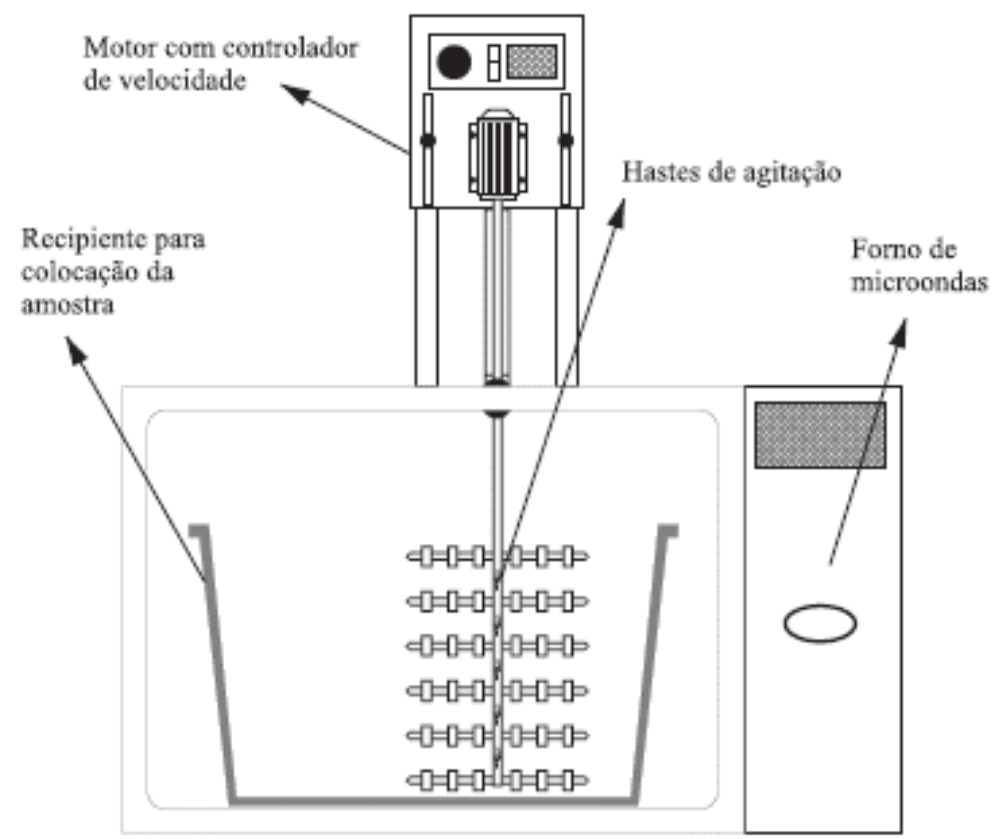

Figura 3. 1 Desenho esquemático do sistema utilizado para desvulcanização do EPDM [102]. 


\subsubsection{OBTENÇÃO DAS BLENDAS DE PANI-DBSA/dEPDM}

Desde sua primeira preparação em 1984 [103,104], as blendas poliméricas condutoras tornaram-se a maneira mais usada para melhorar as propriedades mecânicas de polímeros condutores [9].

O uso de blendas na indústria de borracha é importante porque permite a união das características de um material por usar dois ou mais polímeros com diferentes propriedades na composição.

O EPDM foi escolhido para este trabalho por ser um material que possui ótima resistência mecânica e pela disponibilidade do material.

A PAni é o polímero condutor mais estudado e foi escolhido para este trabalho devido sua alta condutividade elétrica associada à boa estabilidade química e térmica, facilidade de preparação e baixo custo do monômero. Porém, em contraponto, é um polímero rígido e quebradiço.

As blendas de PANI-DBSA/dEPDM foram preparadas por processo mecânico. Primeiro foram misturadas manualmente, PANI-DBSA em forma de pó e dEPDM triturado nas seguintes proporções: 0/100; 02/98; 05/95; 10/90; 20/80; 30/70; 50/50; 70/30 e 90/10; e posteriormente foram passadas, em temperatura ambiente, em uma calandra de rolo para a formação de filmes. Foram obtidos filmes flexíveis; exceto com as proporções de $70 \%$ e $90 \%$ de PANI-DBSA, pois a grande quantidade do polímero rígido tornou os filmes quebradiços. A Figura 3 . $2 \mathrm{~b}$ mostra a flexibilidade de uma das blendas (filme) como resultado do processo. 


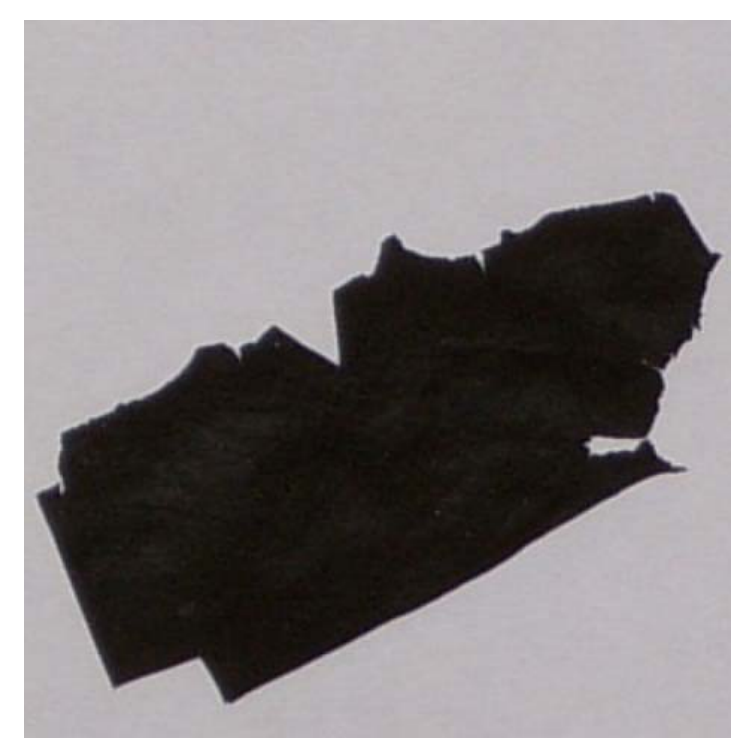

(a)

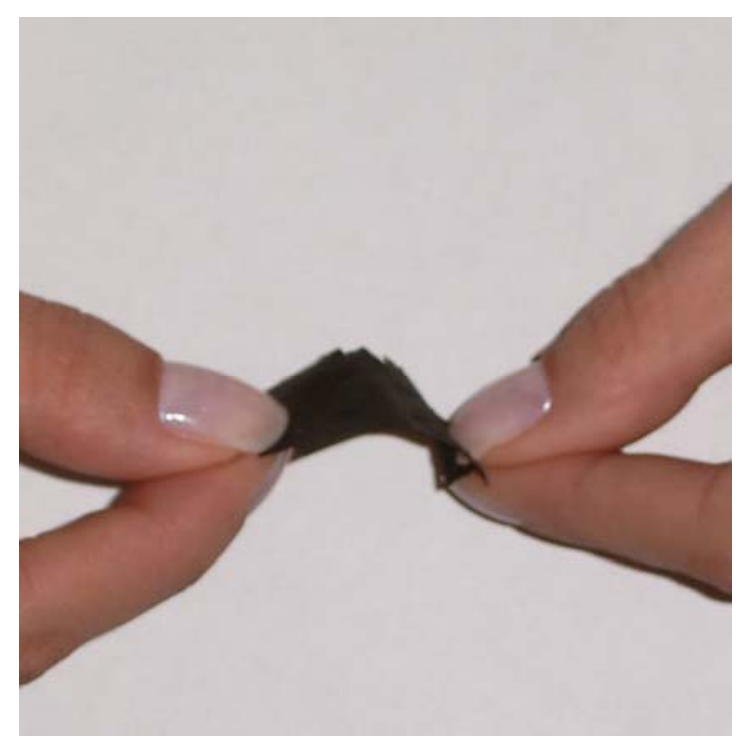

(b)

Figura 3. 2 Imagens do filme obtido por processo mecânico (a) e sua flexibilidade (b). 


\subsection{CARACTERIZAÇÃO DOS MATERIAIS POLIMÉRICOS}

Nesta seção estão apresentados os equipamentos utilizados para a caracterização das blendas poliméricas obtidas e uma breve explicação das respectivas técnicas.

\subsubsection{CARACTERIZAÇÃO MORFOLÓGICA}

A caracterização morfológica presente nas blendas poliméricas obtidas foi realizada com técnicas de microscopia óptica (MO), microscopia eletrônica de varredura (MEV), difratometria de raios-X (DRX), análise térmica dinâmico-mecânica (DMTA) (a ser realizada) e calorimetria diferencial de varredura (DSC). O princípio de cada técnica está descrito a seguir [105].

\subsubsection{Microscopia Óptica (MO)}

A técnica de microscopia óptica foi utilizada para a obtenção de imagens de macroestruturas e microestruturas do filme de dEPDM puro e das blendas de PANIDBSA/dEPDM em diferentes composições. A limitação do aumento das imagens (máximo de 1.000x) não foi suficiente para uma análise mais detalhada e, devido a isso, foi utilizado a técnica de microscopia eletrônica de varredura (MEV).

\subsubsection{Microscopia Eletrônica de Varredura (MEV)}


Nesta técnica, os elétrons são acelerados numa coluna sob tensões de 1 a 30 kV e lentes obrigam o feixe de elétrons bastante colimado (50 a $200 \AA$ Á de diâmetro) a atingir a superfície da amostra. Os elétrons espalhados atingem um coletor e havendo uma correspondência entre o elétron coletado e um ponto particular da amostra, o brilho do mesmo ponto é refletido na tela do tubo resultando na imagem da superfície a ser analisada. Com MEV, qualquer superfície boa condutora elétrica e estável em vácuo pode ser analisada com boa profundidade de foco. Materiais isolantes devem ser recobertos com uma fina camada de material condutor.

Neste trabalho, os filmes de PANI-DBSA/dEPDM foram metalizados com uma fina camada de ouro e as imagens foram obtidas da superfície das amostras. Os ensaios de microscopia eletrônica de varredura (MEV) foram realizados em um equipamento Philips, modelo XL30 sob uma voltagem de 20 kV no Departamento de Engenharia Metalúrgica e de Materiais da Escola Politécnica da USP (PMT EPUSP).

\subsubsection{Difração de Raios-X (DRX)}

O método de difração de raios-X é de grande importância no estudo de estrutura e grau de cristalinidade de materiais poliméricos. Quando um feixe de raios-X incide sobre um material, parte do feixe incidente é absorvida, parte é espalhada e o restante é transmitido sem alteração. $O$ espalhamento de raios- $X$ ocorre como resultado da interação com elétrons no material. Os raios- $X$ espalhados de diferentes elétrons interferem uns com os outros e produzem um padrão de difração que varia com o ângulo de espalhamento. A variação da intensidade espalhada e difratada com o ângulo fornece informação sobre a distribuição de densidade eletrônica e as posições atômicas dentro do material.

Neste trabalho, os ensaios de difração de raios-X dos filmes de PANIDBSA/dEPDM foram realizados no Departamento de Cristalografia do Instituto de Física da USP pelo Dr Antonio C. F. Silveira e pela Prof ${ }^{a}$. Dra. Márcia Fantine. 
O equipamento utilizado foi um RIGAKU gerador de raio-X, modelo RINT 2100, goniômetro modelo RINT Ultima $^{+}$, fonte de cobre (Cu) com $k \alpha$ médio $=1,5418 \AA$. Os ensaios foram feitos sob as seguintes condições: potência do feixe de $40 \mathrm{kV}$ e corrente elétrica de $30 \mathrm{~mA}$, a um passo angular de 0,04 graus e tempo de aquisição em cada ponto de $5 \mathrm{~s}$.

\subsubsection{Análise Térmica Dinâmico-Mecânica (DMTA)}

A análise termodinâmico-mecânica (DMTA) tem como um dos principais objetivos relacionar as propriedades macroscópicas, tais como as propriedades mecânicas, as relaxações moleculares associadas a mudanças conformacionais e as deformações microscópicas geradas a partir de rearranjos moleculares.

As propriedades mecânicas dos materiais são avaliadas a partir de uma solicitação, na forma de uma deformação ou na aplicação de uma tensão mecânica, com o monitoramento da resposta do material, expressa como tensão ou como deformação, respectivamente. A análise dinâmico-mecânica consiste, de modo geral, em aplicar uma tensão ou deformação mecânica oscilatória, normalmente senoidal, de baixa amplitude a um sólido ou líquido viscoso, medindo-se a deformação sofrida por este ou a tensão resultante, respectivamente, sob variação de freqüência ou de temperatura.

Materiais poliméricos apresentam comportamento mecânico intermediário ao elástico e ao viscoso, sendo denominados viscoelásticos. A contribuição elástica e viscosa para o comportamento mecânico do polímero depende da temperatura e da escala de tempo do experimento.

Neste trabalho os ensaios de DMTA foram realizados no Grupo de Polímeros do Instituto de Física da USP, Campus São Carlos pela Prfa . Dra . Débora Balogh. O equipamento utilizado foi Netzsch DMA 242 operando em modo tensão. As medidas 
foram realizadas a uma taxa de aquecimento $2^{\circ} \mathrm{C} / \mathrm{min}$ (de $-100^{\circ} \mathrm{C}$ a $80^{\circ} \mathrm{C}$ ) e freqüência fixa de $1 \mathrm{~Hz}$.

\subsubsection{Calorimetria Exploratória Diferencial (DSC)}

A calorimetria diferencial de varredura (DSC) é uma técnica dominante para a investigação analítica térmica de materiais poliméricos. Esta técnica mede a diferença em quantidade de energia de uma substância e um material de referência que estão submetidos a um programa de controle de temperatura. Ela é muito utilizada para a determinação de capacidade calorífica, calores de transição, calores de reação e temperaturas de transição (temperaturas de transição vítrea e de fusão) para materiais poliméricos.

Neste trabalho os ensaios de calorimetria diferencial de varredura (DSC) dos filmes obtidos foram feitos no Departamento de Engenharia de Materiais da USP, Campus Lorena sob orientação do Prof ${ }^{\circ}$. Dr. Carlos Shigue. O equipamento utilizado foi um DSC Q10 V7.3 Build 249 da TA Instruments. Foram realizadas 2 (duas) corridas de aquecimento, com amostras de aproximadamente $20 \mathrm{mg}$. As condições de análise foram as seguintes: cadinho de alumínio, nitrogênio líquido para o resfriamento, vazão de gás inerte $\left(\mathrm{N}_{2}\right)=50,0 \mathrm{ml} / \mathrm{min}$ e taxa de aquecimento $=$ $10^{\circ} \mathrm{C} / \mathrm{min}$.

\subsubsection{Análise Termogravimétrica (TGA)}

A termogravimetria (TG) é uma técnica de análise na qual a variação da massa da amostra (perda ou ganho) é determinada em função da temperatura e/ou tempo, enquanto a amostra é submetida a uma propagação controlada de temperatura. Esta técnica possibilita conhecer as alterações que o aquecimento 
pode provocar na massa das substâncias, permitindo estabelecer a faixa de temperatura em que elas adquirem composição química, fixa, definida e constante, a temperatura em que começam a se decompor. Também é possível acompanhar o andamento de reações de desidratação, oxidação, combustão, decomposição, etc. Três modos de TG são comumente usados, como ilustrado na Figura 3. 3: a) TG isotérmica, em que a massa da amostra é registrada em função do tempo a temperatura constante. A Figura 3. 3a ilustra um aquecimento rápido até a temperatura $\operatorname{Tn}(n=1,2,3 \ldots)$ que é mantida constante por um certo intervalo de tempo; b) TG quase-isotérmica, em que a amostra é aquecida a uma razão de aquecimento linear enquanto não ocorre variação de massa; a partir do momento em que a balança detecta a variação de massa, a temperatura é mantida constante até se obter um novo patamar, característico de massa constante para a amostra, e assim sucessivamente (Figura 3. 3b); c) TG dinâmica ou convencional (Figura 3. 3c), em que a amostra é aquecida ou resfriada num ambiente cuja temperatura varia de maneira pré-determinada, de preferência, à razão de aquecimento ou resfriamento linear.
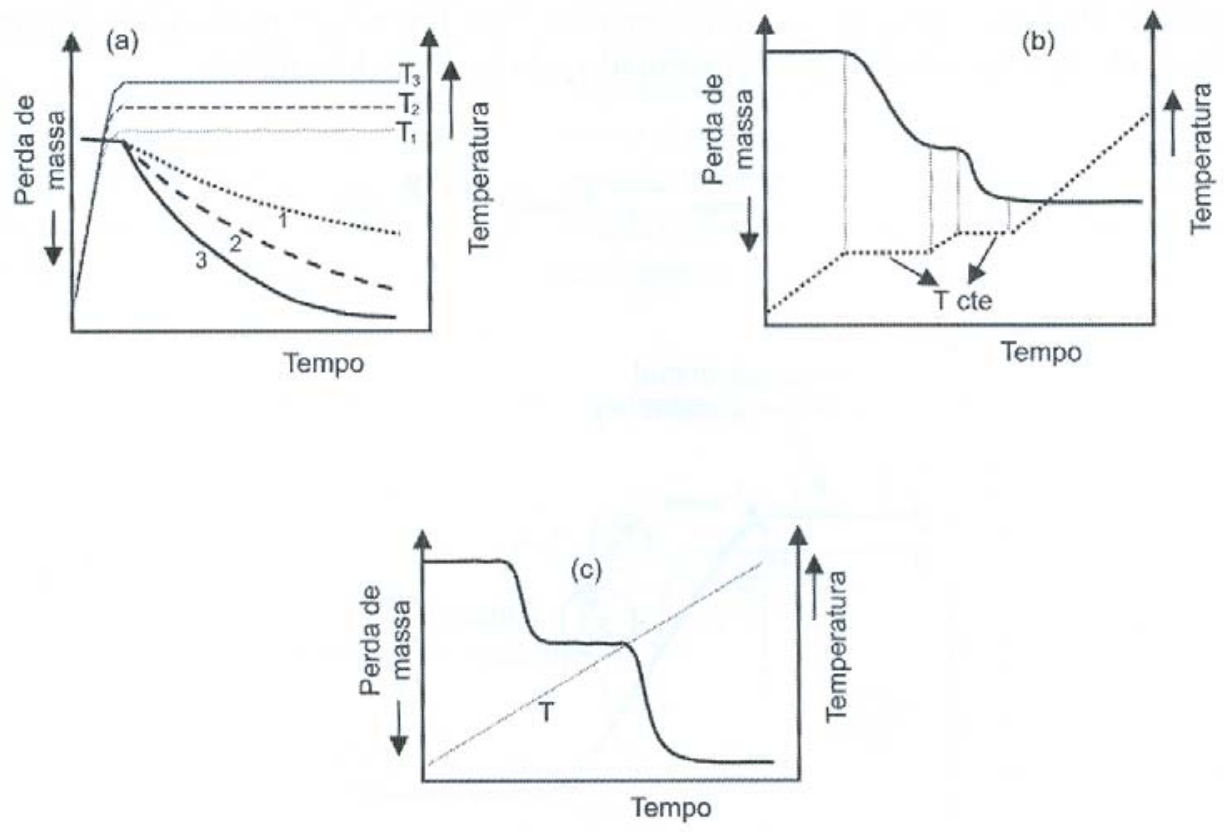

Figura 3. 3. Três modos de termogravimetria. (a) TG isotérmica; (b) TG quaseisotérmica; (c) TG dinâmica. 
Os experimentos para se avaliar as variações de massa de um dado material em função da temperatura são executados mediante uma termobalança (associação forno-balança), que deve permitir o trabalho sob as mais variadas condições experimentais (diferentes atmosferas gasosas e massas de amostra, variadas razões de aquecimento e/ou condições isotérmicas em temperaturas específicas, etc.). As curvas geradas fornecem informações quanto à instabilidade térmica da amostra, à composição e à estabilidade dos compostos intermediários e do produto final. Obviamente que, durante os processos térmicos, a amostra deve liberar um produto volátil devido a processos físicos ou químicos, tais como desidratação, vaporização, dessorção, oxidação, redução etc.; ou deve interagir com o gás da atmosfera atuante no interior do forno resultando em processos que envolvem ganho de massa, tais como: absorção, oxidação de ligas ou metais e óleos, etc. As variações de massa podem ser determinadas quantitativamente, enquanto outras informações obtidas a partir de uma curva TG são de natureza empírica, visto que as temperaturas dos eventos térmicos são dependentes de parâmetros relacionados às características da amostra e/ou fatores instrumentais.

Neste trabalho as curvas termogravimétricas foram obtidas pelo Departamento de Engenharia de Materiais da USP Campus Lorena sob orientação da Prof ${ }^{a}$. Dra. Maria Lúcia C. P. Silva. O equipamento utilizado foi Shimadzu TGA-50H sob as seguintes condições: célula de platina; variação de temperatura de $25^{\circ} \mathrm{C}$ a $800^{\circ} \mathrm{C}$ a uma taxa de $10^{\circ} \mathrm{C} / \mathrm{min}$ em um fluxo constante de gás nitrogênio de $50,0 \mathrm{ml} / \mathrm{min}$.

\subsubsection{CARACTERIZAÇÃO DA ESTRUTURA QUÍMICA}

A caracterização da estrutura química do copolímero dEPDM e das blendas PANI-DBSA/dEPDM foi realizada com espectroscopia no infravermelho (FTIR). O princípio desta técnica será descrito a seguir [48]. 


\subsubsection{Espectroscopia no Infravermelho (FTIR)}

A espectroscopia no infravermelho (FTIR) é uma técnica muito utilizada para caracterizar os materiais poliméricos. Esta técnica envolve os níveis de energia vibracionais de uma molécula, mas, freqüentemente, somente fornece parte do espectro vibracional. Os outros modos vibracionais aparecem no espectro Raman. A espectroscopia de infravermelho (FTIR) pode ser usada para caracterizar materiais poliméricos em diferentes níveis de complexidade. O FTIR é uma técnica rápida e um método fácil para identificação qualitativa dos principais componentes. A utilização de freqüências de grupo e padrões distintos na região de "impressão digital" do espectro ajuda a identificar a amostra polimérica. O FTIR também pode ser utilizado para caracterizar a estrutura de materiais poliméricos, isto é, a composição química da cadeia polimérica e a distribuição das unidades individuais.

Neste trabalho os ensaios de infravermelho (FTIR) dos filmes obtidos foram realizados na empresa Nicolet utilizando um equipamento Nicolet 380 com resolução de $4 \mathrm{~cm}^{-1}$ e 32 varreduras numa faixa de números de onda de 4400 a $400 \mathrm{~cm}^{-1}$.

\subsubsection{MEDIDAS DE CONDUTIVIDADE ELÉTRICA}

As medidas de condutividade elétrica foram obtidas pelo método de quatro pontas, como descrito a seguir.

\subsubsection{Método de Quatro Pontas}

O método de quatro pontas é o mais amplamente utilizado para a determinação da resistividade elétrica de condutores metálicos e semicondutores, 
nas suas mais diversas formas (amostras cilíndricas, circulares, quadradas, etc.) ou arranjos substrato/amostra (e.g. filmes finos depositados sobre substrato condutor ou sobre substrato isolante).

O método da sonda de quatro pontas é útil para medidas de rotina que requerem rapidez e precisão nos resultados. É também um método recomendado pela norma padrão ASTM (F43-99) para medida de resistividade em materiais semicondutores. Neste método, as sondas que monitoram a corrente e a tensão são contatos pontuais, usualmente montados em um suporte especial com as pontas da sonda dispostas em linha, a uma distância equivalente umas das outras (existe também a disposição quadrada). A Figura 3. 4 ilustra o arranjo experimental para a sonda quatro pontas [106].

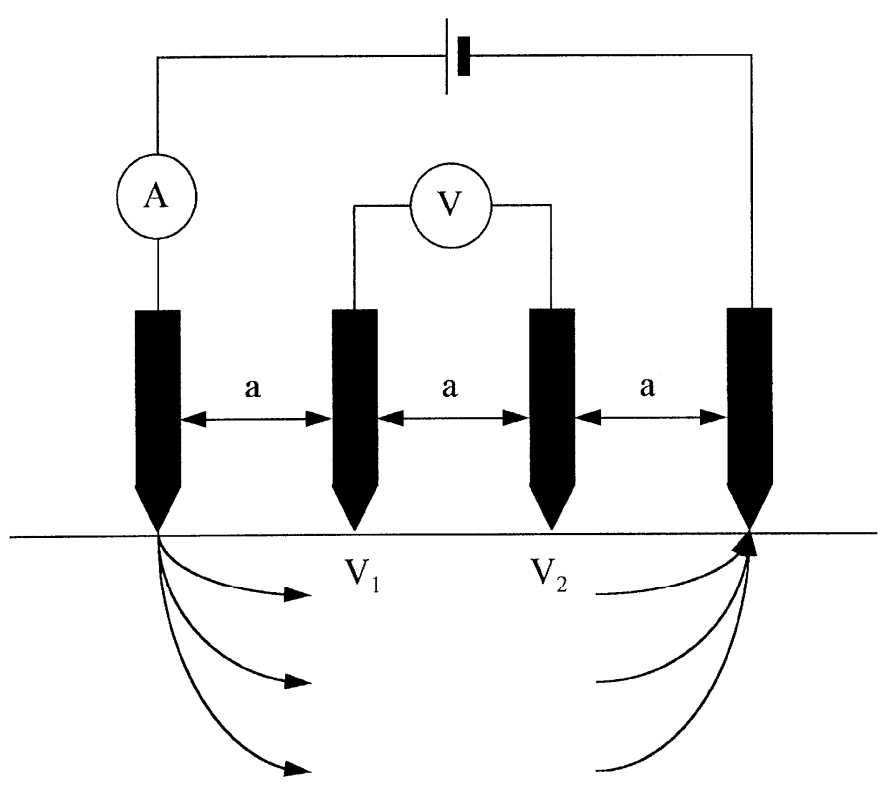

Figura 3. 4 Arranjo para medidas de resistividade pelo método de quatro pontas (quatro terminais). A letra "a" representa a distância entre as pontas, que deve ser conhecida.

O método quatro pontas foi desenvolvido originalmente para medir resistividade de metais e materiais cristalinos (rígidos). Porém, para amostras nãorígidas existem sondas com pontas arredondadas.

Neste trabalho as medidas de condutividade elétrica pelo método de quatro pontas foram realizadas utilizando um equipamento LCR Meter HP4284A no 
Departamento de Física e Química da Universidade Federal de Itajubá sob orientação do Prof ${ }^{\circ}$. Dr. Demétrio A. W. Soares e pelo estudante Wagner S. Machado. 


\section{CAPÍTULO IV: RESULTADOS E DISCUSSÕES}

\subsection{CONTEÚDO DESTE CAPÍTULO}

Neste capítulo são apresentados os resultados experimentais, das técnicas descritas no capítulo anterior, obtidos das caracterizações do filme de dEPDM puro e das blendas de PANI-DBSA/dEPDM em diferentes concentrações.

\subsection{RESULTADOS EXPERIMENTAIS}

\subsubsection{Espectroscopia no Infravermelho (FTIR)}

Nesta seção estão apresentados espectros de infravermelho dos filmes de dEPDM puro e de PAni-DBSA/dEPDM em diferentes composições. Não é apresentado o espectro da PAni-DBSA pura, pois já é muito conhecido e, portanto, os dados foram extraídos da referência de Ho e colaboradores [48].

Os espectros de infravermelho da amostra de dEPDM puro e das blendas de PAni-DBSA/dEPDM em diferentes concentrações estão apresentados na Figura 4. 1. Os picos de absorção de infravermelho característicos dos materiais obtidos estão relacionados na Tabela 4. 1. 


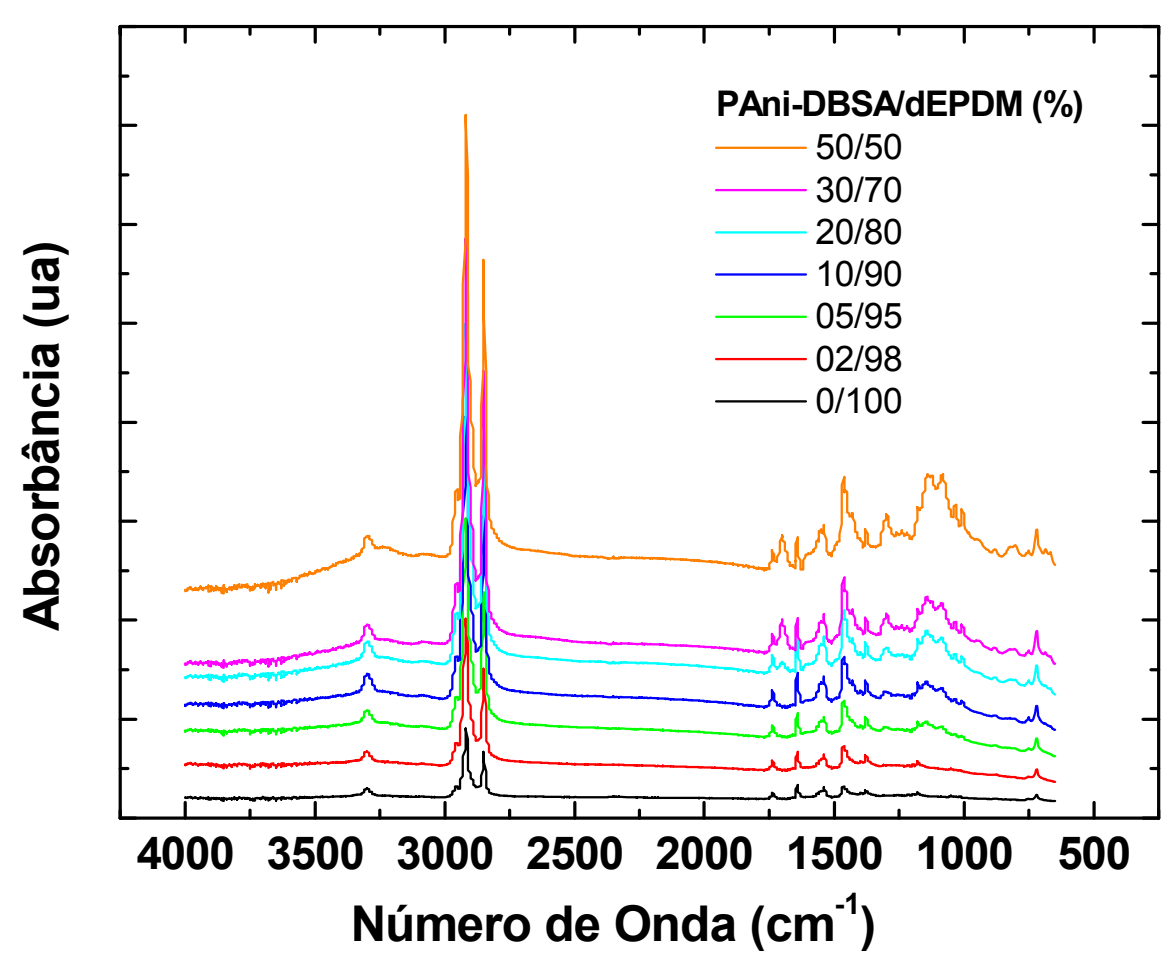

Figura 4. 1. Espectros de infravermelho da borracha dEPDM pura e de PAniDBSA/dEPDM em diferentes composições.

Tabela 4. 1. Picos característicos do dEPDM puro e das blendas de PAniDBSA/dEPDM em diferentes concentrações.

\begin{tabular}{|c|l|l|}
\hline Número de onda $\left(\mathbf{c m}^{-1}\right)$ & Ligações & \multirow{3}{*}{ dEPDM } \\
\cline { 1 - 2 } $3700-3200$ & grupos $(-\mathrm{OH})$ & \\
\hline 2920 & pertencente à cadeia principal C-H & \\
\hline 1735 & grupos carbonilas & \multirow{3}{*}{ PAni-DBSA } \\
\hline 1460 & $\mathrm{C}-\mathrm{H}$ dos grupos laterais $-\mathrm{CH}_{3}$ & \\
\hline 2958 & $\left(-\mathrm{CH}_{3}\right)$ & \\
\hline 2924 & $\left(-\mathrm{CH}_{2}-\right)$ & \\
\hline 1561 & $(-\mathrm{C}=\mathrm{N}-)$ do quinóide dopado & \\
\hline 1467 & $(-\mathrm{C}=\mathrm{C}-)$ do benzóide dopado & \\
\hline 1030 & $(-\mathrm{S}=\mathrm{O})$ do $-\mathrm{SO}_{3} \mathrm{H}$ proveniente do DBSA & \\
\hline 1005 & $(-\mathrm{S}=\mathrm{O})$ do $-\mathrm{SO}_{3} \mathrm{H}$ proveniente do DBSA & \\
\hline 801 & $(\mathrm{C}-\mathrm{H})$ do anel aromático \\
\hline
\end{tabular}


Conforme mostrado na Tabela 4. 1 podem-se verificar alguns picos de absorção de dos espectros de infravermelho (IV) característicos dos dois materiais poliméricos. Para o copolímero dEPDM foram identificados: grupos -OH (3700 $\left.3200 \mathrm{~cm}^{-1}\right)$ atribuídos às partículas de negro de fumo, ligações $\mathrm{C}-\mathrm{H}\left(2920 \mathrm{~cm}^{-1}\right)$ pertencentes à cadeia principal do copolímero EPDM, ligações $\mathrm{C}-\mathrm{H}\left(1460 \mathrm{~cm}^{-1}\right)$ referentes aos grupos laterais $-\mathrm{CH}_{3}$, e grupos carbonilas $\left(1735 \mathrm{~cm}^{-1}\right)$ gerados pela oxidação do copolímero no processo de desvulcanização. Para a PANI-DBSA foram observados: $-\mathrm{CH}_{3}\left(2958 \mathrm{~cm}^{-1}\right)$ e $-\mathrm{CH}_{2}-\left(2924 \mathrm{~cm}^{-1}\right)$ pertencentes a cadeia principal, $\mathrm{C}=\mathrm{N}-\left(1561 \mathrm{~cm}^{-1}\right)$ do quinóide dopado, $-\mathrm{C}=\mathrm{C}-\left(1467 \mathrm{~cm}^{-1}\right)$ do benzóide dopado, $-\mathrm{S}=\mathrm{O}$ $\left(1030\right.$ e $\left.1005 \mathrm{~cm}^{-1}\right)$ do $-\mathrm{SO}_{3} \mathrm{H}$ proveniente do DBSA, e $\mathrm{C}-\mathrm{H}\left(801 \mathrm{~cm}^{-1}\right)$ referente ao anel aromático.

De acordo com Ho e colaboradores [48], a polianilina (base esmeraldina) tem picos de absorção de infravermelho em 590 cm-1 (-C=N- do quinóide), 1497 cm-1 ($\mathrm{C}=\mathrm{C}$ - do benzóide), $1300 \mathrm{~cm}-1$ (-C-N-) e $1165 \mathrm{~cm}-1$ (íons $-\mathrm{NH}$ do quinóide ou benzóide). Alguns destes picos movem-se para outros números de onda após a dopagem pelo ácido protônico. Os grupos quinóide e benzóide dopados deslocamse para 1561 e $1467 \mathrm{~cm}-1$, respectivamente. Também há picos característicos de absorção em 1030 e 1005 cm-1 que correspondem aos grupos sulfônicos. Estes resultados corroboram com aqueles ilustrados no espectro de absorção de IV da Figura 4. 1. Além disso, o espectro de absorção de IV das blendas poliméricas mostram a incorporação gradual da PAni-DBSA na matriz dEPDM, porém não foi notada qualquer modificação nestes espectros, portanto as interações entre os componentes de PAni-DBSA e dEPDM foram, basicamente, físicas. Esta observação foi evidenciada também nos ensaios DSC descritos na seção 4.2 .3 Calorimetria Exploratória Diferencial (DSC), a seguir. 


\subsubsection{Análise Termogravimétrica (TGA)}

Nesta seção são apresentadas as curvas termogravimétricas dos filmes de dEPDM puro, de PAni pura e de PAni-DBSA/dEPDM em diferentes composições.

A estabilidade térmica de PAni-DBSA pura, dEPDM puro e das blendas de PAni-DBSA/dEPDM em diferentes proporções foi avaliada por TGA. As amostras foram aquecidas de $25^{\circ} \mathrm{C}$ a $800^{\circ} \mathrm{C}$ a uma taxa de $10^{\circ} \mathrm{C} / \mathrm{min}$ em um fluxo constante de gás nitrogênio.

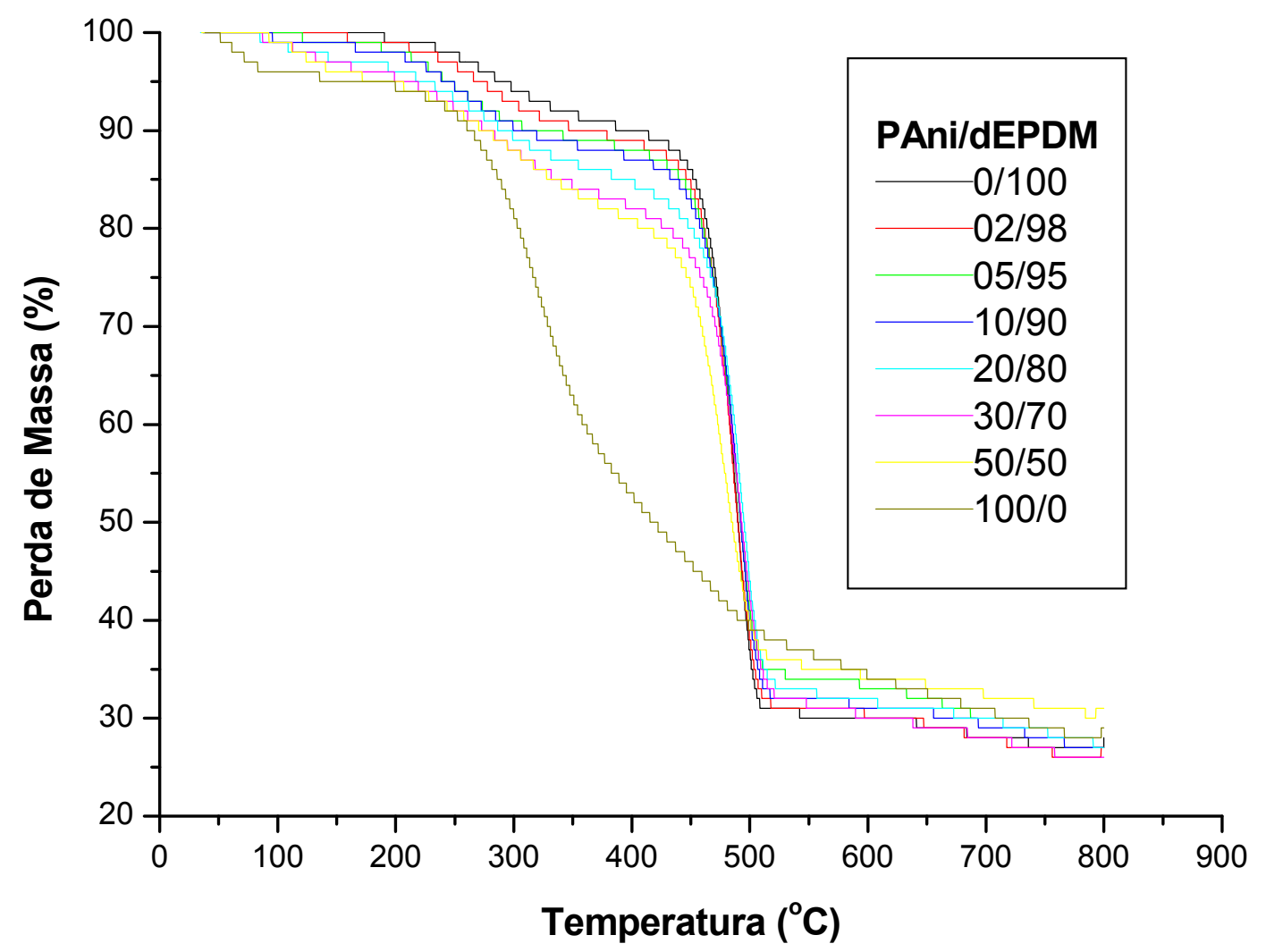

Figura 4. 2. Curvas termogravimétricas de dEPDM puro e blendas de PaniDBSA/dEPDM em diferentes composições.

A partir das curvas termogravimétricas (Figura 4. 2) obtivemos as temperaturas para as perdas máximas de massa. O termograma da PAni-DBSA 
pura revelou três estágios de perda de massa: à $\mathrm{T} \sim 61^{\circ} \mathrm{C}$ (correspondendo à perda de humidade, solvente, ou oligômeros de baixa massa molecular); à $\mathrm{T} \sim 330{ }^{\circ} \mathrm{C}$ (o que pode ser da decomposição da cadeia alifática do DBSA, o que está de acordo com o encontrado por Domenech e colaboradores [2]); e à $\mathrm{T} \sim 557^{\circ} \mathrm{C}$ (correspondendo a mudanças na estrutura do polímero, como, por exemplo, reticulação, seguida pela decomposição da cadeia polimérica).

Para o dEPDM puro foram observados dois estágios de perda de massa: a $\mathrm{T} \sim 284^{\circ} \mathrm{C}$ (devido à desidratação do negro de fumo) e a $\mathrm{T} \sim 489^{\circ} \mathrm{C}$ (atribuído à liberação de hidrocarbonos voláteis, os quais são formados por radicais livres gerados na cadeia principal durante o aquecimento).

A amostra de PAni-DBSA pura começou o processo de degradação em $\mathrm{T} \sim 51,5^{\circ} \mathrm{C}$. A amostra de dEPDM puro iniciou a degradação em $\mathrm{T} \sim 190,3^{\circ} \mathrm{C}$. No entanto, nas blendas, a temperatura de degradação inicial do dEPDM baixou significativamente na medida em que havia maior proporção de PAni-DBSA. Por exemplo, para a blenda de 50\% PAni-DBSA e 50\% dEPDM a degradação iniciou-se a $92,63^{\circ} \mathrm{C}$. Portanto, a PAni-DBSA diminuiu consideravelmente a estabilidade térmica da borracha. 


\subsubsection{Calorimetria Exploratória Diferencial (DSC)}

Nesta seção estão apresentadas as curvas DSC da amostra de dEPDM puro e das amostras de PAni-DBSA/dEPDM nas diferentes composições, pelas quais foi possível checar a miscibilidade das blendas de PAni-DBSA/dEPDM ao comparar as temperaturas de transição vítrea de cada componente. A Tg da PAni-DBSA pura não foi avaliada, porém foi possível distinguir dois pontos de inflexão nas blendas, um da PAni-DBSA e outro da dEPDM, conforme está discutido.

A proposta da mistura de polímeros condutores e isolantes é obter materiais com condutividade e propriedades mecânicas apropriadas; assim, estes polímeros devem apresentar um grau de compatibilidade razoável para produzir filmes flexíveis. A condutividade elétrica das blendas poliméricas é explicada pela teoria de limite de percolação, a qual é baseada na formação de uma rede de material condutor na matriz isolante. Por isso, misturas completamente miscíveis não são totalmente desejadas porque neste caso a rede condutora não é criada. A miscibilidade dos componentes em uma blenda é usualmente examinada por DSC e é evidenciada por um deslocamento na temperatura de transição vítrea (Tg) [2].

Neste trabalho, as curvas DSC mostram as temperaturas de transição vítrea (Tg) da borracha dEPDM pura e das blendas de PAni-DBSA/dEPDM conforme a Figura 4. 3 (segunda corrida de aquecimento), e os valores da Tg de cada amostra estão listados na Tabela 4. 2. 
Tabela 4. 2. Valores de Tg de dEPDM puro e das blendas de PAni-DBSA/dEPDM obtidas por DSC.

\begin{tabular}{|c|c|c|c|}
\hline $\begin{array}{c}\text { PAni- } \\
\text { DBSA/dEPDM }\end{array}$ & Temperatura $\left({ }^{\circ} \mathbf{C}\right)$ & $\begin{array}{c}\text { PAni-DBSA: } \mathbf{T}_{\mathbf{g}} \\
\left({ }^{\circ} \mathbf{C}\right)\end{array}$ & dEPDM: $\mathbf{T}_{\mathbf{g}}\left({ }^{\circ} \mathbf{C}\right)$ \\
\hline $0 / 100$ & -90 a 25 & - & -61 \\
\hline $2 / 98$ & -90 a 250 & 42 & -60 \\
\hline $5 / 95$ & -90 a 250 & 42 & -58 \\
\hline $10 / 90$ & -90 a 250 & 43 & -57 \\
\hline $20 / 80$ & -90 a 250 & 43 & -56 \\
\hline $30 / 70$ & -90 a 250 & 43 & -43 \\
\hline $50 / 50$ & -90 a 250 & 42 & -55 \\
\hline
\end{tabular}

As temperaturas de transição vítrea $(\mathrm{Tg})$ da amostra de dEPDM pura está a cerca de $-61^{\circ} \mathrm{C}$ como ilustrado na Figura 4. 3. A Tg da dEPDM nas blendas aumenta com a PAni-DBSA, significando uma melhor miscibilidade.

Pode-se observar que quando mais de $5 \%$ de PAni-DBSA foi adicionada à matriz de dEPDM, o deslocamento da Tg do dEPDM tornou-se significante, o que implica maior interação entre as moléculas. No entanto, a Tg da PAni-DBSA na blenda permaneceu praticamente constante como está apresentado na Tabela 4. 2. 


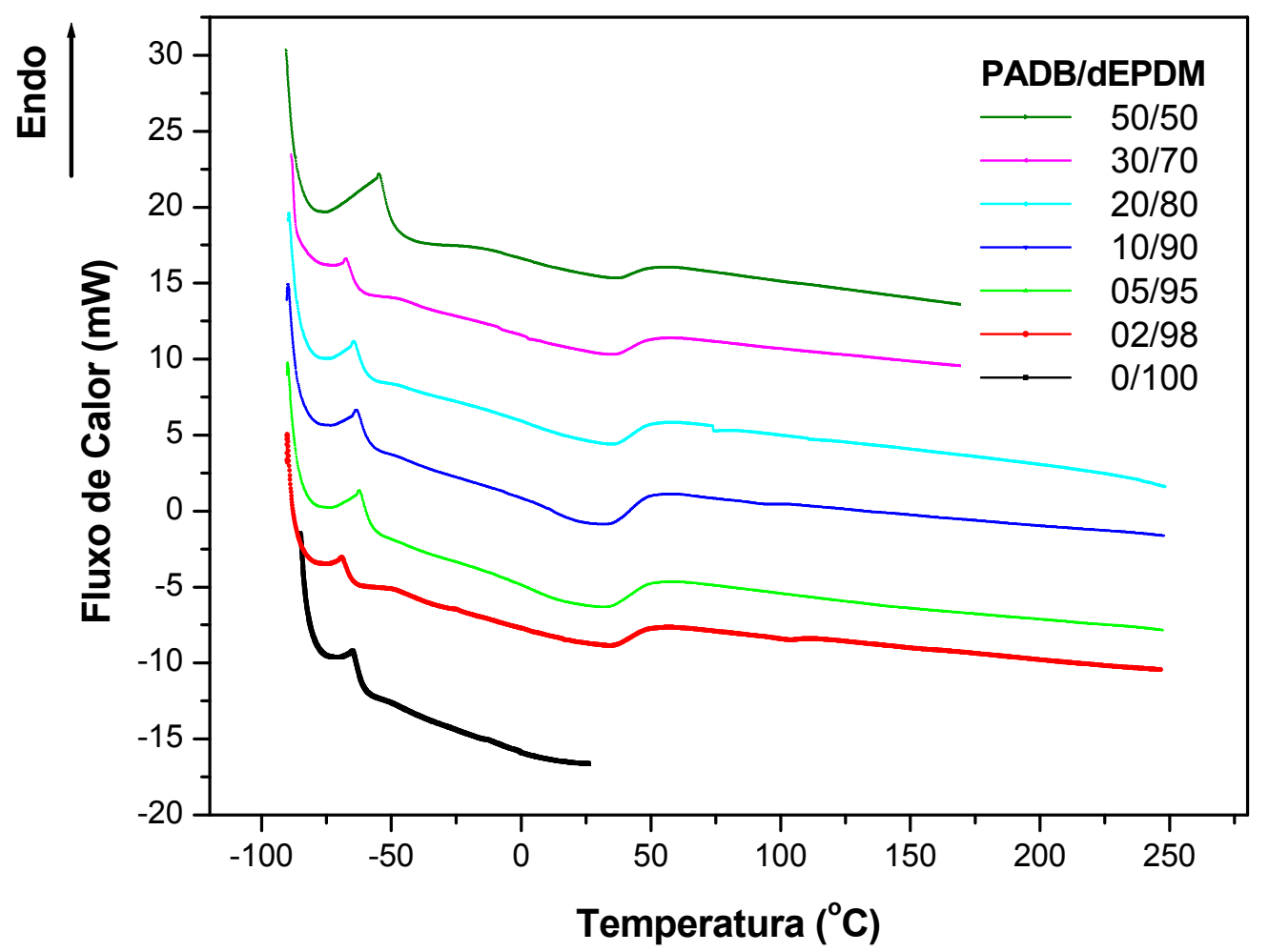

Figura 4. 3. Curvas DSC de dEPDM puro e das blendas de PAni-DBSA/dEPDM.

Ao observar temperaturas de transição vítrea diferentes e bem definidas para cada componente nas blendas, nota-se que não são completamente miscíveis podendo haver formação de rede do material condutor (PAni-DBSA) na matriz elastomérica isolante (dEPDM). Os picos observados entre $-75^{\circ} \mathrm{C}$ e $-50^{\circ} \mathrm{C}$ referemse ao óleo alifático utilizado como plastificante no processamento do EPDM.

Um aumento da Tg da dEPDM é observado conforme o aumento da quantidade de PAni-DBSA na blenda. Essa variação pode ser o resultado da interação de curto alcance da PAni-DBSA com a rede matricial da dEPDM. A rede matricial de dEPDM sofre pequenas deformações enquanto que a PAni-DBSA não é afetada, mantendo um valor de $\mathrm{Tg}$ quase constante. 


\subsubsection{Análise Termodinâmico-Mecânica (DMTA)}

Nesta seção é apresentado o comportamento dinâmico-mecânico de dEPDM puro e de blendas de PAni-DBSA/dEPDM em diferentes composições, a partir da análise dos resultados observados para o módulo de armazenamento e a $\operatorname{tg} \delta$ (tangente de perda).

As análises morfológicas e térmicas revelaram uma clara separação de fase em todos os sistemas de PAni-DBSA/dEPDM investigados, e a imiscibilidade entre os componentes foi evidenciada. O DMTA fornece informação sobre a influência do polímero condutor no módulo de armazenamento $\left(E^{\prime}\right)$ e na tg $\delta$ nas diversas composições das blendas, quando submetidas à deformação dinâmico-mecânica em uma faixa de temperatura. Um valor único correspondente à $T_{g}$ do polímero condutor não foi estabelecido. Esta temperatura é difícil de ser determinada em experimentos DMTA, no caso da polianilina, devido à rigidez do material.

Na Figura 4. 4 pode-se observar um aumento significativo no módulo de armazenamento na região entre -100 e $50{ }^{\circ} \mathrm{C}$, com o acréscimo de PAni-DBSA na mistura, ocorrendo após a transição vítrea o platô borrachoso em todas as misturas. Este aumento no módulo pode ser atribuído ao aumento da rigidez do sistema devido à incorporação do polímero condutor. As curvas referentes às blendas com 10 e $30 \%$ de PAni-DBSA não acompanham o aumento do módulo de armazenamento coerentemente como as outras blendas. Isto pode ser explicado pelo fato dos filmes não serem homogêneos e, portanto, pode haver concentrações diferentes de PAni-DBSA distribuídos pelo material. Sendo assim, a parte retirada destas blendas para os ensaios de DMTA pode conter maior ou menor quantidade do polímero condutor em relação ao polímero isolante.

No gráfico de $\operatorname{tg} \delta$ versus temperatura (Figura 4. 5) observa-se um pico pronunciado a $-48^{\circ} \mathrm{C}$ na curva correspondente ao dEPDM puro, sendo que este pico permanece inalterado quando se adiciona $2 \%$ em massa de PAni-DBSA. Este comportamento indica pouca modificação na mistura e/ou ainda uma boa aderência 
entre as fases. No entanto, a partir de $5 \%$ em massa de PAni-DBSA, verifica-se um progressivo decréscimo na altura do pico com o aumento do polímero condutor. Em termos gerais, observa-se o decréscimo nos valores de $\operatorname{tg} \delta$, que representa a diminuição do amortecimento do sistema, com o aumento da presença da PAni, que é mais rígida que o EPDM; ou seja, a mobilidade da cadeia fica mais limitada. Isto pode ser explicado pela $\mathrm{T}_{\mathrm{g}}$ da PAni pura que possui, de acordo com a literatura, um valor mais elevado $\left(\sim 100^{\circ} \mathrm{C}\right)$ [107]. Uma situação semelhante ocorre quando partículas rígidas são adicionadas a matrizes elastoméricas flexíveis.

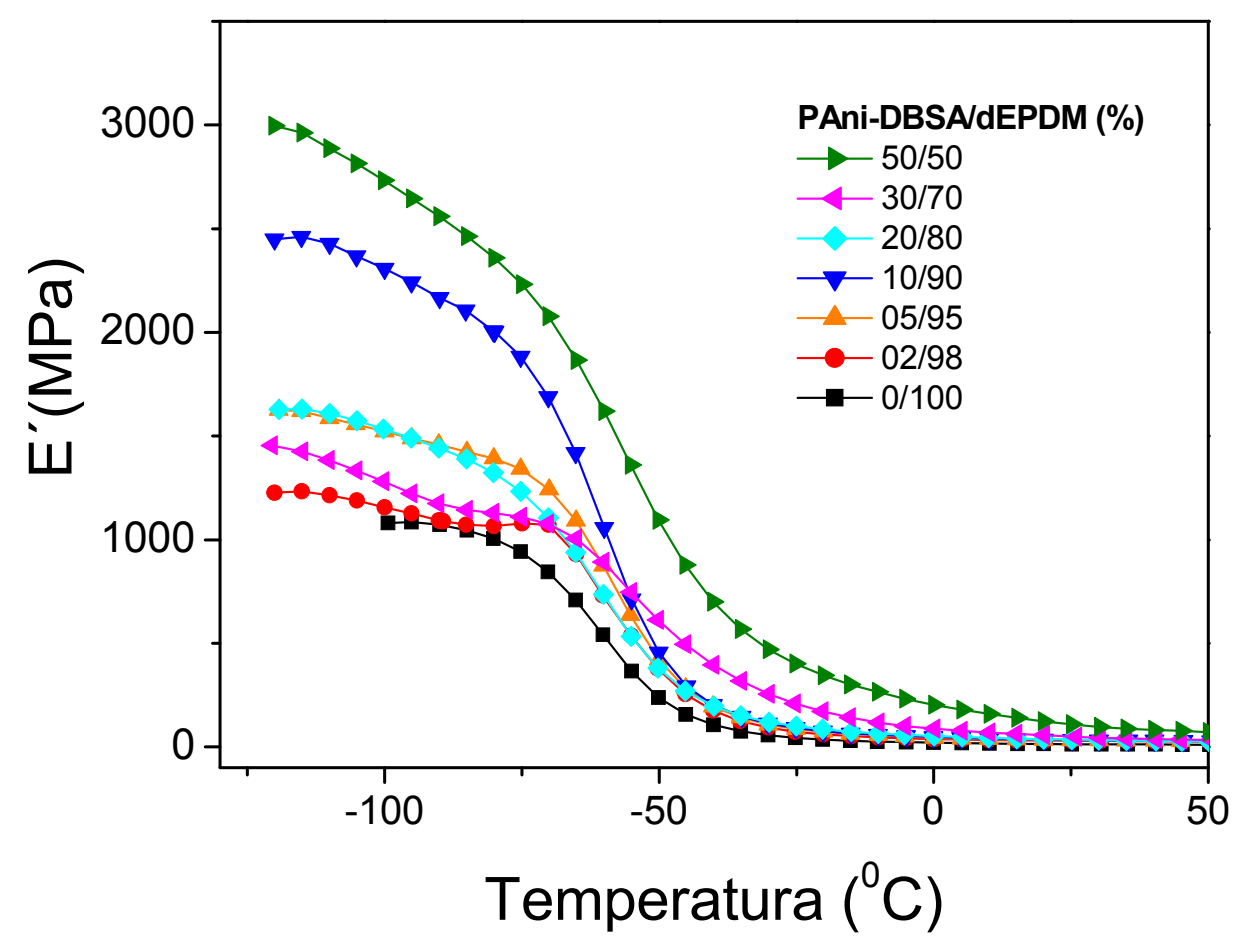

Figura 4. 4. Módulo de armazenamento em função da temperatura de dEPDM puro e blendas de PAni-DBSA/dEPDM em diferentes composições. 


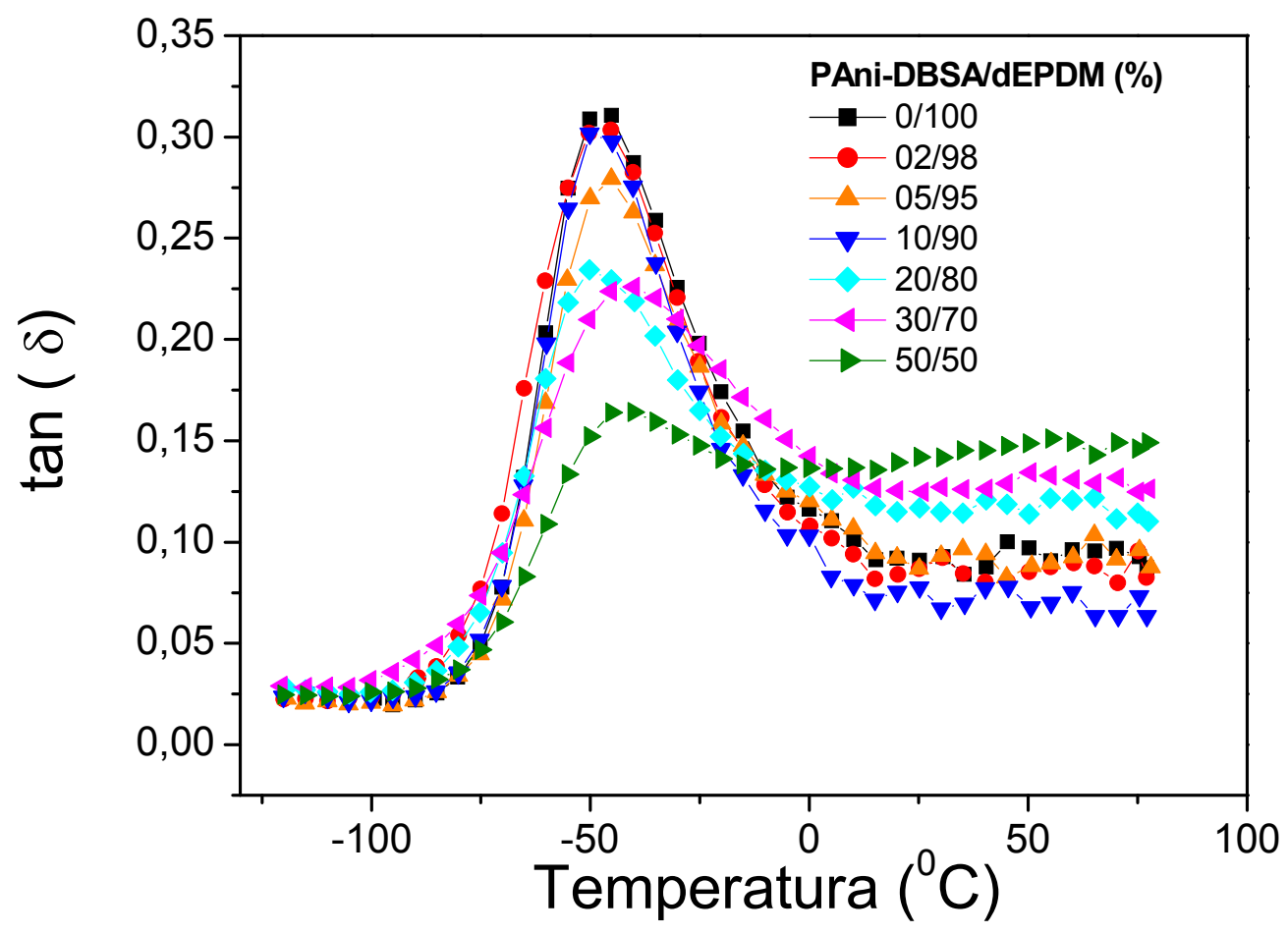

Figura 4. 5. Tan $\delta$ em função da temperatura de dEPDM puro e blendas de PAniDBSA/dEPDM em diferentes composições. 


\subsubsection{Microscopia Óptica (MO)}

Nesta seção são apresentadas imagens obtidas pelo microscópio óptico (MO).

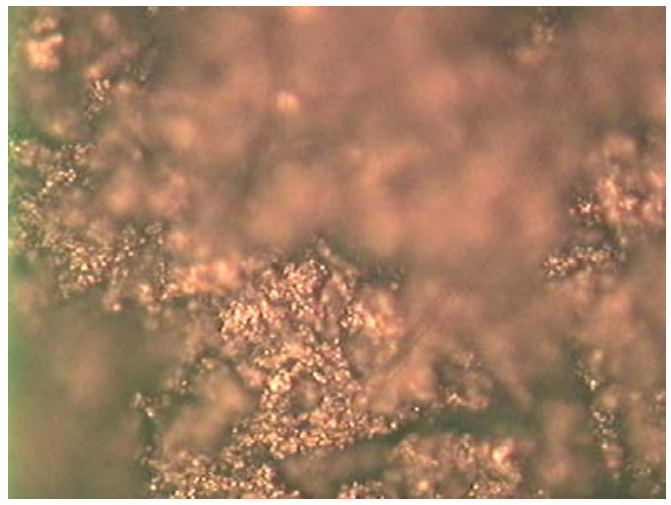

(a)

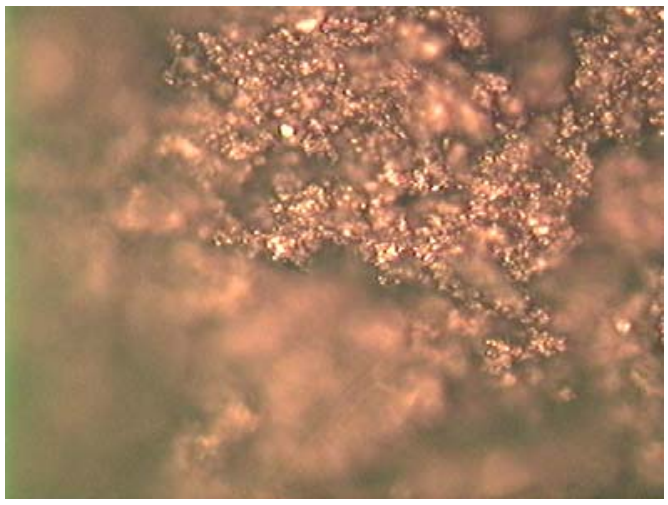

(b)

Figura 4. 6. Imagens de microscopia óptica (MO) da amostra de dEPDM puro em magnitude $1.000 \mathrm{x}$ - (a) foco na parte inferior e (b) foco na parte superior da mesma região.

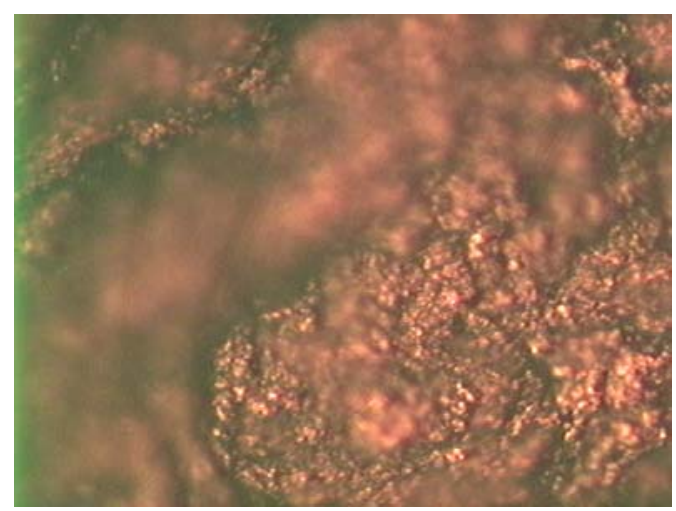

(a)

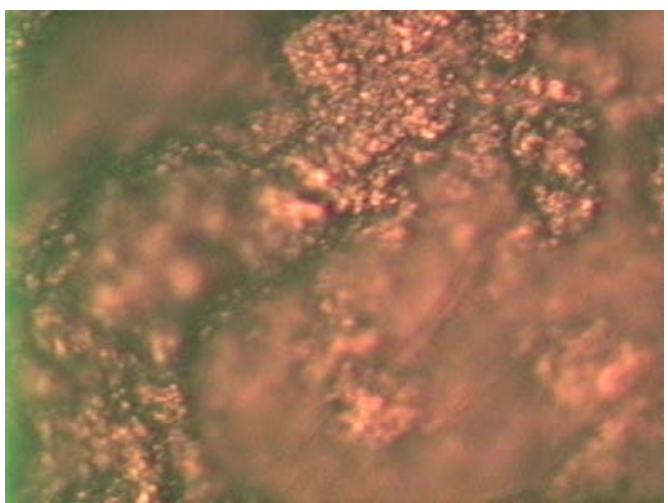

(b)

Figura 4. 7. Imagens de microscopia óptica (MO) da blenda de PAni-DBSA/dEPDM $20 / 80$ em magnitude $1.000 x-(a)$ foco na parte inferior e (b) foco na parte superior da mesma região.

Estão apresentadas imagens de duas amostras (dEPDM puro e PAni-DBSA/dEPDM 20/80) pelo fato de que as imagens obtidas pelo microscópio 
óptico das demais blendas não forneceram novas informações a respeito da morfologia do material. Isto acontece porque as imagens são muito semelhantes como é observado pelas Figura 4. 6 e Figura 4. 7.

As imagens de microscopia óptica apenas mostraram uma superfície rugosa para todas as amostras, pois a ampliação de $1.000 x$ da imagem não foi suficiente para fornecer detalhes da morfologia do material. Como não foi possível aumentar o ganho do MO, foi utilizada a técnica de microscopia eletrônica de varredura (MEV), conforme relatada na seção seguinte com o intuito de obter melhores informações. 


\subsubsection{Microscopia Eletrônica de Varredura (MEV)}

Nesta seção estão apresentadas as micrografias das amostras de PAni-DBSA/dEPDM em diferentes composições e da amostra de dEPDM puro.

A técnica de microscopia eletrônica de varredura foi utilizada para verificar possíveis modificações em suas morfologias. Foram obtidas imagens de cada amostra nas seguintes magnitudes: 640x, 5.000x e 20.000x, onde foi possível analisar a morfologia dos filmes.

A análise foi feita tomando-se como base as micrografias da amostra de dEPDM puro, verificando-se, a partir desta, o comportamento das blendas com a introdução da PAni-DBSA. Conforme ilustrado da Figura 4. 8 à Figura 4. 14. 


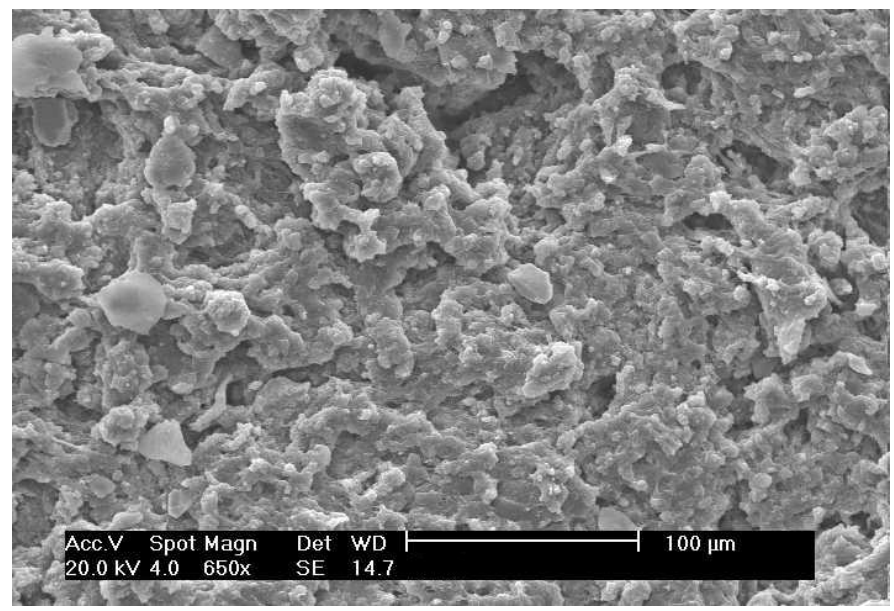

(a)

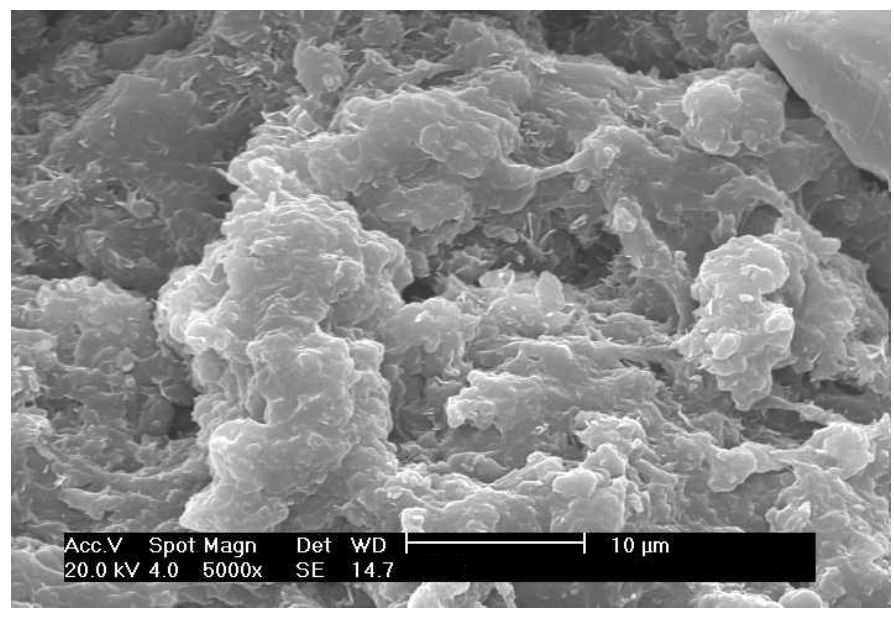

(b)

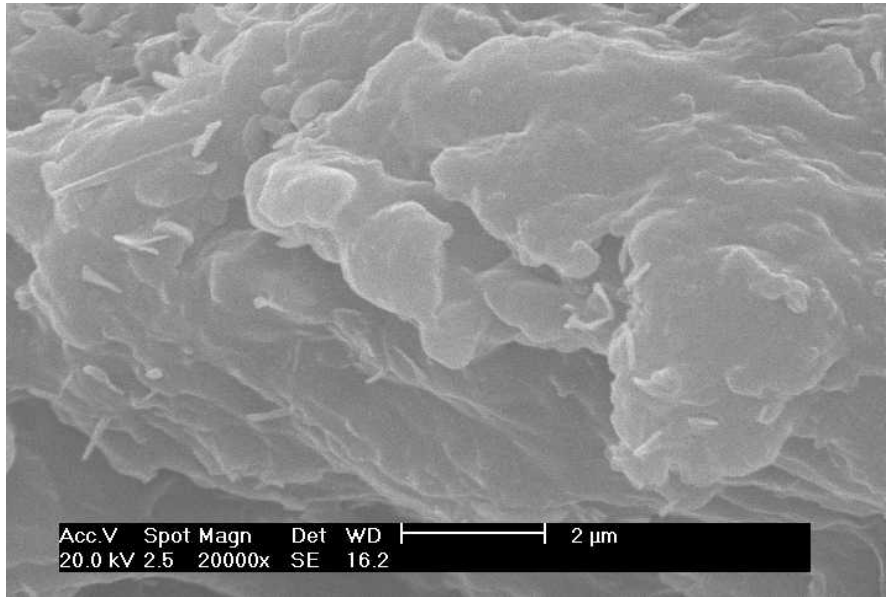

(c)

Figura 4. 8. Imagens de MEV da borracha dEPDM pura em diferentes magnitudes:(a) 650x, (b) 5000x e (c) 20000x. 


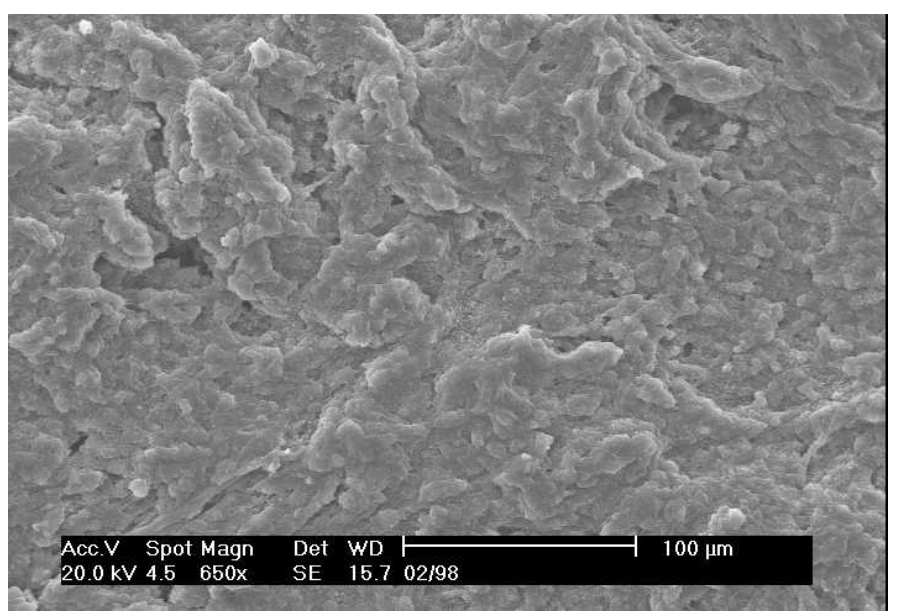

(a)

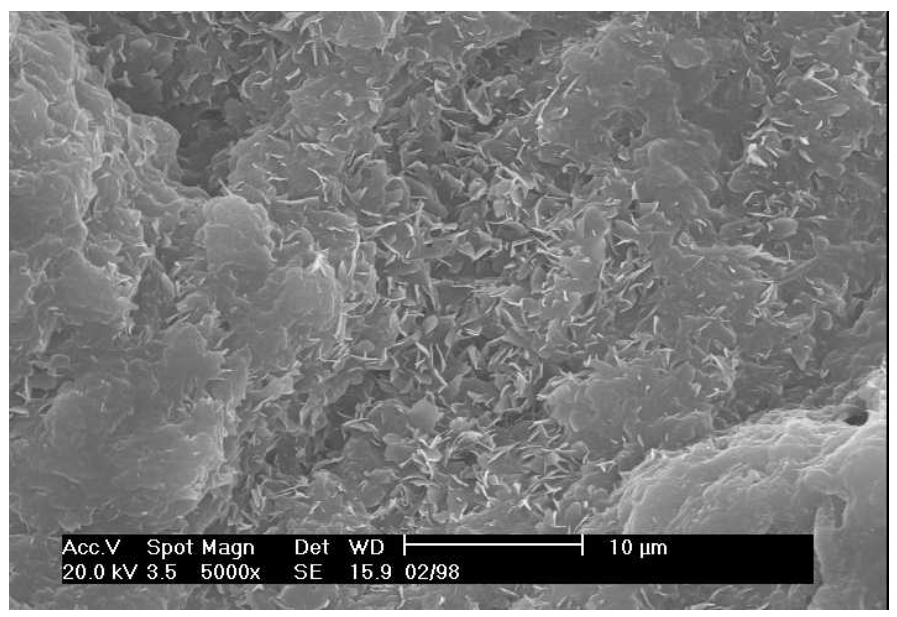

(b)

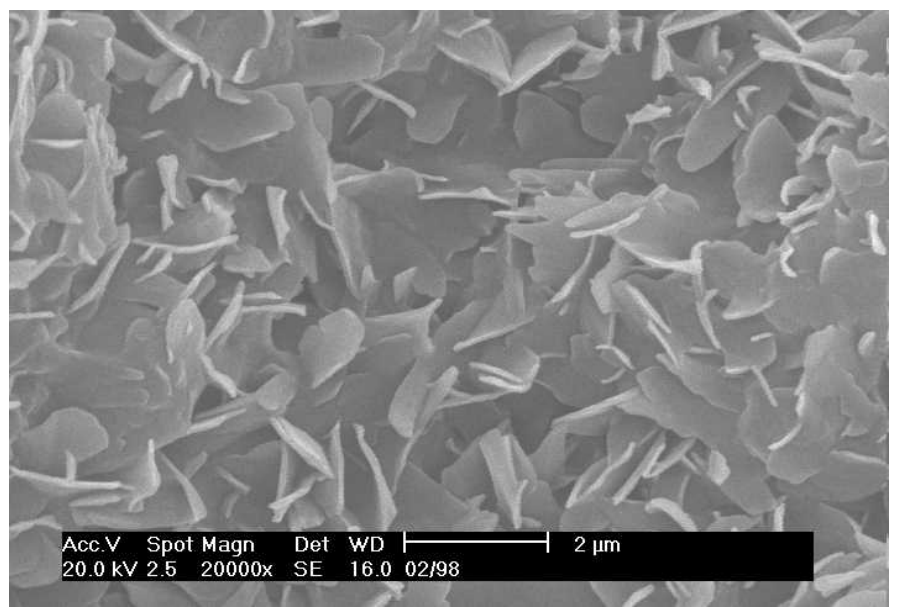

(c)

Figura 4. 9. Imagens de MEV da blenda de PAni-DBSA/dEPDM (02/98) em diferentes magnitudes: (a) 650x, (b) 5000x e (c) 20000x. 


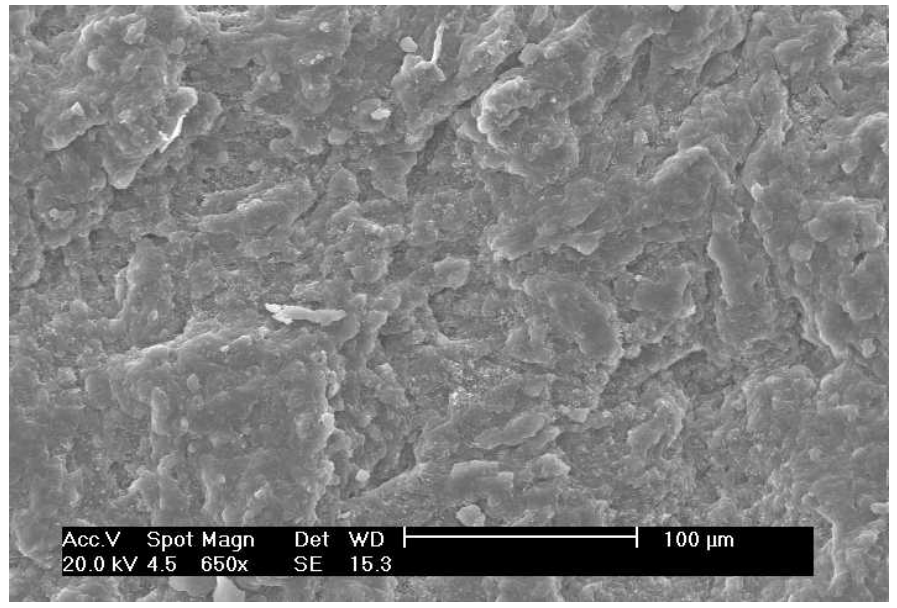

(a)

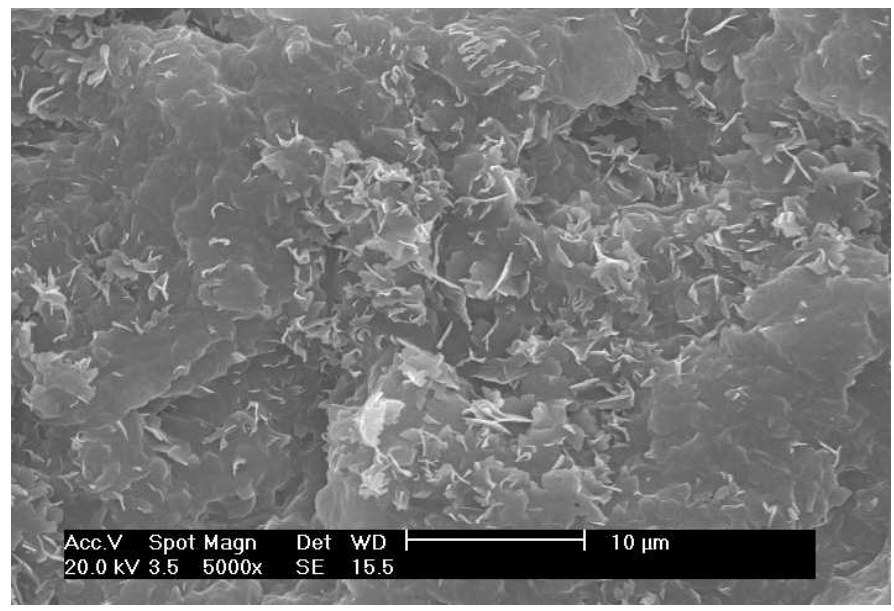

(b)

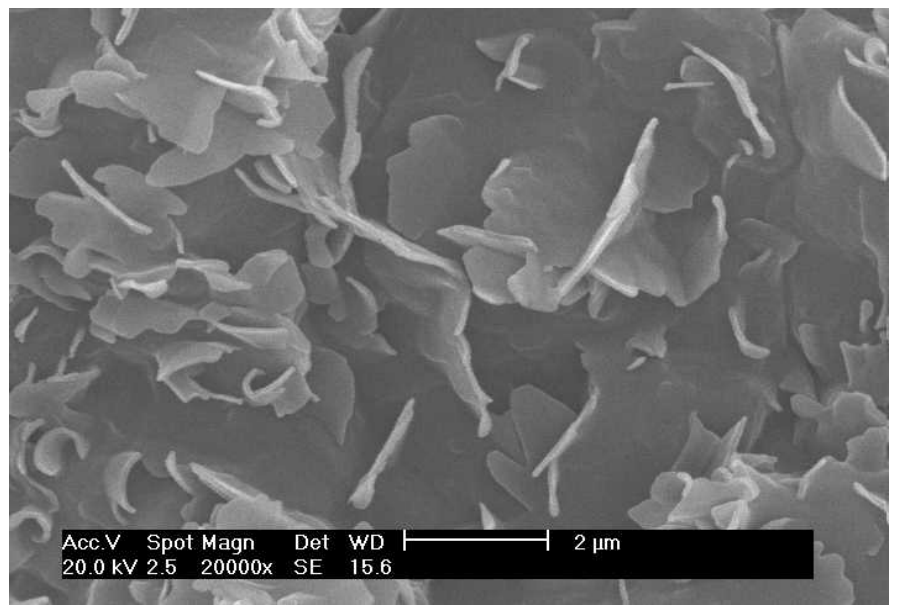

(c)

Figura 4. 10. Imagens de MEV da blenda de PAni-DBSA/dEPDM (05/95) em diferentes magnitudes: (a) 650x, (b) 5000x e (c) 20000x. 


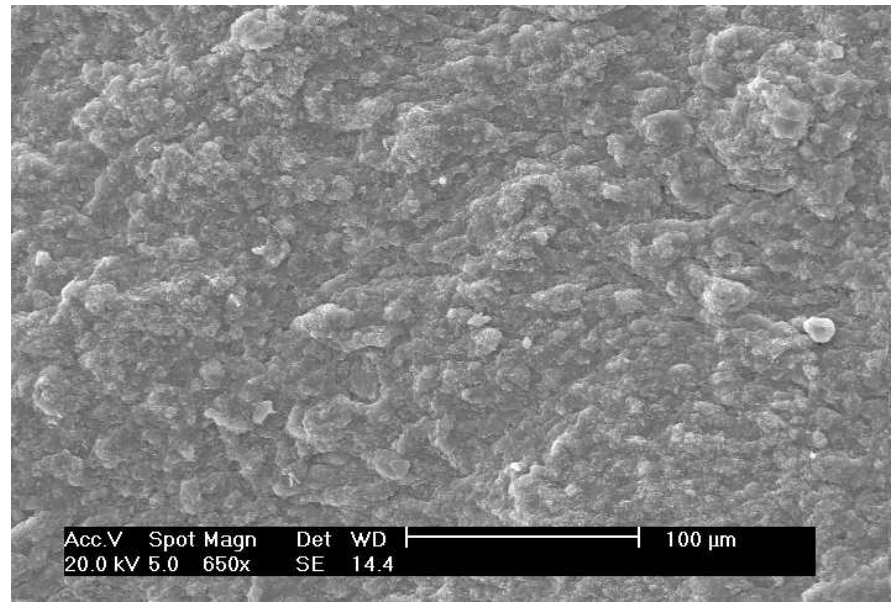

(a)

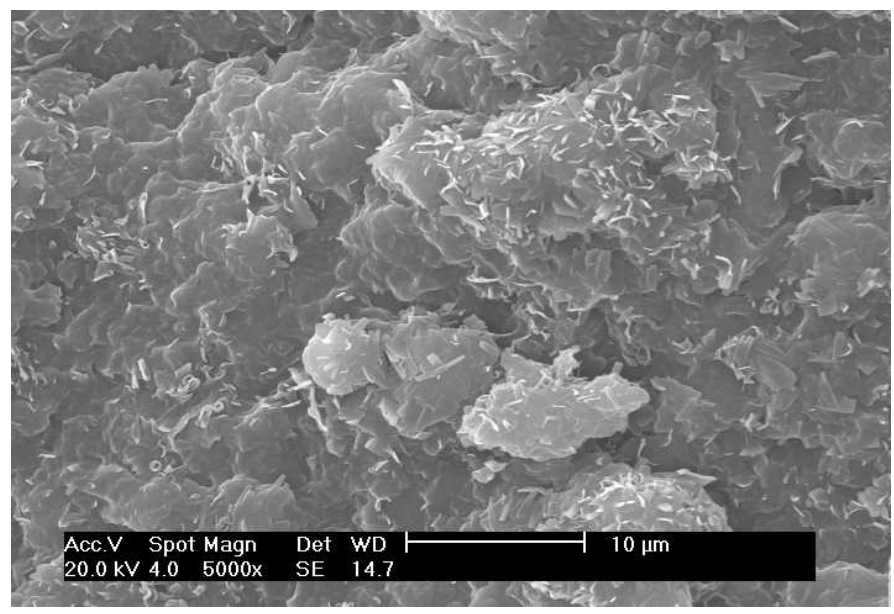

(b)

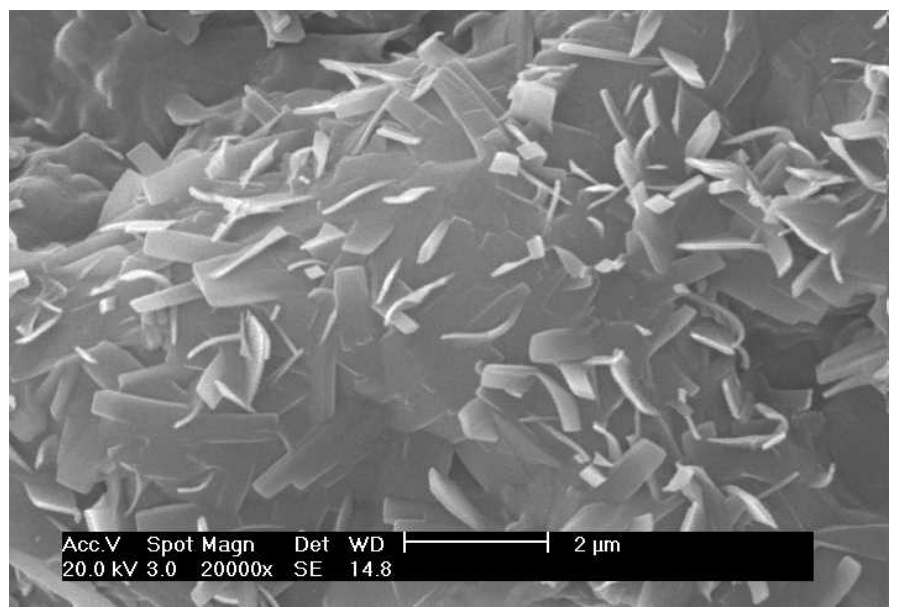

(c)

Figura 4. 11. Imagens de MEV da blenda de PAni-DBSA/dEPDM (10/90) em diferentes magnitudes: (a) 650x, (b) 5000x e (c) 20000x. 


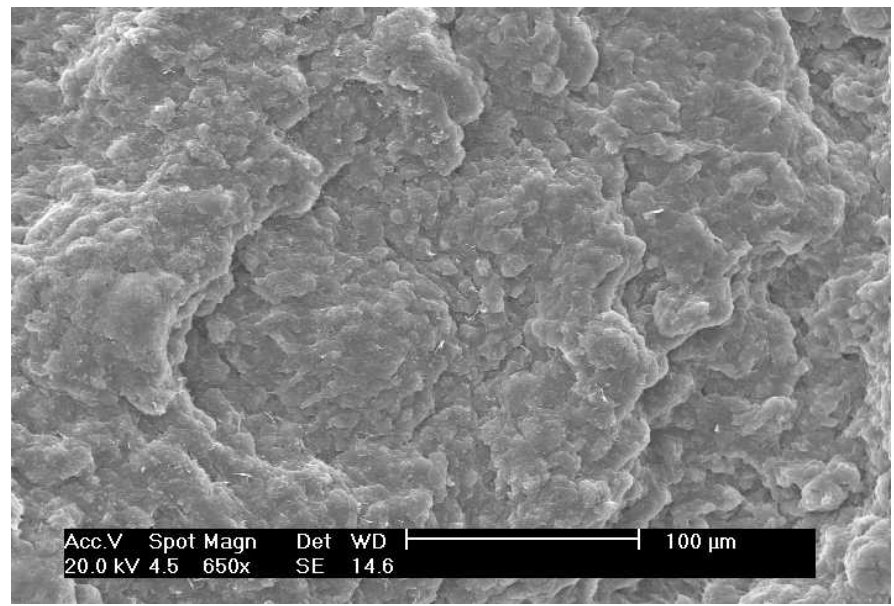

(a)

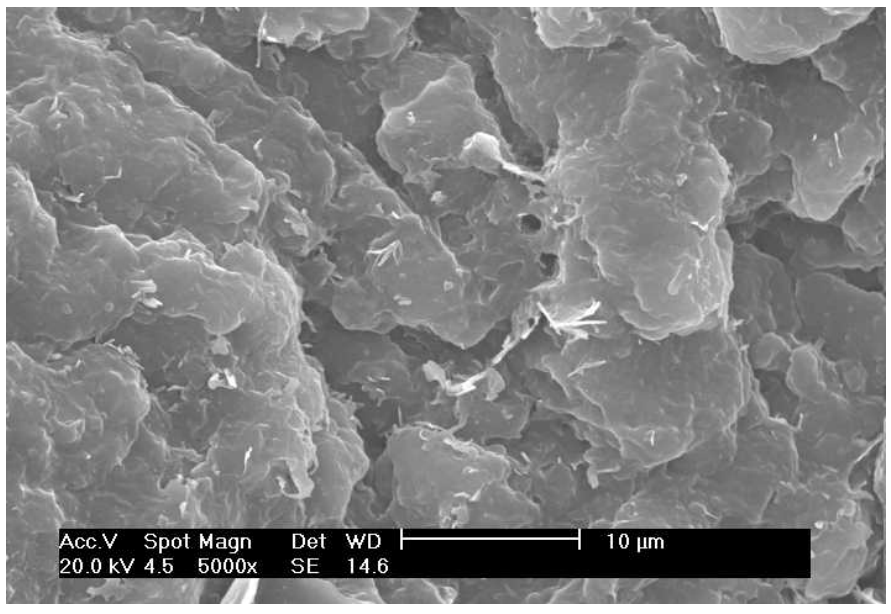

(b)

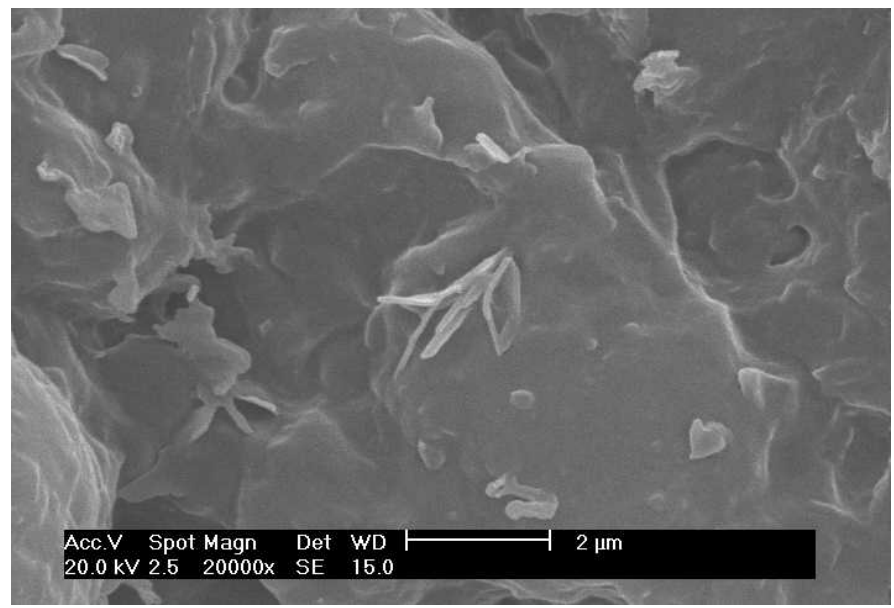

(c)

Figura 4. 12. Imagens de MEV da blenda de PAni-DBSA/dEPDM (20/80) em diferentes magnitudes: (a) 650x, (b) 5000x e (c) 20000x. 


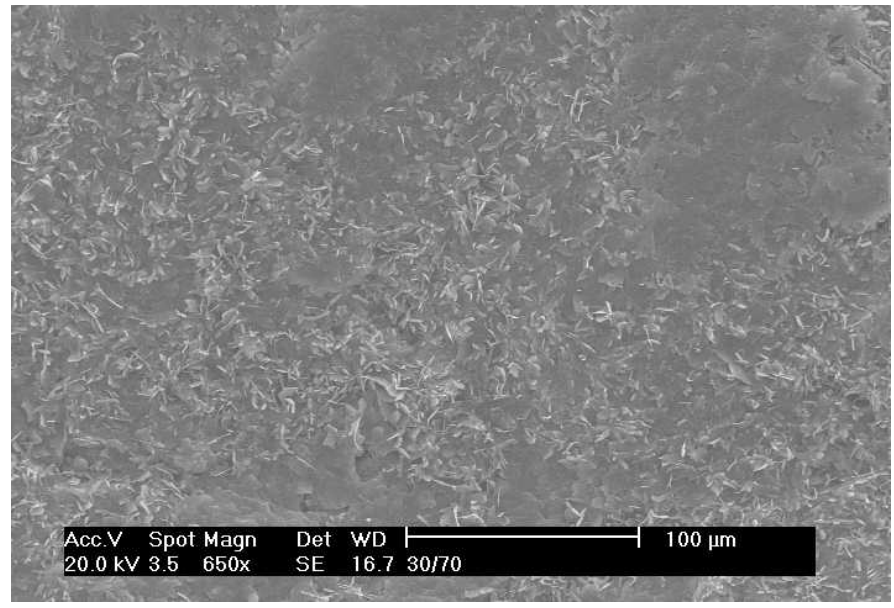

(a)

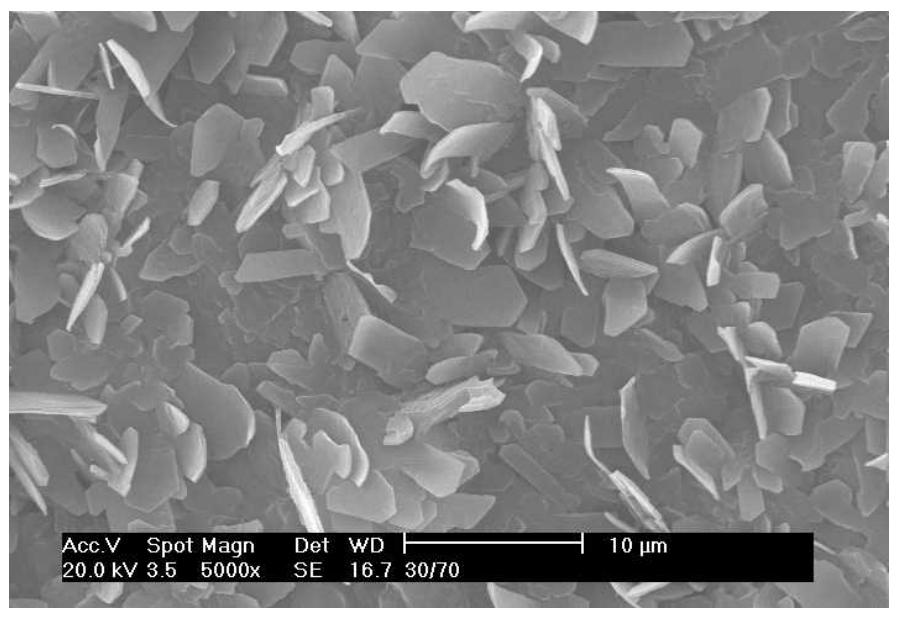

(b)

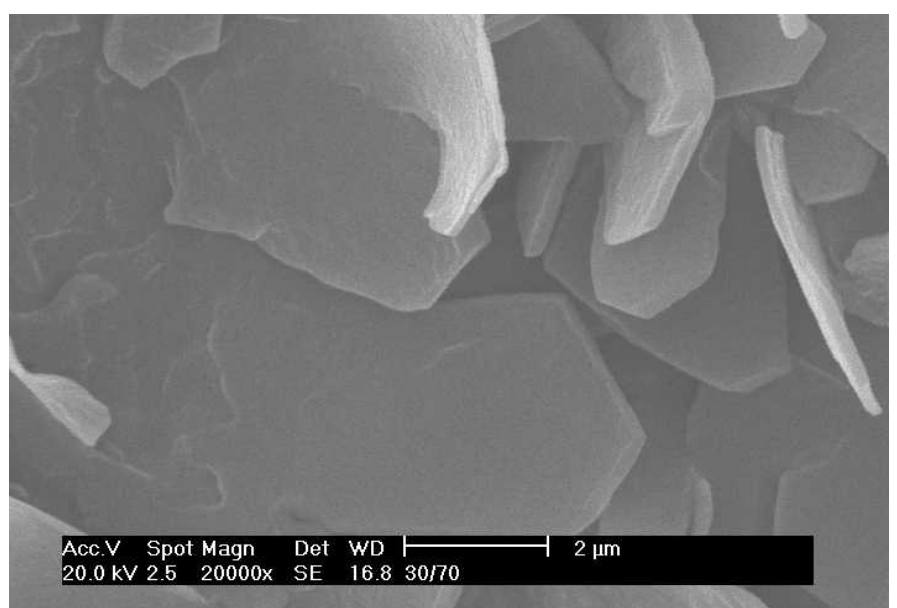

(c)

Figura 4. 13. Imagens de MEV da blenda de PAni-DBSA/dEPDM (30/70) em diferentes magnitudes: (a) 650x, (b) 5000x e (c) 20000x. 


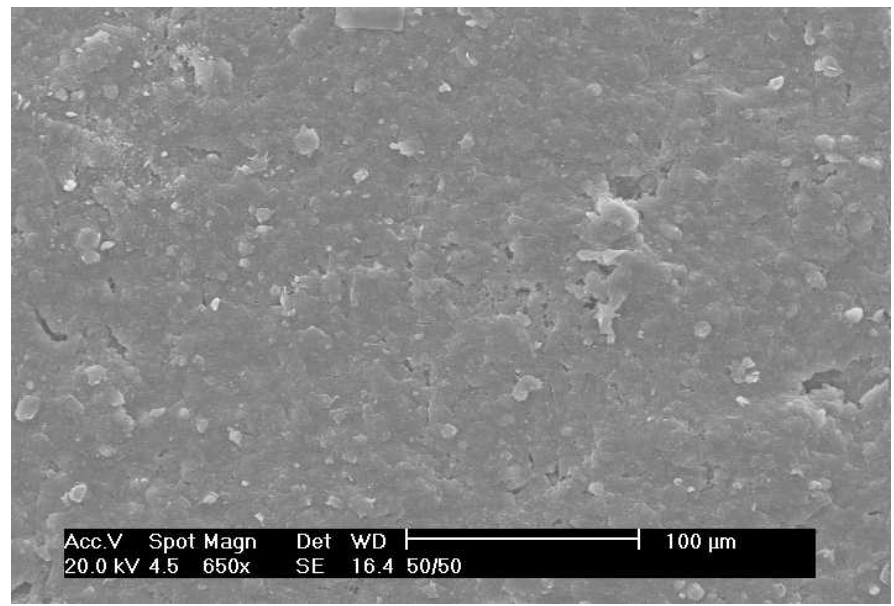

(a)

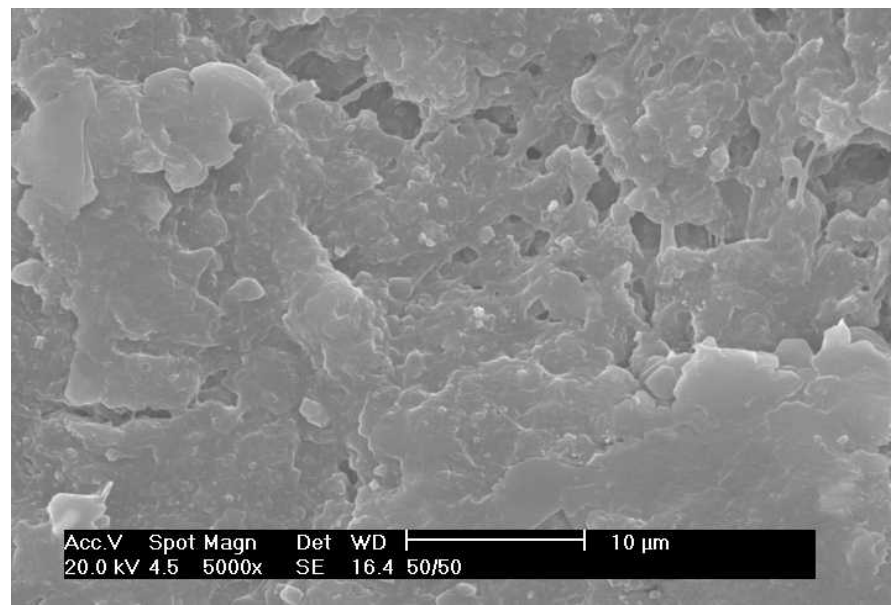

(b)

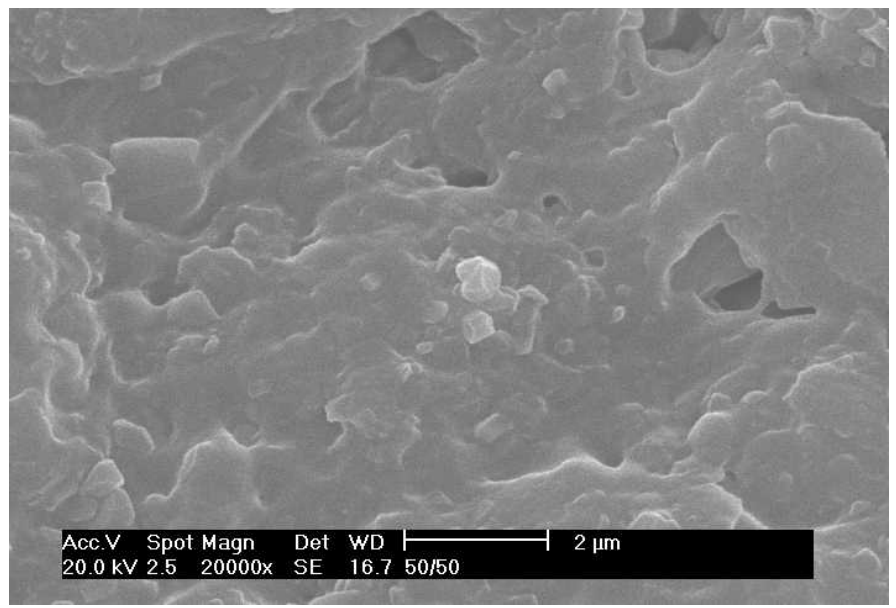

(c)

Figura 4. 14. Imagens de MEV da blenda de PAni-DBSA/dEPDM (50/50) em diferentes magnitudes: (a) 650x, (b) 5000x e (c) 20000x. 
Analisando-se a microscopia das amostras, com aumento de 5.000 a 20.000 vezes, observa-se diferentes formas na morfologia da superfície do material. A partir de $2 \%$ em massa de PAni-DBSA (Figura 4. 9) é possível verificar o aparecimento de superfícies de fraturas, as quais podem ser atribuídas à PAni-DBSA que não se misturou com a fase dEPDM. Essas superfícies de fraturas aumentaram de acordo com a introdução de maiores quantidades de PAni-DBSA, até 30\% deste componente, excetuando-se a amostra que contém $20 \%$ em massa de PAni-DBSA (Figura 4. 12), pois nesta não se observa com clareza tais estruturas.

$\mathrm{Na}$ blenda que contém $50 \%$ de peso de PAni-DBSA e $50 \%$ de peso de dEPDM (Figura 4. 14) não há superfície de fraturas, não sendo possível distinguir as duas fases.

Contudo, de acordo com as imagens de MEV, o efeito da PAni-DBSA na matriz isolante pode ser observado, pois com o aumento da quantidade de PAni-DBSA houve uma mudança na estrutura da matriz de dEPDM puro.

Portanto, as blendas poliméricas de PAni-DBSA/dEPDM, preparadas sob as mesmas condições, apresentaram interação física entre os dois componentes e dispersão de fases para todas as composições. 


\subsubsection{Difração de Raios-X (DRX)}

Nesta seção estão apresentados espectros de raios- $X$ das amostras de PAni-DBSA/dEPDM e da amostra de dEPDM puro. A análise de difração de raio-x juntamente com a microscopia eletrônica foi feita para melhor elucidação das composições e das condições de preparação dos filmes nas propriedades das blendas poliméricas condutoras.

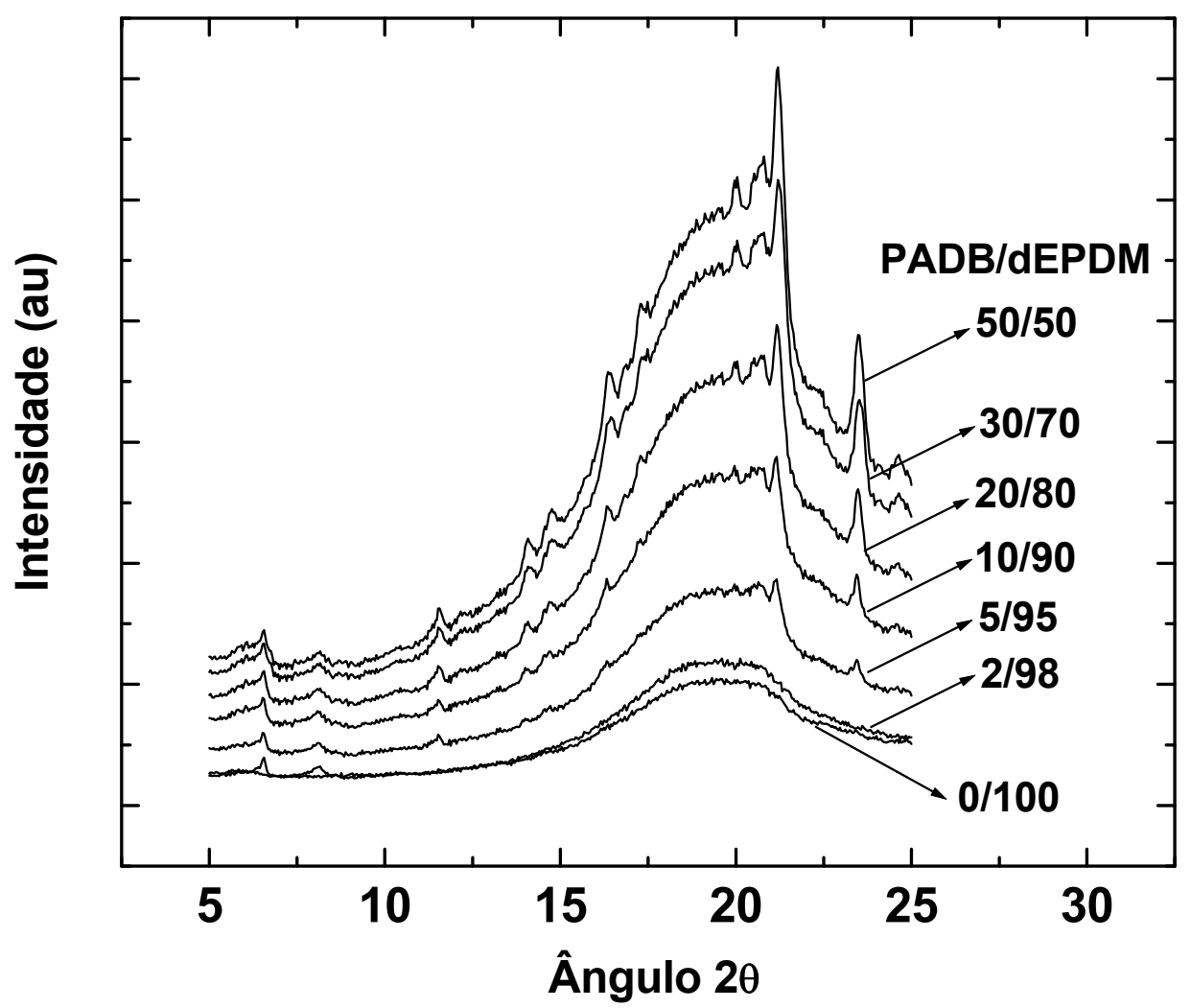

Figura 4. 15. Difratograma de raios-X da dEPDM pura e das blendas de PAniDBSA/dEPDM em diferentes concentrações.

A análise de raios-X confirma a presença de uma fase cristalina no interior das blendas. $\mathrm{Na}$ Figura 4. 15 pode-se observar que os picos cristalinos característicos da PAni-DBSA $[48,108]$ em ângulos $2 \theta=6,5^{\circ}$ e $8^{\circ}$ permanecem 
praticamente em todas as blendas. Já a difração de raios-X do dEPDM puro é completamente amorfa. Picos intensos também podem ser observados para conteúdos de PAni-DBSA acima de $5 \%$ em massa na faixa de ângulos $2 \theta$ de $20^{\circ}$ a $24.6^{\circ}$ e para $2 \theta$ de $16,4^{\circ}$ a $11,5^{\circ}$. Pode-se se observar também o aumento na intensidade dos picos a $21,2^{\circ}$ e $23,5^{\circ}$ o que é atribuído às regiões ordenadas na PAni-DBSA (Figura 4. 15). 


\subsubsection{Condutividade Elétrica}

Nesta seção é apresentada a análise da condutividade elétrica das blendas de PAni-DBSA/dEPDM em diferentes composições, preparadas por processo mecânico. As medidas de condutividade elétrica (corrente contínua) foram feitas nas amostras, em temperatura ambiente, usando o método de quatro pontas.

A Figura 4. 16, apresenta a condutividade elétrica da amostra de dEPDM puro e das blendas de PAni-DBSA/dEPDM de duas maneiras: condutividade aparente e condutividade normalizada. A condutividade normalizada relatada é a condutividade aparente dividida pela porcentagem de massa de PAni-DBSA, que se espera ser constante e igual a da PAni-DBSA pura, o que fornece o comportamento das blendas de acordo com a regra simples de misturas.

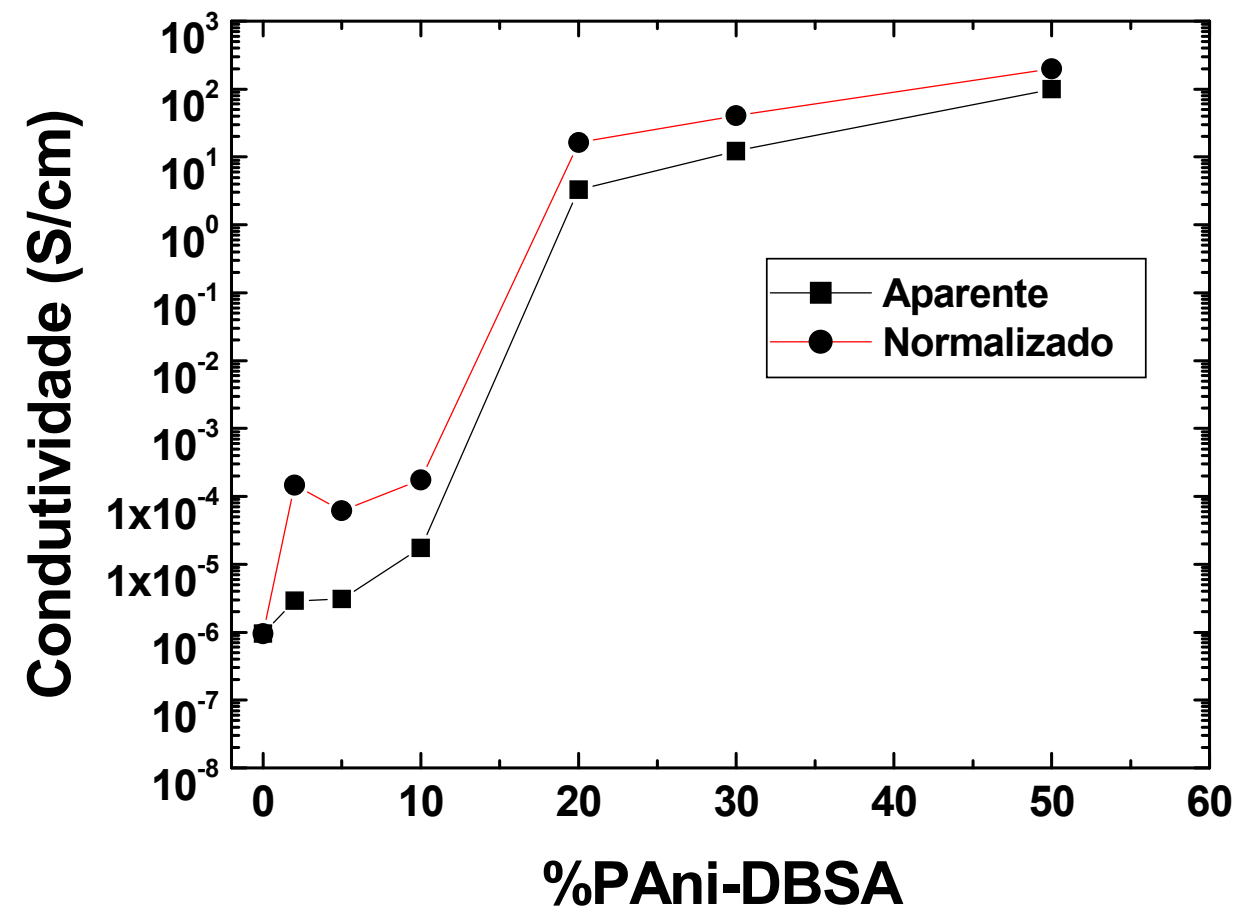

Figura 4. 16. Condutividade elétrica como uma função da composição da blenda para filmes de PAni-DBSA/dEPDM preparados por processo mecânico. 
Para a amostra de dEPDM puro foi verificada uma condução de corrente elétrica muito baixa $\left(\sim 10^{-6} \mathrm{~S} / \mathrm{cm}\right)$, confirmando, então, ser um material isolante. A partir disto, considera-se que o negro de fumo, constituinte da borracha dEPDM, tem apenas o papel de agente de reforço mecânico.

Como esperado, a condutividade elétrica aumenta com a concentração de PAni-DBSA nas blendas, e um baixo limite de percolação pode ser observado devido à condutividade ocorrer para baixas concentrações de material condutor (<20\%). Entre $10 \%$ e $20 \%$ em massa de PAni-DBSA há um súbito aumento da condutividade de, aproximadamente, $10^{-4} \mathrm{~S} / \mathrm{cm}$ a $10^{1} \mathrm{~S} / \mathrm{cm}$. A condutividade máxima alcançada foi de, aproximadamente, $10^{2} \mathrm{~S} / \mathrm{cm}$ para a composição de $50 \%$ de PAni-DBSA em massa. Essas medidas não foram realizadas em amostras acima de $50 \%$ de PAni-DBSA por causa da impossibilidade de processá-las em forma de filmes, devido à rigidez do polímero condutor.

Este salto na condutividade entre as blendas compostas por $10 \%$ e $20 \%$ de PAni-DBSA pode ser explicado pelas ilhas eletricamente condutoras formadas pelo material condutor dentro da matriz isolante. Com a introdução de PAni-DBSA formam-se ilhas condutoras na matriz de dEPDM. Quando há pequenas quantidades do material condutor, essas ilhas situam-se mais espaçadas, havendo maior dificuldade em formar uma rede condutora. Este espaçamento este preenchido pelo dEPDM que é um isolante elétrico e, portanto, com baixa condutividade elétrica $\left(<10^{-3} \mathrm{~S} / \mathrm{cm}\right)$. Porém, com maiores quantidades de PAni-DBSA, têm-se ilhas maiores e em maior quantidade, as quais ficam mais próximas umas das outras, favorecendo a formação da rede condutora mais facilmente e, conseqüentemente, obtendo um aumento da condutividade. Isto pode ser observado nas blendas com mais de $20 \%$ de PAni-DBSA. A partir deste ponto, não se observa grandes aumentos na condutividade, permanecendo praticamente constante. Isto se deve ao fato de que a rede condutora na matriz isolante está praticamente completa (sem muitos pontos falhos) e a introdução de mais material condutor a partir deste ponto não acarreta grandes mudanças na rede. 


\section{CONCLUSÕES}

As principais conclusões deste trabalho são:

1. Filmes condutores elétricos flexíveis e não quebradiços, de Polianilina dopada com ácido dodecilbenzeno sulfônico (PAni-DBSA) e borracha de etilenopropileno-monômero dieno desvulcanizada por microondas (dEPDM), foram obtidos por processo mecânico.

2. Foram produzidos filmes de PAni-DBSA/dEPDM em diversas proporções; porém, não foi possível obter filmes das blendas contendo acima de $50 \%$ em massa do polímero condutor (PAni-DBSA) devido a sua rigidez mecânica, pois os filmes se tornaram quebradiços.

3. As análises de FTIR das blendas poliméricas mostraram a incorporação gradual da PAni-DBSA na matriz dEPDM, porém não foi notada qualquer modificação nos espectros. Portanto, as interações entre os componentes de PAni-DBSA e dEPDM foram, basicamente, físicas e não químicas.

4. A partir dos ensaios de TGA foi verificada a estabilidade térmica da PaniDBSA pura, do dEPDM puro e das blendas de PAni-DBSA/dEPDM. A amostra de PAni-DBSA pura começou o processo de degradação em $T$ $\sim 51,5^{\circ} \mathrm{C}$. A amostra de dEPDM puro iniciou a degradação em $\mathrm{T} \sim 190,3^{\circ} \mathrm{C}$. No entanto, nas blendas, a temperatura de degradação inicial do dEPDM baixou significativamente na medida em que havia maior proporção de PAni-DBSA. Por exemplo, para a blenda de 50\% PAni-DBSA e 50\% dEPDM a degradação iniciou-se a $92,63^{\circ} \mathrm{C}$. Portanto, a PAni-DBSA diminuiu consideravelmente a estabilidade térmica da borracha.

5. Os ensaios de DSC apresentaram dois pontos de inflexão que podem ser atribuídos um à PAni-DBSA e outro ao dEPDM. Isto indica que as blendas não são totalmente miscíveis, o que corrobora os resultados obtidos pelo 
FTIR. E também foi observado um aumento significativo da Tg do dEPDM conforme a introdução de maiores quantidades de PAni-DBSA.

6. Os ensaios de DMTA mostraram a diminuição do amortecimento do sistema ocasionado pela presença da PAni, que é mais rígida, no segmento flexível do EPDM; ou seja, a mobilidade da cadeia fica mais limitada.

7. As imagens obtidas pela microscopia eletrônica de varredura (MEV) mostraram o aparecimento de superfícies de fraturas conforme o aumento da PAni-DBSA nas blendas. Isto pode ser explicado pelo fato dos componentes poliméricos não apresentarem total miscibilidade nas blendas, observado também no DSC.

8. A análise de raios-X confirmou a presença de uma fase cristalina no interior das blendas que é atribuída à PAni-DBSA, pois picos cristalinos característicos da PAni-DBSA foram observados em ângulos $2 \theta=6,5^{\circ}$ e $8^{\circ} \mathrm{e}$ permanecem em todas as blendas, por outro lado, a difração de raios-X do dEPDM puro é completamente amorfa.

9. A introdução de PAni-DBSA contribuiu para a condutividade elétrica e as blendas de PAni-DBSA/dEPDM apresentaram um baixo limite de percolação de cargas, pois se observou ocorrência de condutividade elétrica mesmo nas blendas de menores concentrações de material condutor ( $<20 \%$ em massa de PAni-DBSA).

10. A condutividade máxima foi alcançada para a blenda de $50 \%$ em massa de PAni-DBSA. 


\section{SUGESTÕES PARA TRABALHO FUTURO}

1. Utilização da blenda na construção de dispositivos:

- Sensíveis ao toque

- Sensores de:

o Pressão;

- Deslocamento / Deformação e

o Presença (por deformação).

2. Estudo da condutividade elétrica da blenda de PAni-DBSA/dEPDM em função da temperatura, tempo, radiação ultravioleta, na presença de materiais corrosivos como ácidos e bases em geral, entre outros. 


\section{REFERÊNCIAS}

[1] Schmidt, V.; Domenech, S. C.; Soldi, M. S.; Pinheiro, E. A.; Soldi, V. Thermal stability of polyaniline/ethylene propylene diene rubber blends prepared by solvent casting. Polym. Degrad. and Stabil., v. 83, n. 3 p. 519, 2004.

[2] Domenech, S. C.; Bortoluzzi, J. H.; Soldi, V.; Gronski, W.; Radusch, H. J. Characterization, Morphology, Thermal and Mechanical Properties of Conductive Polyaniline-Functionalized EPDM Elastomers Obtained by Casting, Journal of Polymer Science: Part B: Polymer Physics, v. 42, p. 1767, 2004.

[3] Cao, Y.; Smith, P.; MacDiarmid, A. G. Counter-ion induced processibility of conducting polyaniline and of conducting polyblends of polyaniline in bulk polymers. Synth. Met., v. 48, p. 91, 1992.

[4] Yang, C. Y.; Cao, Y.; Smith, P.; Heeger, A. J. Morphology of conductive, solution-processed blends of polyaniline and poly(methyl methacrylate). Synth. Met., v. 53, p. 293, 1993.

[5] Jousseaume, V.; Morsli, M.; Bonnet, A.; Tesson, O.; Lefrant, S. Electrical properties of polyaniline-polystyrene blends above the percolation threshold $\mathrm{J}$. Appl. Polym. Sci, v. 67, p. 1205, 1998.

[6] Roichman, Y.; Titelman, G. I.; Silverstein, M. S.; Siegman, A.; Markis, M. Polyaniline synthesis: influence of powder morphology on conductivity of solution cast blends with polystyrene. Synth. Met., v. 98, p. 201, 1999.

[7] Valenciano, G. R.; Job, A. E.; Mattoso, L. H. C. Improved conductivity of films of ultra high molecular weight polyethylene and polyaniline blends prepared from an $m$-cresol/decaline mixture. Polymer, v. 41, p. 4757, 2000.

[8] Yang, C. Y.; Heeger, A. J.; Cao, Y. Microstructure of gel-processed blends of conjugated polymer and ultrahigh molecular weight polyethylene. Polymer, $\mathrm{v}$. 41, n. 11, p. $4113,2000$.

[9] Faez, R.; Gazzoti, W. A.; De Paoli, M. A. An elastomeric conductor based on polyaniline prepared by mechanical mixing. Polymer, v. 40, n. 20, p. 5497, 1999. 
[10] Wessling, B. Dispersion as the link between basic research and commercial applications of conductive polymers (polyaniline). Synth. Met., v. 93, n. 2, p. 143, 1998.

[11] Anand, J.; Palaniappan, S.; Sathyanarayma, N. D. Conducting polyaniline blends and composites. Prog. Polym. Sci., v. 23, n. 6, p. 993, 1998.

[12] Roth, S.; Graupner. W. Conductive polymers: Evaluation of industrial applications. Synth. Met., v. 57, n. 1, p. 3623, 1993.

[13] Ranby, B. In Conjugated Polymers and Related Materials. The Interconnection of Chemical and Electronic Structure. Oxford Science Publications, p. 502, 1993.

[14] Campbell, I. M. Introduction to Synthetic Polymers. Oxford Science Publications, p. 213, 1994.

[15] Faez, R.; Reis, Cristiane; Freitas, P. S., Kosima, O. K.; Ruggeri, G.; De Paoli, M. A. Polímeros Condutores; Revista Química Nova na Escola, n. 11, p. 13, 2000.

[16] Min, G. Conducting Polymers and Their Applications in the Film Industry Polyaniline/Polyimide Blended Films. Synth. Met., v. 102, p. 1163, 1999.

[17] www.panipol.com - acesso em 17/11/2006.

[18] Rocha, R. C. Polímeros Condutores: Descoberta e Aplicações. Química Nova na Escola, v. 12, p. 11, 2000.

[19] Chiang, G. K.; Fincher, C. R.; Park, Y.; Heeger, A. J.; Shirakawa, H.; Louis, E. J.; Gau, S. C.; MacDiarmid, A. G. Electrical-conductivity in doped polyacetylene. Phys. Rev. Lett., v. 39, p. 1098, 1977.

[20] Kaner, R. B.; Macdiarmid, A. G. Plastics that conduct electricity. Scient. American, v. 258, p. 106, 1998.

[21] Okabayashi, K.; Goto, F.; Abe, K.; Yoshida, T. Electrochemical studies of polyaniline and its application. Synth. Met., v. 18, p. 365, 1987. 
[22] MacDiarmid, A. G.; Epstein, A. J. Proceedings of the first conference on frontiers of polymer research. Índia; Jan 1991.

[23] Genies, E. M.; Lapkowski, M.; Santier, C.; Vieil, E. Polyaniline, spectroelectrochemistry, display and battery. Synth Met., v 18, p. 631, 1987.

[24] Watanabe, A.; Mori, K.; Iwasaki, Y.; Nakamura, Y.; Niizuma, S. Electrochromism of polyaniline film prepared by electrochemical polymerization. Macromolecules, v. 20, p. 1793, 1987.

[25] MacDiarmid, A. G.; Yang, L. S.; Huang, W. S.; Humphrey B. D. Polyaniline electrochemistry and application to rechargeable batteries. Synth. Met., v. 18, p. 393, 1987.

[26] Mattoso, L. H. C. Polianilinas, síntese, estrutura e propriedades. Química Nova, v. 19, p. 388, 1996.

[27] Gustafsson, G.; Cao, Y.; Treacy, G. M.; Klavetter, F.; Colaneri, N.; Heeger, A. J. Flexible light-emitting-diodes made from soluble conducting polymer. Nature, $v$. 357, p. 477, 1992.

[28] Heeger, A. J. Semiconduction and Metallic Polymers: the fourth generation of polymeric material. Synth. Met., v. 125, p. 23, 2002.

[29] Akcelrud, L.; Electroluminescent Polymers. Prog. Pol. Sci., v. 28, p. 875, 2003.

[30] MacDiarmid, A. G.; Epstein, A. J.; Faraday Discuss. Chem. Soc. v. 88, p. 317, 1989.

[31] Chiang, J. C.; MacDiarmid, A. G. Polyaniline: Protonic acid doping of the emeraldine form to the metallic regime Synth. Met., v. 13, p. 193,

[32] MacDiarmid, A. G.; Chiang, J. C.; Richter, A. F.; Epstein, A. J. Polyaniline - a new concept in conducting polymers. Synthetic Metals, v. 18, p. 285, 1987. 
[33] Huang, W. S.; Humpfrey, B. D.; MacDiarmid, A. G. Polyaniline, novel conducting polymer - morphology and chemistry of its oxidation and reduction in aqueous-electrolytes. J. Chem. Soc., Faraday Trans. 1, v. 82, p. 2385, 1986.

[34] Shoch, K. F.; Saunders, H. E. IEEE Spectum, 1, June, 1992.

[35] Genies, E. M.; Boyle, A.; Lapkowski, M.; Tsintavis, C.; Polyaniline: A historical survey. Synth. Met.. v. 36, p.139, 1990.

[36] MacDiarmid, A. G.; Epstein, A. J. The polyaniline: a novel class of conducting polymers, In: Conducting polymers, emerging technologies. Technical Insights Inc.: New Jersey, 27, 1989.

[37] Wang, B.; Tang, J.; Wang, F. Electrochemical polymerization of aniline Synth. Met., v. 18, p. 323, 1987.

[38] MacDiarmid, A. G.; Manhohar, S. K.; Mattoso, L. H. C. High molecular weight polyanilines and synthetic methods therefore. Patent Application, N: UPN-1157, USA, filed, nov. 06, 1994.

[39] Mattoso, L. H. C.; MacDiarmid, A. G.; Epstein, A. J. Controlled synthesis of high molecular weight polyaniline and poly(o-methoxyaniline). Synth. Met., $v$. 68, p. 1, 1994.

[40] Adams, P. N.; Laughlin, P. J.; Monkmam, A. P.; Bernhoeft, N. A further step towards stable organic metals - oriented films of polyaniline with high electrical - conductivity and anisotropy Solid State Comm., v. 91, p. 875, 1994.

[41] Nechtschein, M.; Genoud, F.; Nenardo, C.; Nizoguchi, K.; Travers, J. P.; Villeret, B. On the natureof the conducting state of polyaniline. Synth. Met., v. 29, p. E211, 1989.

[42] MacDiarmid, A. G.; Epstein, A. J. Mater. Res. Symp. Proc. v. 328, p. 133, 1994.

[43] Kohlman, R. S; Joo, J.; Epstein, A. J.; in : J. E. Mark (Ed). Physycal Properties of Polymers Handbook. AIP Press, New York, 1996, p. 453.

[44] Melo, C. P. Ciência Hoje, v. 6, p. 38, 1987. 
[45] Yue, J.; Epstein, A. J. Synthesis of self-doped conducting polyaniline. J. Am. Chem. Soc., v. 112, p. 2800, 1990.

[46] MacDiarmid, A. G.; Epstein, A. J.; Anais do 20 Congresso Brasileiro de Polímeros, p. 544, 1993.

[47] Min, Y.G.; Xia, Y. N.; MacDiarmid, A. G.; Epstein, A. J. Vapor - phase secondary doping of polyaniline. Synth. Met., v. 69, p. 159, 1995.

[48] Ho, K. S. Effect of phenolic based polymeric secondary dopants on polyaniline. Synth. Met., v. 126, p. 151, 2002.

[49] Pouget, J. P.; Jozefowicz, M. E.; Epstein, A. J.; Tang, X.; MacDiarmid, A. G. Xray structure of polyaniline. Macromolecules, v. 24, p. 779, 1991.

[50] Jozefowicz, M. E.; Laversanne, R.; Javadi, H. H. A.; Epstein, A. J.; Pouget, J. P.; Tang, X.; MacDiarmid, A. G.; Multiple lattice phases and polaron - lattice spinless - defect competion in polyaniline. Physical Review B. v. 39, p. 1295, 1989.

[51] Wang, F.; Tang, J.; Wang, L.; Zhang, H.; Mo, S. Mol. Cryst. Liq., v.160, p. 175, 1988.

[52] Kitani, A.; Kaya, M.; Tsujioka, S. I.; Sasaki, K. Flexible polyaniline. J. Polym. Sci. - Polym. Chem., v. 26, p. 1531, 1988.

[53] Mattoso, L. H. C.; Faria, R. M.; Bulhões, L. O.; MacDiarmid, A. G. Synthesis, doping and processing of high-molecular-weight poly(o-methoxyaniline). J. Polym. Sci. - Polym. Chem., v. 32, p. 2147, 1994.

[54] Wan, M. The influence of polymerization method and temperature on the absortion spectra and morphology of polyaniline. Synth. Met., v. 31, p. 51, 1989.

[55] Chiang, C. K.; Fincher, C. R.; Park, Y.; Heeger, A. J.; Shirakawa, H.; Louis, E. J.; Gau, S. C.; MacDiarmid, A. G. Electrical-conductivity in doped polyacetylene. Phys. Rev. Lett., v. 39, p. 1098, 1977. 
[56] Donato, A. M. Desvulcanização de Compostos de Borracha Etileno Propileno Dieno Monômero (EPDM) através de microondas. Dissertação de Mestrado, São Carlos, UFSCar, 2006, 168p.

[57] Hofmann, W. Rubber Technology Handbook. Hanser Publishers, Distributed in Canada by Osford University Press, 1989.

[58] Mark, J. E.; Erman, B.; Eirich, F. R.; Sci. and Technology of Rubber. Academic Press, New York, 1994.

[59] Hepbum, C. H.; Rapra Review Report, v.97, n.9 (1) p. 3, 1997.

[60] Green, J.; Rapra Review Report, v. 44, n. 4 (8), p. 3, 1991.

[61] Moreira, J. C.; Síntese de Copolímeros em Bloco de Poli (p-Acetoxiestirenob-Isopreno) e Misturas Derivadas, São Paulo, 2004, Tese de Doutorado, Escola Politécnica, Universidade de São Paulo.

[62] Santoro Jr., A.; Estudo das Propriedades Físico-Químicas do Copolímero em Bloco Poli(estireno-co-butadieno), São Paulo, 2002, 60 p. Trabalho de Formatura, Escola Politécnica, Universidade de São Paulo.

[63] State of the Art: Recycling of EPDM Rubber Vulcanizates; Chapter 1; www.dissertations.ub.rug.nl/files/faculties/science/2006/p.sutanto/01_c1.pdf; acesso em 20/10/2006.

[64] Piva, A. M.; Wiebeck, H. Reciclagem do Plástico - Como fazer da reciclagem um negócio lucrativo. Copyright 2004 by Artliber Editora Ltda.

[65] Rader, C. P.; Baldwin, S. D.; Cornell, D. D.; Sadler, G. D.; Stockel, R. F. Plastics, Rubber, and Paper Recycling - A Pragmatic Approach. Copyright 1995 by American Chemical Society.

[66] Jacob, C.; De, P. P.; Bhowmick, A. K.; De, S. K. Recycling of EPDM Waste 1. Effect of Ground EPDM Vulcanizate on Properties of EPDM Rubber. Journal of Applied Polymer Science, v. 82, p. 3293, 2001. 
[67] Verbruggen, M. A. L. et al, Mechanisms Involved in the Recucling of NR and EPDM. Rubber Chemistry and Technology, v. 72, p. 731, 1999.

[68] Sutanto, P. Continuous Devulcanization of EPDM Rubber in a Extruder. http://ospt.tnw.utwente.nl/pdf/posterbook/posters/RuG-Janssen-Sutanto.pdf - acesso em 25/10/2006.

[69] Montenegro, R. S. P.; Pan, S. S. K; Vianna, K.; Negro de Fumo, Informe Setorial - Complexo Químico (BNDES), nº 9, 1998.

[70] www.negro-de-fumo.com.br/oque.asp - acesso em 29/10/2006.

[71] Martins, A. F.; Napolitano, B. A.; Visconde, L. L. Y.; Nunes, R. C. R. Propriedades Mecânicas e Dinâmico-Mecânicas de Composições de Policliropreno com Negro de Fumo. Polímeros: Ciência e Tecnologia, v. 12, n. 003, p. 147-152.

[72] Dannenberg, E. M. Rubber Chem. Technol., v. 48, p. 411, 1975.

[73] Medalia, A. I.; Kraus, G. Reiforcement of Elastomers by Particulate Fillers; Sci and Technology Rubber, $2^{\mathrm{a}}$ edição, cap. 8, Academic Press, New York, 1994.

[74] Neto, J. R. A.; Pacheco, E. B. A. V.; Visconte, L. L. Y.; Furtado, C. R. G. Jornal de Pláticos, junho de 2005.

[75] Adihkari, B.; De, D.; Maiti, S. Reclaiming of rubber by a renewable resource material (RRM) III. Evaluation of properties of NR reclaim; J. of Applied Polym. Sci., v. 75, p. 1493, 2000.

[76] Adihkari, B.; De, D.; Maiti, S. Reclamation and recycling of waste rubber; Progress in Polym. Sci., v. 25, p. 909, 2000.

[77] Thonstenson, E. T.; Chou, W. Microwave processing: fundamentals and applications; Composites: Part A, v. 30, p. 1055, 1999.

[78] Metaxas, A. C.; Meredith, R. J. Industrial Microwave Heating; Peter Peregrinus Ltd., London, 1983. 
[79] Goodyear Tire \& Rubber Co., Microwave Devulcanization of Rubber, Elastomerics, 38-40, 1980.

[80] Lucchese, L.; Liauw, M.; Allen, S. Use of microwave dielectric loss spectroscopy for characterization of Natural Rubber I Carbon Black composites; Polymer Bulletin, v. 44, p. 187, 2000.

[81] Novotny, D. S.; Windsor, Vt.; Marsh, R. L.; Springfield, Mo.; Masters, F. C.; Palmyra, N.; Tally, D. N.; Arvada, C. Microwave Devulcanization of Rubber; United States Patent 4.104.205., August 1, 1978.

[82] Gedde, U. W. Polymer Physics, London; New York: Chapman \& Hall, 1995.

[83] Cao,Y.; Smith, P.; Heeger, A. J. Counterion induced processibility of conducting polyaniline. Synth. Met., v. 57, p. 3514, 1993.

[84] Heeger, A. J. Polyaniline with surfactant counterions - conducting polymer materials which are processible in the conducting form. Synth. Met., v. 55, p. 3471, 1993.

[85] Ikkala, O. T.; Laakso, J.; Väkiparta, K.; Virtanen, E.; Ruohonen, H.; Lärvinem, H.; Taka, T.,; Passiniemi, P.; Österholm, J. E. Conducting induced processibility of polyanilin - conducting melt processible polymer blends. Synth. Met., v. 69, p. 97, 1995.

[86] Yang, C. Y.; Cao, Y.; Smith, P.; Heeger, A. J. Morphology of polyaniline in solution processed blends with poly(methyl methacrylate). Polym. Prepr., v. 205, p. 443, 1993.

[87] Rocha, I. S.; Mattoso, L. C. H.; Malmonge, L. F.; Junior, R. G. Effect of low contents of a polyaniline derivative on the crystallization and electrical properties of blends with PVDF. J. Polym. Sci. - Polym. Chem., v. 37, p. 1219, 1999.

[88] Malmonge, J. A.; Malmonge, L. F.; Mattoso, L. H. C.; XI CEBCIMAT, Águas de São Pedro - SP, dez., 1994.

[89] Davies, S. J.; Ryan, T. G.; Wilde, C. J.; Beyer, G. Processable forms of conductive polyaniline, Synth. Met., v. 69, p. 209, 1995. 
[90] Titelman, G. I.; Zilberman, M.; Siegmann, A.; Haba, Y.; Narkis, M. Thermal dynamic processing of polyaniline with dodecylbenzene sulfonic acid. J. App. Polym. Sci., v. 66, p. 2199, 1997.

[91] Zilberman, M.; Titelman, G. I.; Siegmann, A.; Haba, Y.; Narkis, M.; Alperstein, D. J. Conductive blends of thermally dodecylbenzene sulfonic acid-doped polyaniline with thermoplastic polymers. J. App. Polym. Sci., v. 66, p. 243,1997.

[92] Kim, S.; Ko, J. M.; Chung, I. J. Electrical conductivity change of polyanilinedodecylbenzene sulfonic acid complex with temperature. Polym. Advanced Technol., v. 7, p. 599-603, 1996.

[93] Faez, R.; De Paoli, M. A. A conductive rubber based on EPDM and polyaniline - I. Doping method effect. Eur. Polym. J., v. 37, p. 1139, 2001.

[94] Barra, G. M. O.; Crespo, J. S.; Bertolino, J. R.; Soldi, V.; Pires, N. A. Maleic anhydride grafting on EPDM: Qualitative and quantitative determination. J. Braz. Chem. Soc., v. 10, p. 31, 1999.

[95] Rajeev, R. S.; De, S. K.; Bhowmick, A. K.; John, B. Studies on thermal degradation of short melanine fibre reinforced EPDM, maleated EPDM and nitrile rubber composites; Polymer Degradation and Stability, v. 79, p. 449, 2003.

[96] Zaharescu, T.; Jipa, S.; Podina, C. Thermal behavior of ethylene-propylene elastomer. Polym Testing, v. 17(2), p. 99, 1998.

[97] Gamlin, C.; Dutta, N.; Roy-Choudhury, N.; Kehoe, D. Matisons, J.; Influence of ethylene-propylene ratio on the thermal degradation behavior of EPDM elastomers. Thermochim Acta, v. 367, p. 185, 2001.

[98] Zaharescu, T.; Giurginca, M.; Mihalcea, I. Effects of some anti-oxidants on the stability of ethylene-propylene elastomers; Polym Degrad. and Stab., v. 48, p. $151,1995$.

[99] Faez, R.; Schuster, R. H.; De Paoli, M. A. A conductive elastomer base don EPDM and polyaniline. II. Effect of the crosslinking method. Eur. Polym. J., v. 38, p. 2459, 2002. 
[100] Novotny, D. S.; Marsh, R. L.; Masters, F. C.; Tally, D. N; Microwave devulcanization of rubber - Patent US 4104205 (1978).

[101] Wicks; G. G.; Schulz; R. L.; Clark; D. E.; Folz; D C. Microwave treatmentof vulcanized rubber; Patent US 6420457 (2002).

[102] Scuracchio, C. H.; Waki, D. A. Caracterização Térmica e Reológica de Borracha de Pneu Desvulcanizada por Microondas. Polímeros: Ciência e Tecnologia, v. 16, $n^{\circ} 1$, p. 46, 2006.

[103] De Paoli, M. A.; Waltman, R. J.; Diaz, A. F.; Bangon, J.; J. Chem. Soc. Commun., p. 1015.

[104] De Paoli, M. A.; Waltman, R. J.; Diaz, A. F.; Bangon, v. 23, p. 1687, 1984.

[105] Kroschwitz, J. I. Polymers: Polymer Characterization and Analysis, John Wiley \& Sons, Inc., 1990.

[106] Girotto, E. M. and Santos, I. A. Medidas de Resistividade Elétrica DC em Sólidos: Como Efetuá-las Corretamente. Química Nova, v. 25, nº. 4, p. 639, 2002.

[107] Wei, Y.; Jang, G. W.; Hsueh, K. F.; Scherr, E. M.; MacDiarmid, A. G.; Epstein, A. J. - Polymer, 33, p314 (1992).

[108] Mattoso, L. H. C.; Malmonge, L. F.; Mantovani, G. L. and MacDiarmid, A. G. Curr. Trends in Polym. Sci. 3 (1998) 99. 